\title{
Phasic vs Sustained Fear in Rats and Humans: Role of the Extended Amygdala in Fear vs Anxiety
}

\author{
Michael Davis ${ }^{\star, 1}$, David L Walker ${ }^{1}$, Leigh Miles ${ }^{1}$ and Christian Grillon ${ }^{2}$ \\ ${ }^{1}$ Department of Psychiatry, Yerkes National Primate Center, Emory University, and the Center for Behavioral Neuroscience, \\ Atlanta, GA, USA; ${ }^{2}$ Unit of Affective Psychophysiology, Mood and Anxiety Disorder Program, Intramural Research Program, \\ National Institute of Mental Health, National Institutes of Health, Bethesda, MD, USA
}

\begin{abstract}
Data will be reviewed using the acoustic startle reflex in rats and humans based on our attempts to operationally define fear vs anxiety. Although the symptoms of fear and anxiety are very similar, they also differ. Fear is a generally adaptive state of apprehension that begins rapidly and dissipates quickly once the threat is removed (phasic fear). Anxiety is elicited by less specific and less predictable threats, or by those that are physically or psychologically more distant. Thus, anxiety is a more long-lasting state of apprehension (sustained fear). Rodent studies suggest that phasic fear is mediated by the amygdala, which sends outputs to the hypothalamus and brainstem to produce symptoms of fear. Sustained fear is also mediated by the amygdala, which releases corticotropin-releasing factor, a stress hormone that acts on receptors in the bed nucleus of the stria terminalis (BNST), a part of the so-called 'extended amygdala.' The amygdala and BNST send outputs to the same hypothalamic and brainstem targets to produce phasic and sustained fear, respectively. In rats, sustained fear is more sensitive to anxiolytic drugs. In humans, symptoms of clinical anxiety are better detected in sustained rather than phasic fear paradigms.

Neuropsychopharmacology Reviews (2010) 35, 105-135; doi: I0.1038/npp.2009.109; published online 19 August 2009
\end{abstract}

Keywords: amygdala; bed nucleus stria terminalis; startle; CRF; SSRIs; context conditioning

\section{INTRODUCTION}

This review describes a series of experiments in rats and humans whose ultimate goal is to develop more operational methods in order to study fear and anxiety, and to determine how these different models respond to clinically effective and/or theoretically relevant drugs. The review will focus on studies that use the acoustic startle reflex, a very short latency reflex that is mediated by a simple brainstem and spinal cord pathway that can be measured in several species, including humans. The major premise of this study is that although the symptoms of fear and anxiety are very similar, they differ in terms of certain key dimensions. In particular, fear is a generally adaptive state of apprehension to an imminent threat. It begins rapidly and dissipates rapidly once the threat is removed. Fear is prompted by imminent and real danger, and galvanizes active defensive responses. In contrast, anxiety is often elicited by less specific and less predictable threats, or by those that are

${ }^{*}$ Correspondence: Professor M Davis, Yerkes National Primate Center, Emory University, 954 Gatewood Drive NE Room 5200, Atlanta, GA 30329, USA, Tel: + 1404727 3591, Fax: + 1404727 3436,

E-mail: mdavis4@emory.edu

Received 16 March 2009; revised 26 June 2009; accepted 14 July 2009 physically or psychologically more distant. Anxiety is a future-oriented mood state activated by distal and potential threat, and is associated with arousal and vigilance. As a result, anxiety can be defined as a more long-lasting state of apprehension that can become pathological if it becomes extreme. These two states may map onto two distinct clinical entities: one characterized by elevated cuedfear reactivity (eg, phobias) and the other by pervasive anxious apprehension (Kruger et al, 1999; Vollebergh et al, 2001).

The separation of fear and anxiety into different entities has received support from ethological analyses of defensive responses in rodents, which provides a useful perspective for modeling and interpreting human responses to threat in the laboratory. Briefly, the defense pattern in rodents is determined by the physical distance from a threat (Blanchard et al, 1993; Bolles and Fanselow, 1980; Fanselow, 1986). Three defensive stages have been described: preencounter defense emerges in an area where a predator has been previously encountered but is not present; postencounter defense is activated when the predator is identified at a distance; and circa-strike defense is activated when physical contact with the predator is made or is imminent (Fanselow, 1986). Defensive behavior shifts from 
sustained risk assessment at the greatest threat distance to fight and flight during the circa-strike stage. The state of anxiety has been linked to the potential (pre-encounter) or distal (post-encounter) presence of a predator, whereas fear is evoked by the clear and imminent threat (circa strike). The Blanchards distinguished between two types of defensive behaviors: fear, which is elicited by a predator, and anxiety, which is evoked by the potential presence of a predator. Pharmacological analyses of these defensive behaviors show that anxiety is sensitive to anxiolytic drugs, whereas fear is not (Blanchard et al, 1993).

By analogy, fear and anxiety evoked experimentally in humans may be framed according to the same defensive distance continuum. For example, as humans are endowed with a cognitive system that enables symbolic representation of aversive experience, the knowledge of future aversive events is sufficient to create a threatening context. Participation in an experiment in which subjects know that they will eventually receive shocks at a later time may be akin to the pre-encounter stage and may thus elicit mild anxiety.

Research in humans has mostly focused on the study of aversive responses to discrete cues using short-duration presentation of aversively conditioned or unconditioned stimuli. Although Fanselow (1986) used fear-potentiated startle to a short cue as a model of post-encounter threat behavior, we will use fear-potentiated startle to a short cue as a model of circa-strike, as the fearful stimulus (ie, air blast or shock) is imminent and will take place in seconds. Recently, our laboratories have been trying to evoke more sustained forms of startle potentiation in both rats and humans. To simplify the nomenclature, we will define fear as discussed above (eg, circa-strike) as 'phasic fear' and anxiety as defined above (eg, potential (pre-encounter) or distal (post-encounter)) as 'sustained fear.' In the laboratory, phasic fear can be measured using a short, discrete cue that is predictably paired with an aversive event. This elicits a state of fear highly time-locked to the fear-inducing stimulus that begins quickly and dissipates quickly once the fear stimulus is removed (Davis et al, 1989; de Jongh et al, 2003). In contrast, sustained fear is measured using a more diffuse cue, or cues, arranged so that the subject does not know when during the aversive event will occur. This elicits a state of fear that can last for a much longer period of time and often decays more slowly after the fearful signal is removed (de Jongh et al, 2003). Most importantly, rodent studies suggest that phasic and sustained fear are mediated by similar, highly inter-related, yet importantly different, neural substrates. The peptide corticotropinreleasing factor (CRF) has a special role in sustained fear. Moreover, in both rats and humans, sustained fear appears to be more sensitive to clinically effective anti-anxiety drugs or treatments, perhaps as a result of the different neural substrates of each. Finally, clinical symptoms of several anxiety disorders can be modeled more accurately with sustained rather than phasic fear tests.
The translation of basic findings into human research involves conceptual as well as practical issues. One conceptual issue is that basic research in animals generally examines normative responses to threat, whereas research in humans focuses on psychopathology (Blanchard et al, 2001). Research in healthy humans may thus provide a promising avenue to bridge the gap between basic and clinical science. However, such an approach is hampered by methodological difficulties. Most animal models are far removed from the human experience in the way that aversive states are evoked and measured. However, we believe that using the startle reflex and its modulation by phasic $v s$ sustained fear sets the stage for a powerful translational approach to anxiety. The eyeblink component of the startle reflex in humans shows many of the same characteristics seen in the whole-body startle response in rodents. In particular, both are increased by anticipation of aversive stimuli and during the processing of negatively valenced information (Brown et al, 1951; Lang et al, 2000). In addition, the eyeblink component of the startle reflex has face validity for studying aversive states and anxiety disorders. For instance, the DSM-IV-R lists exaggerated startle as a criterion for posttraumatic stress disorder (PTSD). Startle presents several advantages as a tool for investigating short- and long-duration aversive states. Obviously, a key advantage is the convergence and similarities of experiments that can be conducted in humans and in rodents (Grillon and Baas, 2003), allowing for greater hypothesis testing and generalizability of the results (Risbrough and Stein, 2006). However, startle also presents a unique methodological advantage. Unlike most traditional psychophysiological measures (eg, heart rate, skin conductance) of emotion, startle increases are typically sensitive to valence and not simply arousal (Lang et al, 2000).

\section{MODELS TO STUDY PHASIC FEAR IN RATS AND HUMANS}

Various procedures have been developed to examine startle modulation during aversive emotional states, including fear conditioning, verbal threat, unpleasant-picture processing, and mental imagery. These procedures can be divided into two broad classes of experiments that are distinguishable based on whether aversive events (eg, shocks) are administered or anticipated. This review will focus on the former types of experiments because they more closely mimic the phenomena studied in animals. Although it has been proposed that human subjects watching unpleasant pictures are in a state analogous to that of animals confronted with distal threat (Lang et al, 2000), potentially reflecting a state of anxiety when activation is relatively low, such a procedure elicits a short-duration emotional state that is more compatible with a state of fear. Furthermore, as unpleasant pictures are usually of different specific contents (eg, threat to self, threat to others, mutilated bodies, 
pollution, and contamination), they may examine a general tendency for negative affectivity rather than fear/anxiety.

\section{Fear-Potentiated Startle}

In this procedure, initially developed in rats by Brown et al (1951), animals receive pairings of an initially neutral, soon-to-be conditioned stimulus ( $\mathrm{CS}$ - eg, a 3.7-s tone, light, or odor) and an aversive unconditioned stimulus (US - in almost all cases a 0.5 -s footshock that terminates with the CS). Rats are later tested for fear to the CS by eliciting the startle reflex with a series of brief (ie, $50 \mathrm{~ms}$ ) noise bursts, some presented in the presence of the CS, and others in its absence. Startle amplitude is measured automatically with special sensors beneath the rat cage. Fear-potentiated startle is defined operationally as greater startle amplitude to the startle stimulus in the presence $v s$ the absence of the CS. In this conditioned procedure, the light is on for a very short time and the shock is highly predictable because it begins at $3.2 \mathrm{~s}$ after the CS onset. Fear-potentiated startle is closely time-locked to the CS; hence, it is generally maximal during testing at the time after the CS onset when the shock occurred in training (Davis et al, 1989). Fear-potentiated startle can also be used in mice (Falls et al, 1997) and rhesus monkeys (Winslow et al, 2002).

In humans, a similar procedure can be implemented by pairing discrete stimuli, such as lights (Grillon and Davis, 1997) or pictures (Hamm et al, 1991b), with shock and measuring the eyeblink component of the startle reflex elicited by a loud sound using small electrodes beneath the eye. In each case, the startle reflex is enhanced when evoked in the presence of the cue that predicts the shock.

\section{Verbal Threat}

During verbal threat, subjects are informed that when a cue begins they are at risk of getting an aversive US (Grillon et al, 1991). Verbal instruction experiments mimic the mode of communication of danger typically involved in everyday life, without direct experience with the aversive event (eg, one fears and avoids swimming in shark-infested waters not because one has been bitten by a shark, but because one has been forewarned of the risk; Olsson and Phelps, 2007). This method presents several advantages over conditioning for exploring the expression of fear and anxiety. First, as the anticipation of shock is dependent on verbal instruction rather than actual CS-US pairing, the shock itself may not be required at all. A few shocks may be given to maintain the credibility of the experiment, especially when subjects are tested on several occasions, but this is not always necessary (Baas et al, 2002). Second, verbal instructions eliminate the potential confound of inter-individual variability in associative learning that occurs during conditioning. Third, the magnitude of phasic fear-potentiated startle is generally larger for a verbal threat. For example, we have shown that startle magnitude can be doubled during verbal threat (Grillon et al, 1991, 1993a, b), whereas we and others have reported startle potentiation of $<50 \%$ during fear conditioning paradigms (Baas et al, 2004; Lipp et al, 1994, 2003), although it can be higher in certain patients (Jovanovic et al, 2009). Finally, as learning is minimized during verbal threat, such procedures can be used in repeated designs. A recent study showed no reduction of fear-potentiated startle when a verbal threat procedure was repeated either four times in a single day or once per day for 4 days (Klumpers et al, 2008). This is a very important characteristic for drug studies, which may involve testing several doses of a compound in addition to placebo in the same subjects.

\section{MODELS FOR THE STUDY OF SUSTAINED FEAR IN RATS AND HUMANS}

\section{Light-Enhanced Startle}

One of the problems in conditioning models of fear and anxiety is that when a treatment blocks the fear measure, it may do so either because it is indeed anxiolytic or, instead, because the treatment is amnestic, where the animal forgets the previous association between the CS and the US. Hence, we wanted to develop models that were anxiogenic but that did not depend on conditioning. Rodents live in burrows and forage at night, and are averse to bright light and open spaces (eg, Crawley, 1981; DeFries et al, 1966; File and Hyde, 1978). Capitalizing on this, we developed a paradigm in which acoustic startle amplitude is measured during two consecutive test phases, each lasting 20 min (Walker and Davis, 1997a). During the first phase, rats are tested in the dark. During the second phase, rats are tested again in the dark or, alternatively, in the presence of bright light. Exposure to bright light for 5-20 min led to a significant increase in acoustic startle amplitude going from the dark to the light (light-enhanced startle) compared with startle amplitude when the rats remained in the dark. Lightenhanced startle was reduced selectively by both benzodiazepine (ie, chlordiazepoxide) and non-benzodiazepine (ie, flesinoxan, buspirone, and propranolol) anxiolytics (de Jongh et al, 2002; Walker and Davis, 1997a, 2002a). This procedure differs markedly from fear-potentiated startle, in that it does not depend on learning and memory processes and leads to a state of uncertainty about potential danger for the rat. That is, when the light comes on, the rat has no way of knowing when and whether something harmful might happen and thus remains in a state of sustained apprehension, based on the sustained increase in startle amplitude seen across the 20 -min light phase.

\section{Dark-Enhanced Startle in Humans and Monkeys}

In contrast to rodents, humans are diurnal and feel more vulnerable in the dark (Schaller et al, 2003), and darkness is sufficiently anxiogenic in humans to potentiate startle (Grillon et $a l, 1997 \mathrm{~b})$. Dark-enhanced startle is replicable across laboratories (Grillon et al, 1999), and can be observed in both 
adolescents (Grillon et al, 1999) and adults (Coplan et al, 1998; Grillon and Ameli, 1998b; Grillon et al, 1997b). It is blocked by the benzodiazepine diazepam (Baas et al, 2002) and is increased in PTSD (Grillon et al, 1998b). Data based on heart rate as a measure of emotion suggest that darkness is more anxiogenic in individuals with panic disorder than in healthy controls (Melzig et al, 2007). We have also found this effect in rhesus monkeys that underwent a brief separation from their mothers during development (Parr et al, 2002).

\section{Predictable vs Unpredictable Shock}

Another way to produce a sustained level of fear is to make an aversive event unpredictable. For example, in phasic fear conditioning experiments, two groups are typically used: one where the US is presented at the end or immediately after presentation of the CS (paired group) and the other where the CS and US are not paired, in order to better assess whether the predicted increase in fear is associative (unpaired group). A fear response is seen to a cue reliably paired with the shock and not to a cue in the unpaired group. However, the interesting point for this discussion on sustained fear is that the level of fear is typically greater to the context in the unpaired than in the paired group. That is, context conditioning is greater in the unpaired group, a finding that is exactly predicted by contemporary learning theory. A cue paired with a US becomes the best predictor of the US. The cue overshadows the context, which then elicits little context conditioning (Rescorla and Wagner, 1972). In contrast, when the CS and US are not paired, the context becomes the only predictor of the US, although a poor one, leading to increased context conditioning (Odling-Smee, 1975a, b; Rescorla and Wagner, 1972). This also occurs with trace conditioning, in which the offset of the US is separated in time from the onset of the US. The longer the duration of the trace interval, the less predictable the US becomes, resulting in greater context conditioning (Marlin, 1981). These results suggest that context conditioning measured with acoustic startle amplitude should be greater after temporally unpredictable shocks compared with predictable shocks in humans, and this is exactly what we found (Grillon and Davis, 1997). In our experiment, human subjects were presented with a 6-s duration light either paired or unpaired with a shock over two sessions on separate days (Grillon and Davis, 1997). A non-aversive conditioning task, in which the US was a signal for reaction time, was also implemented as an experimental control. Although fear-potentiated startle to the cue was retained at the 1-week test, baseline startle amplitude in the absence of the cue was greater in the unpaired group compared with that in the paired group and lowest in the group that received no shocks (Figure 1).

\section{Context Conditioning}

A variant of the unpaired procedure is to simply deliver unsignaled aversive events to rats or humans in a distinctive

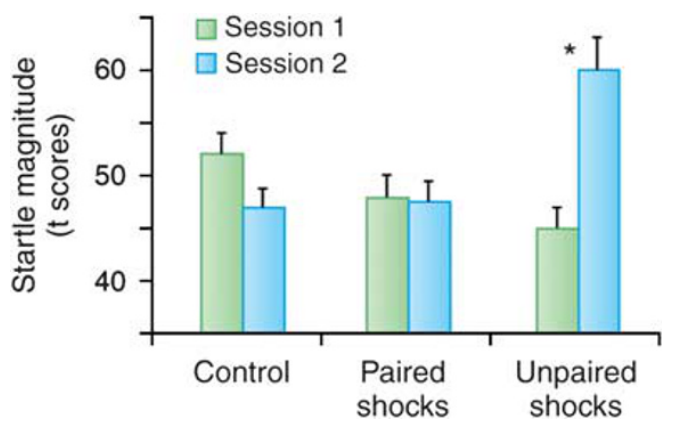

Figure 1. Context conditioning after paired CS shock (predictable shocks), unpaired CS shock (unpredictable shocks), and non-aversive conditionings (control) in a between-group design. During non-aversive conditioning, the US was a signal for button press. Subjects underwent conditioning in two experimental sessions separated by 4-5 days. Context conditioning was assessed by delivering startle stimuli at the beginning of sessions 1 and 2, before conditioning occurred. The figure shows that when subjects received unpaired CS-US, startle magnitude was significantly larger when they returned for testing (session 2) compared with before initial conditioning (session 1). In contrast, during the non-aversive condition, startle decreased (because of long-term habituation) between sessions 1 and 2. Startle magnitude in the paired CS-US condition was intermediate between these two conditions, suggesting weak context conditioning. *Significant difference in startle magnitude between sessions 1 and 2 .

context. Rather than being associated with a discrete cue, the aversive event will be associated with contextual cues. In contrast to discrete cues that precisely signal the timing of US delivery, contextual cues are constant reminders of the US, but are less predictive of their occurrence; they leave the organisms in a sustained state of fearful apprehension. In animals, it is easy to make a distinct context showing that an increase in various fear measures such as fearpotentiated startle or freezing in a certain context results from conditioning to those contextual cues rather than sensitization. Thus, after pairing a context with a shock in rats, the rats will show a fear reaction in that context but not in a novel one, ruling out sensitization to shock.

\section{Verbal Threat with Unpredictable Aversive Events}

Under certain conditions, verbal threat can also be used as a model of sustained fear. Figure 2 (left panel) shows the result of an experiment during which subjects received predictable or unpredictable shocks (Grillon et al, 2004). In this study, the subjects were informed they would get no shock in one context, a shock paired with a cue in another context, or that shocks could occur at any time in a third context. Replicating the pattern of responses seen in conditioning studies, subjects showed a large startle potentiation during the threat cue in the predictable condition. They also showed a linear increase in startle reactivity during the inter-trial interval that reflected the progressive increase in reactivity (ie, anxiety) from the no shock to the predictable shock to the unpredictable shock condition. The verbal threat procedure provides an objective assessment of phasic and sustained fear. As noted above, phasic fear is 

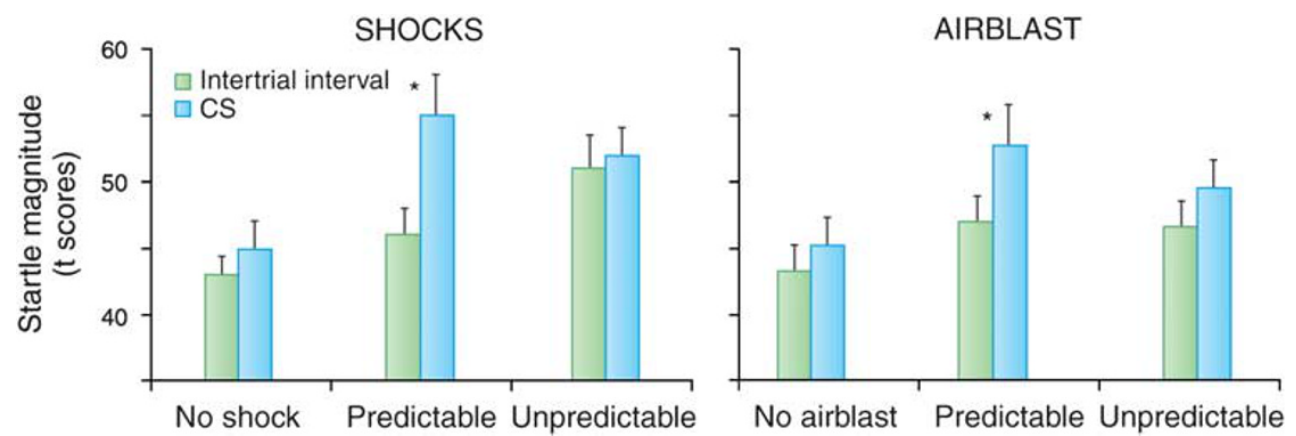

Figure 2. Verbal instruction experiment. Subjects were verbally instructed that they would be safe in the no shock (N) condition, that they would receive aversive stimuli signaled by a threat cue in the predictable $(\mathrm{P})$ condition, and that they would receive unsignaled aversive stimuli in the unpredictable (U) condition. An 8-s duration cue was presented in each context. The cue signaled the aversive stimulus in the $\mathrm{P}$ context, but had no signal value in the $\mathrm{N}$ and $U$ contexts. Two types of aversive stimuli were used in this between-group design: a shock, or a blast of air directed to the throat at the level of the larynx. In the P condition, startle was larger during the CS compared with ITI (fear-potentiated startle). In addition, startle during ITI (green bars) increased linearly from the control, to the $\mathrm{P}$, to the $\mathrm{U}$ condition. However, such a pattern of response was not seen in the airblast group. *Significant increase in startle magnitude during the cue compared to ITI.
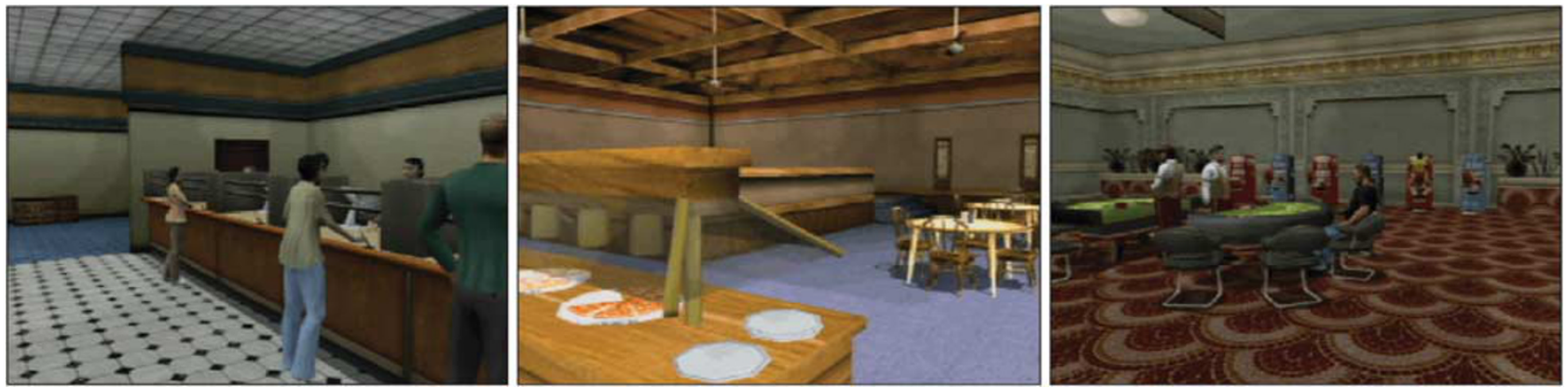

Figure 3. Context conditioning using virtual reality. Subjects were presented with three virtual environments in which they underwent different types of aversive conditioning counterbalanced across contexts in a within-subjects design. The three contexts were a casino, a bank, and a restaurant. Subjects were safe in the no-shock $(\mathrm{N})$ context. They received paired CS shock in the predictable $(\mathrm{P})$ context and unpaired CS shock in the unpredictable (U) context. An 8-s cue (a light) was presented in each context (data not shown). The cue signaled the shock in the P context, but had no signal value in the $\mathrm{N}$ and $\mathrm{U}$ contexts.

operationally defined as the increase in startle during the threat cue in the predictable condition (fear-potentiated startle) and sustained fear (anxiety) as the increase in startle during the inter-trial interval in the predictable or unpredictable conditions (context-potentiated startle). During shock anticipation, context-potentiated startle is greater in the unpredictable context compared with that in the predictable context (Figure 2).

These results indicate that contextual anxiety is robust. However, it depends on a sufficiently aversive US. Figure 2 (right panel) shows the results with less aversive airpuffs directed to the neck at the level of the larynx. Both shock and airpuffs evoke robust and reliable cued fear-potentiated startle (Grillon and Ameli, 1998a; Norrholm et al, 2006). However, airpuffs do not generate sustained contextual anxiety when administered unpredictably (Figure 2, right panel), suggesting that unpredictability per se does not elicit anxiety (Staub et al, 1971), but see (Herry et al, 2007). These results show that, given the appropriate aversive stimulus, the verbal threat of predictable and unpredictable US is a reliable paradigm to explore cued fear and contextual anxiety, providing a useful tool for extending research into the clinical domain.

\section{COMBINING CONTEXT CONDITIONING WITH PREDICTABLE vs UNPREDICTABLE AVERSIVE EVENTS IN HUMANS}

In humans, context conditioning studies with spatial contexts require testing subjects in different experimental rooms, which is often time-consuming and impractical. As an alternative, computer-generated virtual reality (VR) environments provide access to distinct spatial contexts while keeping the subjects stationary in the laboratory (Alvarez et al, 2007; Baas et al, 2004). Such procedures also facilitate within-subject experiments. Grillon et al (2006a) presented subjects with three virtual contexts, each associated during acquisition with no shock, paired lightshock, or unpaired light-shock in a counterbalanced manner (see Figure 3 legend of Grillon et al, 2006a for a description of the experiment). As expected, startle was significantly potentiated by the light in the paired context condition only, reflecting cued phasic fear. Context conditioning was indexed by measuring baseline startle in the absence of the light during the inter-trial interval in each virtual context. Consistent with the animal data, context 
conditioning was found to be greater in the unpredictable context compared with that in the no shock and predictable contexts (Figure 4).

\section{Avoidance of Contexts of Unpredictable Aversive Events}

Behavioral avoidance is particularly significant for research on anxiety. Functional accounts of anxiety emphasize its role in avoidance of aversive stimuli. In addition, behavioral avoidance is a central feature of most anxiety disorders. Individuals who seek treatment for anxiety disorders do so primarily because their avoidant behavior interferes with normal daily functioning (Beck and Emery, 1985). In animals, behavioral avoidance is a reliable measure of context conditioning (Bouton and King, 1983). Such behavior is guided by predictability. Given the choice between moving into a place where they have been conditioned with predictable and unpredictable shocks, rats will avoid the unpredictable context in favor of the predictable context (Odling-Smee, 1975a,b). Human subjects show a similar behavioral avoidance of unpredictability. In the above VR study, a behavioral test was set up after conditioning. Subjects were asked to navigate freely in the various contexts with a joystick to find monetary rewards. Their first choice was overwhelmingly the no shock context. However, when they were forced to choose between the predictable and unpredictable contexts, most subjects (80\%) avoided the unpredictable context (Grillon et al, 2006a). These results show that human studies of fear conditioning in VR can extend research beyond investigations of cue fear conditioning. VR increases the face validity of experimental models of fear, anxiety, and avoidance based on conditioning processes by incorporating research on contextual cues and overt behavior.

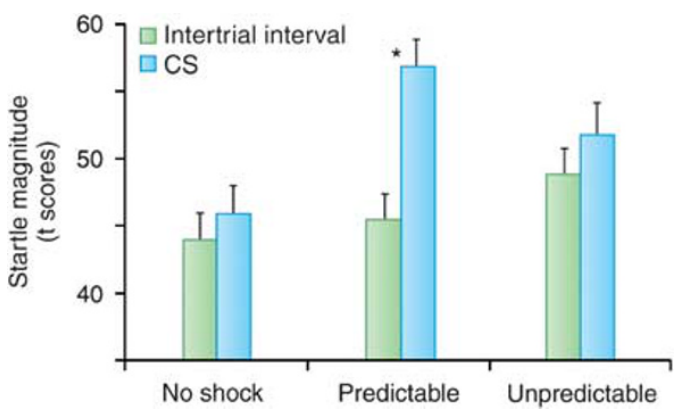

Figure 4. Magnitude of startle in each virtual context in the presence and absence of the CS (during inter-trial interval or ITI). As expected, startle was significantly larger during the CS compared with ITI (fear-potentiated startle) only in the predictable condition, when the cue signaled the shock (two middle bars). Startle during ITI (green bars) is a measure of context conditioning, reflecting the degree of contextual anxiety associated with each context. Startle increased linearly from the control, to the predictable, to the unpredictable contexts confirming that (1) context conditioning develops to environments associated with an aversive event and (2) context conditioning is affected by the predictability of the aversive event, with unpredictable environments resulting in greater context conditioning compared with predictable environments. *Significant increased in startle magnitude during the cue compared with ITI.

\section{Sustained Fear Using Long-Duration Cues Paired with Shock in Rats}

In animal studies, the context traditionally refers to the place where conditioning took place. Although context conditioning is a reliable and often-used method to produce sustained fear, most rodent literature does not rely on this procedure for that purpose. Instead, context conditioning serves as a model of hippocampal (and amygdala)dependent fear conditioning, as opposed to phasic cue conditioning, which depends on the amygdala but not the hippocampus (Kim and Fanselow, 1992; Phillips and LeDoux, 1992). A problem with context conditioning, as it is typically used, is that a treatment cannot be evaluated for its effects on the behavior being used to measure fear in the absence of exposure to the context. For example, imagine that rats are given shock in a context and then later tested for startle in that context after chronic administration of a selective serotonin reuptake inhibitor (SSRI) vs a vehicle injection. The experimenter finds that after conditioning, the rat has higher startle amplitude in that context than it did before conditioning and that 21 days of the SSRI reduced this elevation in startle compared with the vehicle. The problem is that the drug may simply have depressed startle (a performance effect). To test this, another group of rats that did not receive context conditioning would have to be tested after chronic administration of the SSRI to see whether this would reduce startle amplitude compared with a control group treated for 21 days with vehicle. Else, these context-conditioned rats would also have to be tested in a context different from the one paired with shock. Using freezing as a measure of fear, it would not be possible to determine whether this was a performance effect on freezing per se or a reduction of fear because rats only freeze in a state of fear; hence, these control groups would not be informative. Freezing to a cue paired with shock can be used to measure the effect of a treatment on freezing, but if the treatment also blocks this, once again there is no way to determine whether this is a performance effect on freezing itself (eg Burghardt et al, 2004).

An additional problem is that in context conditioning, it is necessary for the animal to form a multimodal representation of the context that is paired with the shock. Hence, a treatment might block context anxiety, not because it was anxiolytic, but because it interfered with a representation of context. In fact, this is typically what is concluded when a treatment, such as a hippocampal lesion, blocks the expression of context but not cued fear conditioning (Blanchard et al, 1976; Fanselow, 1986).

However, animal learning theorists consider that context is not necessarily a spatial location but a set of static background stimuli present during training (Otto and Poon, 2006; Rescorla and Wagner, 1972). Unlike discrete CSs, which are highly predictive of the US, contexts are thus conceptualized as stimuli that are poor predictors of danger. In order to develop a method that had better stimulus control of this type of context conditioning, we used the 


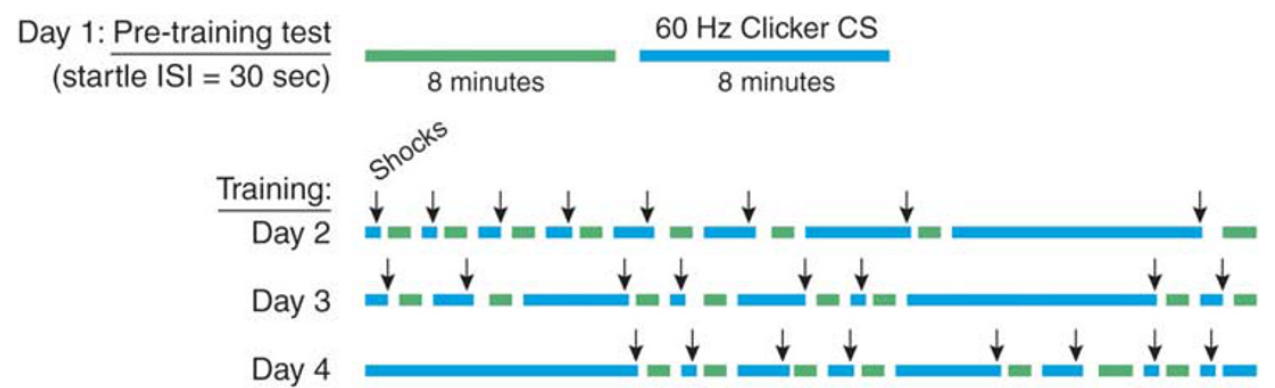

Day 5: Post-training test

(startle ISI = $30 \mathrm{sec}$ )

Figure 5. Sustained Startle Test and Conditioning Procedure. For conditioning, rats received eight presentations of variable duration (3, 10, 20 s, 1, 2, $4,6$, and $8 \mathrm{~min}$ ) of $60-\mathrm{Hz}$ clicker stimulus together with co-terminating footshock. Startle amplitude to $50 \mathrm{~ms}$ of $95-\mathrm{dB}$ noise bursts (ISI $=30 \mathrm{~s})$ was measured before and after conditioning, for $8 \mathrm{~min}$ in the absence and then for $8 \mathrm{~min}$ in the presence of the clicker. In normal rats, the clicker did not increase startle before conditioning, but did increase startle after conditioning. Blue bars indicate periods when the clicker was present and arrows indicate footshock.

design depicted in Figure 5. Rats received eight presentations on each of 3 days of a variable duration $(3 \mathrm{~s}-8 \mathrm{~min})$ of $60-\mathrm{Hz}$ clicker stimulus $(72 \mathrm{~dB}, 0.1 \mathrm{~ms}$ pulse width, provided by a Grass Instruments $\mathrm{S} 44$ stimulator) together with coterminating footshock $(0.35 \mathrm{~mA}, 0.5 \mathrm{~s})$. At $24 \mathrm{~h}$ before the first conditioning session and $48 \mathrm{~h}$ after the last, rats were presented with a series of startle-eliciting noise bursts presented first in the absence (phase I- $8 \mathrm{~min}$ ) and then in the presence (phase II - also $8 \mathrm{~min}$ ) of the CS (interstimulus interval (ISI) $=30 \mathrm{~s}$ ). Training and testing was carried out in the startle test box, but various contextual elements were changed in order to minimize fear response to the context itself. During training, the context consisted of constant white light (54 lux as measured from the center of test cage), alcohol-wetted gauze pads as an odor element placed just outside the test cage, shock bar floor exposed, and two hanging beaded chains. For the pre- and post-conditioning tests, the context consisted of lights off, ambient odor only, sandpaper flooring, and no chains. As the duration of the CS during conditioning varies, fear was maintained for the duration of the CS during testing $(8 \mathrm{~min}$ ) because the rats could not predict in advance when the CS would end and when the US would occur. In fact, during testing the US did not occur at all, but the rat had no way of knowing this in advance. Figure 6 shows that this procedure produced fearpotentiated startle throughout the duration of the clicker compared with little or no potentiation before or after the clicker, so that fear was sustained across the 8-min period when the clicker was on. Interestingly, startle amplitude was highest during the first minute, perhaps reflecting mostly strong phasic fear at the beginning of the clicker, followed by a lower, but more sustained, level of fear over the next several minutes. As Figure 6 highlights, there was no pre- to post-conditioning increase in baseline startle (ie, in the absence of the clicker), indicating that the startle baseline, against which startle to the clicker was measured, was not influenced by contextual fear, as predicted for startle by changing the context between training and test sessions (McNish et al, 1997).

\section{CRF-Enhanced Startle}

One pharmacological model of sustained fear in rats uses the peptide corticotropin-releasing hormone (CRF). CRF was first discovered in the paraventricular nucleus of the hypothalamus (PVT) and is critical to the peripheral stress response. However, CRF cell bodies and receptors are found in high concentrations in other brain areas (Swanson et al, 1983) and CRF antagonists are known to block many physiological and behavioral effects associated with stress (Dunn and Berridge, 1990). In 1986, Swerdlow et al reported that infusions of CRF into the lateral cerebral ventricle markedly increased the amplitude of the acoustic startle response in rats (CRF-enhanced startle). The benzodiazepine anxiolytic, chlordiazepozide, reduced this effect, but in control studies it did not reduce startle increases produced by the inhibitory glycine receptor antagonist strychnine, which influences startle by acting on receptors in the brainstem and the spinal cord (Kehne et al, 1981); this has not been implicated in anxiety. Liang et al (1992b) reported large, dose-dependent increases in startle amplitude that began $\sim 30$ min after CRF infusion, grew steadily over the course of a 2-h test period, and lasted for several hours thereafter. These increases were prevented by pretreatment with $\alpha$-helical CRF $\left(\alpha \mathrm{hCRF}_{9-41}\right)$, a CRF antagonist, and were reversed by delayed $\alpha \mathrm{hCRF}_{9-41}$ infusions (see also Swerdlow et al, 1989). The effects of intra-cerebroventricular (i.c.v.) infusions were mimicked by intracisternal (fourth ventricle) but not by intrathecal (in the space around motor neurons in the spinal cord) CRF infusions and were not disrupted by lesions of the PVT (Liang et al, 1992a). Together, these findings indicated that the effects of CRF on startle were directly mediated by CRF receptors in the brain, and did not involve activation of the CRF-regulated 


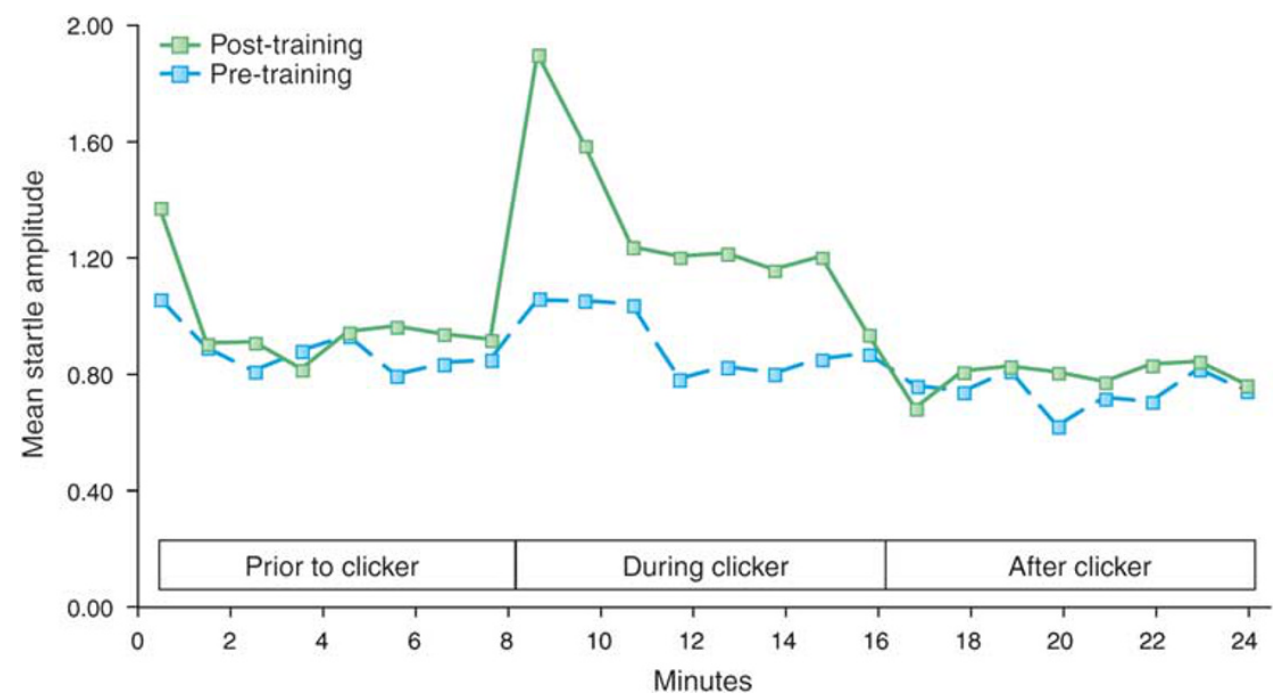

Figure 6. Mean startle amplitude over minutes for 8 min before the CS, the 8 min during the CS, and the 8 min after the CS. In this particular case, startle amplitude increased abruptly with the CS onset and returned abruptly to pre-conditioning baseline with CS offset. However, on several other occasions we have observed that startle amplitude remains elevated for up to several minutes after CS offset.

hypothalamic-pituitary-adrenal axis. Thus, CRF-enhanced startle leads to a sustained increase in startle amplitude, is sensitive to benzodiazepines, and does not involve conditioning.

In summary, several models of phasic and sustained fear in both rats and humans have been developed. Fearpotentiated startle to a discrete cue predictably paired with an aversive cue or with a verbal threat is a measure of phasic fear. Light-enhanced startle in rats, dark-enhanced startle in humans, context conditioning or verbal threats that involve unpredictable aversive events in rats and humans, longduration cues paired with shocks in rats, or CRF infusion into the rat brain all produce longer, sustained states of fear. Importantly, as we will see later, phasic and sustained fear differ both in terms of their anatomy and their susceptibility to different pharmacological treatments.

\section{ANATOMICAL DIFFERENCES BETWEEN PHASIC vs SUSTAINED FEAR: THE CONCEPT OF THE EXTENDED AMYGDALA}

On the basis of early observations by Johnston (1923), the concept of the 'extended amygdala' was developed and explored in great detail by Alheid et al (1998) and Alheid and Heimer (1988). They showed that the central (CeA) and medial (MeA) nuclei of the amygdala and the bed nucleus of the stria terminalis (BNST) were connected by columns of cells located throughout the stria terminalis, the fiber tract that connects these amygdala nuclei with the BNST, and also in a ventrally located part of the basal forebrain. They also showed that the CeA projected primarily to the lateral division of the BNST $\left(\mathrm{BNST}_{\mathrm{L}}\right.$ ) and that the MeA projected primarily to the medial division of the BNST $\left(\mathrm{BNST}_{\mathrm{M}}\right)$. They termed this continuum of cells 'the extended amygdala.' Moreover, the CeA and the $\mathrm{BNST}_{\mathrm{L}}$ are highly similar anatomically in terms of inputs, outputs, cell types, and neurochemical makeup, especially with respect to the high levels of several peptides found in both structures (Alheid et al, 1995). Indeed, Johnston (1923) further suggested that the two nuclei were the same, but had been separated during development. The basolateral nucleus of the amygdala (BLA) also projects not only to the CeA but also to the $\mathrm{BNST}_{\mathrm{L}}$, particularly from the caudal part of the BLA $\left(B_{c}\right.$ ) (Dong et al, 2001; McDonald, 1991; Weller and Smith, 1982). In fact, $B_{C A}$ fibers that project to the $B_{N S T}$ go right through the CeA (Figure 7). This is an extremely important finding because it indicates that electrolytic lesions of the CeA will not only block outputs of the CeA but also disconnect the BLA from the BNST and we believe many effects that have been found after electrolytic lesions of the CeA may result from this disconnection.

\section{Evidence for Independent Roles of the $\mathrm{CeA}_{M}$ vs the $\mathrm{CeA}_{\mathrm{L}}$}

The CeA can be divided into several subnuclei that include, most notably, the medial $\left(\mathrm{CeA}_{\mathrm{M}}\right)$ and lateral $\left(\mathrm{CeA}_{\mathrm{L}}\right)$ subdivisions. Although both areas project to the $\mathrm{BNST}_{\mathrm{L}}$ (Bourgeais et al, 2001; Dong et al, 2001; Petrovich and Swanson, 1997; Sun et al, 1991), they are otherwise very different. First, the $\mathrm{CeA}_{M}$ has many projections to the hypothalamus and the brainstem nuclei that elicit a pattern of somatic and autonomic responses that collectively define a hypothetical state of fear (cf, Davis, 2000; Davis and Whalen, 2001), including areas that mediate or modulate the acoustic startle response (Fendt et al, 1994; Meloni and Davis, 1999; Rosen et al, 1991; Shammah-Lagnado et al, 1987; Shi et al, 2002). In contrast, $\mathrm{Ce}_{\mathrm{L}}$ projections to these areas are much more limited (Gray and Magnuson, 1992; Gray and Magnusson, 1987; Schwaber et al, 1982; Veening et al, 1984). The $\mathrm{CeA}_{\mathrm{L}}$ instead projects to the substantia 


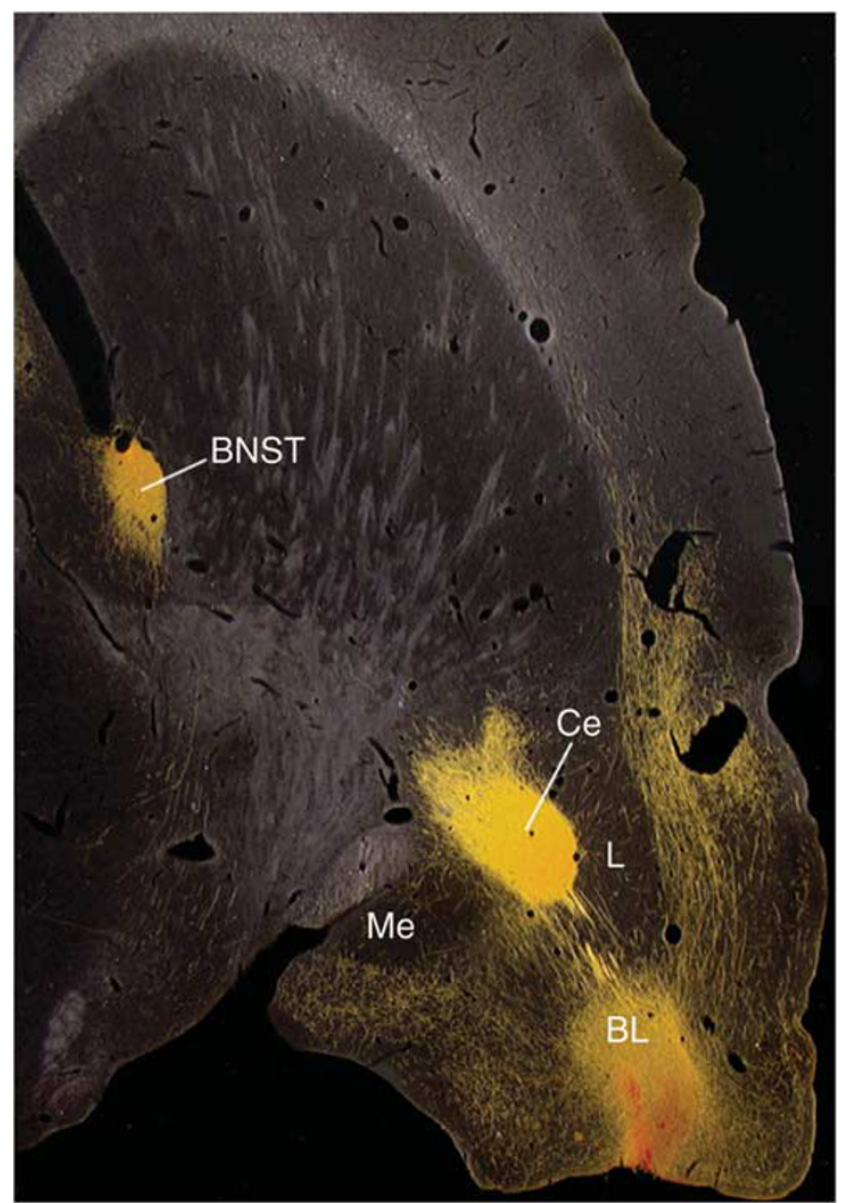

Figure 7. Photomicrographs prepared and provided by Dr Chungjun Shi of 30- $\mu \mathrm{m}$ horizontal sections through a rat brain, cut at a slight angle to include the amygdala and BNST in the same sectional plane. Infusions of the anterograde tracer biotinylated dextran-amine (BDA) into the posterior BLA (BLAP) show strong projections both to the medial and lateral $\mathrm{CeA}$ (labeled here as $\mathrm{CM}$ and $\mathrm{CL}$ ) and also to the BNST. As those that project to the BNST pass directly through the CeA, electrolytic CeA lesions or intra-CeA infusions of sodium channel blockers such as TTX would interrupt this pathway.

innominata, perhaps to the $\mathrm{CeA}_{\mathrm{M}}$, and quite prominently to the $\mathrm{BNST}_{\mathrm{L}}$ (Bourgeais et al, 2001; Dong et al, 2001; Petrovich and Swanson, 1997; Sun et al, 1991).

The $\mathrm{CeA}_{M}$ and $\mathrm{CeA}_{L}$ also differ in terms of their neurotransmitter content. Although $\mathrm{CeA}_{\mathrm{L}}$ neurons stain for various neuropeptide transmitters, these same peptides are largely absent from $\mathrm{CeA}_{\mathrm{M}}$ neurons (Cassell et al, 1986; Day et al, 1999; Gray and Magnusson, 1987; Moga and Gray, 1985; Otake et al, 1995; Shimada et al, 1989; Veening et al, 1984; Wray and Hoffman, 1983). One peptide found in great abundance in the $\mathrm{CeA}_{\mathrm{L}}$ is CRF. In fact, $\mathrm{CeA}_{\mathrm{L}}$ neurons are a major source of $\mathrm{BNST}_{\mathrm{L}} \mathrm{CRF}$. This was shown by Sakanaka et al (1986), who found that electrolytic CeA, but not BLA, lesions dramatically reduced $\mathrm{BNST}_{\mathrm{L}} \mathrm{CRF}$ immunoreactivity, nearly depleting it entirely from the dorsal $\mathrm{BNST}_{\mathrm{L}}$. Many neurons within the $\mathrm{BNST}_{\mathrm{L}}$ are themselves CRF-positive (Cintra et al, 1987; Cummings et al, 1983; Day et al, 1999; Gray and Magnuson, 1992; Gray and Magnusson, 1987; Makino et al, 1994a, b; Phelix and Paul, 1990; Shimada et al,
1989; Veinante et al, 2003; Watts and Sanchez-Watts, 1995), and CRF-positive neurons in both areas invariably express gamma-aminobutyric acid (GABA; Day et al, 1999; Veinante et al, 1997). As high-frequency stimulation is known to favor peptide release (eg, Bartfai et al, 1988; Bourque, 1991; Ip, 1994; Lundberg et al, 1986; Whim, 1989), the findings suggest that the influence of these neurons (ie, either inhibitory or excitatory) on downstream structures may vary as a function of the pattern of afferent activity. More specifically, sustained high-frequency activation may favor the release of CRF. It is also of some interest that CRFpositive neurons in the $\mathrm{CeA}_{\mathrm{L}}$ and dorsal $\mathrm{BNST}_{\mathrm{L}}$ express glucocorticoid receptors (Cintra et al, 1987; Honkaniemi et al, 1992; Lechner and Valentino, 1999).

Another difference is that in the rat, the $\mathrm{CeA}_{M}$ receives input from almost all other nuclei within the amygdala, whereas the $\mathrm{CeA}_{\mathrm{L}}$ receives virtually no amygdala input at all (Jolkkonen and Pitkanen, 1998). Instead, prominent inputs to the $\mathrm{CeA}_{\mathrm{L}}$ include those from insular and entorhinal cortices (McDonald et al, 1997; Sun et al, 1994; Yasui et al, 1991), as well as from the PVT (Berendse and Groenewegen, 1991; Li and Kirouac, 2008; Moga et al, 1995; Turner and Herkenham, 1991; Vertes and Hoover, 2008); all of these are areas that project very lightly to the $\mathrm{CeA}_{\mathrm{M}}$.

\section{Projections from the PVT to the $\mathrm{CeA}_{\mathrm{L}}$}

Projections from the PVT to the $\mathrm{CeA}_{\mathrm{L}}$ are especially interesting insofar as the PVT is one of the most stressresponsive areas in the brain, based on the induction of a marker of cellar activity, c-Fos, with various stressors (Beck and Fibiger, 1995; Bhatnagar and Dallman, 1998, 1999; Bubser and Deutch, 1999; Chastrette et al, 1991; Duncan et al, 1996). In fact, Bhatnagar and Dallman (1998) suggested that the PVT to the amygdala pathway is a key regulator of the hypothalamic-pituitary-adrenal response to stress. Moreover, PVT fibers appear to make contact onto CRF-containing neurons in the $\mathrm{CeA}_{\mathrm{L}}(\mathrm{Li}$ and Kirouac, 2008), suggesting that they can directly modulate CRF transmission. Interestingly, the PVT also appears to be involved in circadian rhythms, and the BNST shows periodicity in clock gene expression that is highly similar to, and dependent upon, the suprachiasmatic nucleus (Amir et al, 2004). Hence, it is possible that dysregulation of the BNST might contribute to the sleep disturbances associated with anxiety and depression.

\section{Cortical Inputs to the $\mathrm{CeA}_{\mathrm{L}}$}

Cortical inputs to the $\mathrm{CeA}_{\mathrm{L}}$ are also interesting, in that they raise the intriguing possibility that these inputs might mediate some of the cognitive aspects of apprehension in both animals and humans. In fact, several functional magnetic resonance imaging (fMRI) studies have found that the insular cortex becomes active when human subjects are told to anticipate shock (Phelps et al, 2001), or learn to expect other aversive stimuli in the course of conditioning 
procedures (Buchel et al, 1998; Ploghaus et al, 1999); similar results have also been found for the BNST (and see also Kalin, 2005 for threat-induced BNST activation in nonhuman primates; Straube et al, 2007). The insular cortex also projects heavily to the $\mathrm{BNST}_{\mathrm{L}}$ as well as to the posterior part of the BLA (BLA P (eg, McDonald et al, 1999; Yasui et al, 1991), which itself projects to the $\mathrm{BNST}_{\mathrm{L}}$. On the basis of the many similarities between these two components of the extended amygdala, our laboratory began to evaluate the role of both the CeA and the $\mathrm{BNST}_{\mathrm{L}}$ in our models of fear and anxiety. This study was thoroughly reviewed in Walker et al (2003) and Walker and Davis (2008) and will only be summarized briefly here.

\section{Differential Involvement of the CeA vs the BNST in Phasic vs Sustained Fear}

Similar to earlier study in which freezing was used as a fear measure (Iwata et al, 1986; LeDoux et al, 1988), we found that lesions of the CeA, but not the $\mathrm{BNST}_{\mathrm{L}}$, blocked fearpotentiated startle, in this case to a 3.7-s light that had been previously paired with footshock (Hitchcock and Davis, 1986, 1991). In contrast to fear-potentiated startle to shortduration CSs, light-enhanced startle was not blocked by local infusion of the $\alpha$-amino-3-hydroxy-5-methyl-4-isoxazolepropionate (AMPA) receptor antagonist NBQX into the CeA, but was blocked by local infusions into the BNST. On the other hand, both fear-potentiated and light-enhanced startle were blocked by inactivation of the BLA, which projects to both the CeA and the $\mathrm{BNST}_{\mathrm{L}}$. Infusion into the caudal BLA was the most effective (Figure 8), consistent with caudal BLA projections to the BNST (Dong et al, 2001; McDonald, 1991; Weller and Smith, 1982).

We also found that the $\mathrm{BNST}_{\mathrm{L}}$, but not the CeA, was involved in CRF-enhanced startle. For instance, excitotoxic

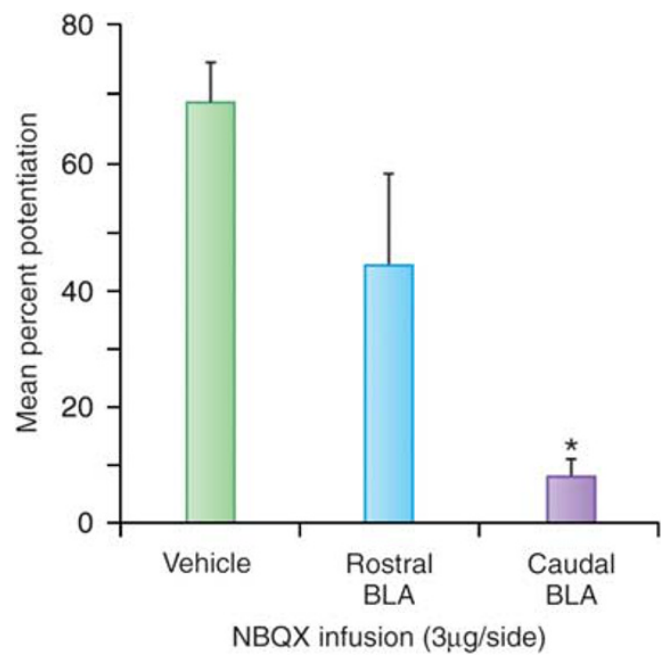

Figure 8. Infusions of NBQX, an AMPA receptor antagonist, into the caudal rather than the rostral BLA blocked light-enhanced startle. It can be noted that the caudal part provides most of the input from the BLA to the BNST .
$\mathrm{BNST}_{\mathrm{L}}$ lesions, or local infusions of a CRF antagonist into the $\mathrm{BNST}_{\mathrm{L}}$, completely blocked CRF-enhanced startle, although similar lesions of the CeA, or infusions into the CeA, did not (Lee and Davis, 1997). Below, we describe how inactivation of the BLA also blocks CRF-enhanced startle, similar to light-enhanced startle (Table 1).

\section{Independence of CeA and BNST Fear Systems}

As further evidence for the hypothesis that short and longer duration fear states are mediated by independent systems, we tested a prediction borne of this hypothesis, namely, that the influence of startle on treatments that acted through different systems (ie, the CeA or BNST) would be additive, whereas the effects on startle of treatments that acted through the same system (ie, both CeA or both BNST) would occlude one another (Walker and Davis, 2002b). Results from a series of experiments seemed to confirm this prediction (see Figure 9 for the results of two such experiments). First, fear-potentiated startle to a 3.7-s visual CS was occluded by co-presentation of a 3.7-s auditory CS in rats that had previously been fear conditioned to both (ie, in independent trials - left bars). Here, occlusion was expected because the startle-potentiating effects of both types of stimuli were mediated by the $\mathrm{CeA}_{\mathrm{M}}$, but not by the BNST (Hitchcock and Davis, 1986, 1987, 1991; LeDoux et al, 1988). In marked contrast to these results, fear-potentiated startle to a 3.7-s visual CS in other rats was not occluded by i.c.v. CRF infusions, although these infusions caused a much bigger increase in 'baseline' startle (right bars). This was also expected on the basis of previous evidence that CRFenhanced startle is mediated by the BNST but not by the CeA. Overall, these results and several others (see Walker and Davis, 2002b) were consistent with the view that the effects of shorter and longer duration fear states on startle are mediated by partially independent systems. However, it should be restated that we believe both effects involve the BLA, although we cannot say for certain whether the same or different BLA neurons are involved. If the same neurons are involved, then these results would suggest that the ceiling for startle increases is determined by the CeA and the BNST, and not by the upstream BLA. Results from a recent study by Ponder et al (2007) found that rats selectively bred for high levels of context-elicited freezing also show higher than normal levels of fear-potentiated startle to a discrete fear CS. This suggests that at some level (quite possibly the BLA and perhaps elsewhere as well), these systems do interact and are thus not totally independent from each other, probably with respect to outputs from the CeA and BNST.

\section{The BNST is Required for a Sustained State of Apprehension}

Given the many similarities between fear-potentiated and light-enhanced startle - ie, both use increased startle as a behavioral measure and light as a stimulus to produce this 
Table 1 Effects of Local Infusion of the Glutamate Antagonist NBQX or Neurotoxic Lesions of Various Brain Areas in Phasic vs Sustained Fear

\begin{tabular}{lllll}
\hline Brain area & $\begin{array}{l}\text { Phasic fear } \\
\text { to short cue }\end{array}$ & $\begin{array}{l}\text { Sustained fear } \\
\text { to long cue }\end{array}$ & $\begin{array}{l}\text { Sustained fear- } \\
\text { light-enhanced startle }\end{array}$ & $\begin{array}{l}\text { Sustained fear- } \\
\text { CRF-enhanced startle }\end{array}$ \\
\hline BLA & Block & Block & Block & Block \\
CeA & Block & No Block & No block & No block (lesion) \\
BNST & No block & Block & Block & Block (lesion) \\
\hline
\end{tabular}

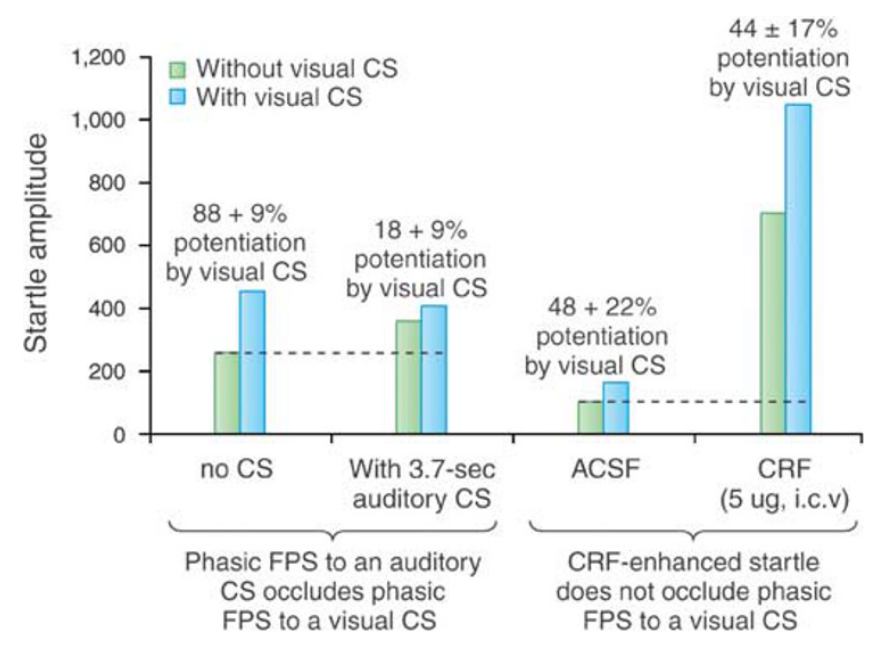

Figure 9. Fear-potentiated startle to a 3.7-s visual CS, dependent on glutamate receptors in the $\mathrm{CeA}_{\mathrm{M}}$, was occluded by fear-potentiated startle to a 3.7-s auditory CS, also dependent on glutamate receptors in the $\mathrm{CeA}_{M}$ (left bars), but not by CRF-enhanced startle, which depends on CRF receptors in the BNST (right bars). Percent potentiation scores to the visual CS are indicated above each set of bars. Dashed lines indicate baseline startle (ie, on noise-alone trials).

effect-their differential susceptibility to CeA $v s$ BNST inactivation is perhaps surprising. However, these similarities are also quite useful, in that they greatly constrain the range of possible interpretations for the dissociations just noted. We previously suggested that there are two major possibilities at play: either that the CeA has a special role in mediating conditioned fear responses, whereas the BNST mediates unconditioned responses or, alternatively, that the CeA has a special role in mediating short-duration fear responses and the BNST mediates longer duration responses (Walker and Davis, 1997a).

To discriminate between these two alternatives, we have been evaluating the effects of CeA and BNST inactivation in our model of sustained fear involving a CS that is both conditioned and also of long duration. If BNST inactivation were to disrupt this measure of sustained fear, then the conditioned $v s$ unconditioned hypothesis would no longer seem tenable, whereas the short- $v s$ long-duration hypothesis would remain viable. We have now developed procedures to assess these alternatives, and have found that the short- $v s$ long-duration hypothesis is more likely.

Using an earlier version of this design (eight presentations per day of a noise CS), we first evaluated the effect of

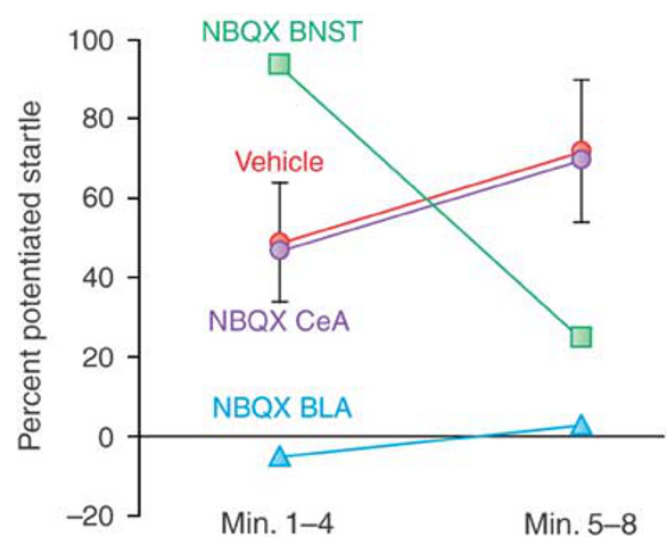

Figure 10. The effect on fear-potentiated startle to 8-min auditory CS was evaluated in rats after intra-cranial infusions of the AMPA receptor antagonist NBQX ( $3 \mu \mathrm{g}$ per side in $0.5 \mu \mathrm{l}$ phosphate-buffered saline). Intra-BNST infusions $(N=11)$ decreased the sustained component of fear-potentiated startle, but augmented the early component, relative to vehicle infusions ( $N=25$, pooled across structures). Owing to an extreme outlier in the PBS group (606\% potentiation during block 1) that distorted the normal distribution, these data were analyzed non-parametrically by the Mann-Whitney test on block 2-block 1 difference scores, reflecting an interaction effect $(p<0.019)$. After histological verification of cannula placement, rats were divided into $\mathrm{BLA}(\mathrm{N}=6)$ or $\mathrm{CeA}(\mathrm{N}=8)$ groups. Intra-BLA infusions disrupted both the early and sustained components of fear-potentiated startle, whereas intra-CeA infusions disrupted neither.

pre-test $\mathrm{NBQX}$ infusions into the $\mathrm{BLA}$, the CeA, and the BNST. As shown in Figure 10, BNST infusions decreased the late component of fear-potentiated startle (ie, minutes 5-8 of the CS) but actually increased the early component (ie, minutes 1-5). These results are consistent with the idea that the BNST selectively mediates sustained fear responses. The increase of startle during the early part of the CS is consistent with the finding that local infusion of muscimol, a GABA agonist, into the BNST increases fear-potentiated startle to a short-duration cue (Meloni et al, 2006). Both of these observations may reflect the tonic inhibition of phasic fear by the BNST. Infusions into the BLA blocked both components and, in this study, infusions into the CeA blocked neither. The ineffectiveness of CeA infusions was a surprise, given the previous findings that electrolytic (Hitchcock and Davis, 1987) or chemical (Campeau and Davis, 1995) CeA lesions, or intra-CeA NBQX infusions (Walker and Davis, 1997b) all blocked fear-potentiated startle to 3.7-s CSs. It is possible that the cutoff for shortduration fear is very short and that we simply missed the 
CeA's involvement (or more precisely, the involvement of CeA AMPA receptors). A finer-scale analysis with more animals will be required to determine when short-duration fear becomes long-duration fear as defined by this measure (eg, Figure 6).

Sullivan et al (2004) reported that post-training electrolytic $\mathrm{BNST}_{\mathrm{L}}$ lesions disrupt freezing, as well as corticosterone responses to a context CS, but do not affect these same responses to a brief auditory CS, whereas CeA lesions disrupt freezing to both. Later we discuss how the effects of CeA lesions may have been because of destruction of the $\mathrm{CeA}_{\mathrm{L}}$, which we believe is particularly involved in sustained fear through projections to the BNST. On the basis of those findings, Sullivan et al (2004) proposed that the BNST has a special role in context-elicited fear. However, in light of our most recent findings, we wonder whether a more conservative interpretation may be that $\mathrm{BNST}_{\mathrm{L}}$ lesions disrupt contextelicited freezing simply because context CSs are invariably long in duration, and so also are the responses they evoke.

Resstel et al (2008) reported that pre-test intra-BNST infusions cobalt chloride, which block neurotransmitter release but not action potential propagation, disrupted context-elicited freezing, and decreased heart rate and arterial blood pressure. Time-course analyses of context-evoked tachycardia suggested that the effect of BNST inactivation increased with time (10-min test), although the effects on context-evoked blood pressure changes did not. Thus, evidence for the preferential involvement of the BNST in the early $v s$ the late component of these responses was mixed, depending on the particular response being considered. Indirect evidence consistent with BNST involvement in context-elicited fear was also observed by Waddell et al (2006), who reported that the reinstatement of extinguished fear by footshock - a phenomenon believed to depend on conditioning to the shock-paired context (Bouton and Bolles, 1979) - was disrupted by i.c.v or intra-BNST infusions of a CRF receptor antagonist (see below). Overall, there is good evidence from several recent studies that an intact and functional BNST is required for context fear expression.

\section{THE ROLE OF CRF IN SUSTAINED FEAR}

As mentioned earlier, CRF cell bodies and receptors are found in high concentrations in several brain areas, especially the $\mathrm{CeA}_{\mathrm{L}}$ and BNST (Swanson et al, 1983), and CRF antagonists are known to block many of the physiological and behavioral effects associated with stress (Dunn and Berridge, 1990). As the BNST is implicated in sustained fear, and because CRF facilitates startle for a long time once infused into the brain, we wondered whether CRF itself might mediate sustained fear. Several lines of evidence suggest this is true.

\section{Light-Enhanced Startle}

The involvement of the BNST in both CRF- and lightenhanced, but not fear-potentiated startle, suggests that light-enhanced startle, and perhaps BNST-dependent responses more generally, might be especially sensitive to CRF receptor blockade. Indeed, de Jongh et al (2003) reported that i.c.v. infusions of the CRF-R1/2 antagonist $\alpha \mathrm{hCRF}_{9-41}$ had no effect on fear-potentiated startle to a 3.7-s light, but significantly disrupted light-enhanced startle at an intermediate $(5 \mu \mathrm{g})$ but not at a higher dose $(25 \mu \mathrm{g})$. Those results are consistent with the preferential involvement of CRF receptors in BNST- vs CeA-mediated effects. Nevertheless, they might also reflect preferential access of i.c.v.infused $\alpha \mathrm{hCRF}_{9-41}$ to the BNST neurons that lie immediately adjacent to the lateral ventricle rather than more restricted access to the CeA. However, using oral administration of the selective CRF-R1 antagonist GSK876008 (Di Fabio et al, 2008), at doses that dose dependently (linear) disrupt CRFenhanced startle, we also observed a non-monotonic disruption of light-enhanced startle but no disruption of fear-potentiated startle in the same animals at the same doses (Figure 11) (Walker et al, 2009).

\section{Long Duration Cues Paired with Shock}

As noted above, we believe that CRF receptors participate preferentially in BNST- as opposed to CeA-dependent responses. As such, we also compared the effect of CRFR1 blockade (oral administration) on short- $v s$ longduration startle increases to conditioned fear stimuli. Data are shown for two experiments; the first compared the effect of a CRF1 antagonist on startle increases to a short (3.7-s) vs long-duration (8-min) low-frequency-filtered white noise CS (Figure 12, left panel). The second experiment compared the effects of the same drug on startle increases to a short (3.7-s) vs long-duration (8-min) 60-Hz clicker CS (Figure 12, right panel). In both cases, oral administration of the CRFR1 antagonist dose dependently blocked fear-potentiated startle to an 8-min CS presentation, but did not disrupt fearpotentiated startle to 3.7-s CS presentations, and even enhanced it in some animals. The CRF1 antagonist also had no effect on phasic startle increases (ie, to a 3.7-s clicker CS presentation) in rats trained using the sustained fear conditioning paradigm, confirming that it is the duration of the fear response during testing that confers sensitivity to CRF-R1 blockade, and not the nature of the training. We also found that local infusion into the BNST of this CRF1 antagonist blocked sustained fear to the 8-min clicker, in contrast to the lack of effect of the local infusion of a CRF antagonist into the CeA on phasic fear (Lee and Davis, 1997).

Hence, these data indicate that the BNST does indeed have an important role in the expression of conditioned fear responses, provided those responses are maintained for a relatively long time. On the basis of finding that an unconditioned visual stimulus begins to increase startle $\sim 60 \mathrm{~s}$ after light onset (Davis et al, 1989), and the fact that BNST inactivation does not disrupt fear-potentiated startle to a 3.2-s visual CS (Walker and Davis, 1997a), we suspect that the transition from $\mathrm{CeA}_{\mathrm{M}}$ to $\mathrm{BNST}_{\mathrm{L}}$ involvement may 
a

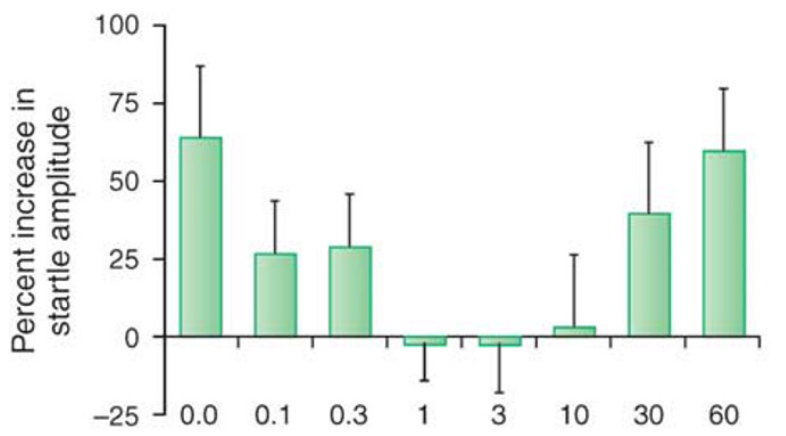

b FEAR-POTENTIATED STARTLE

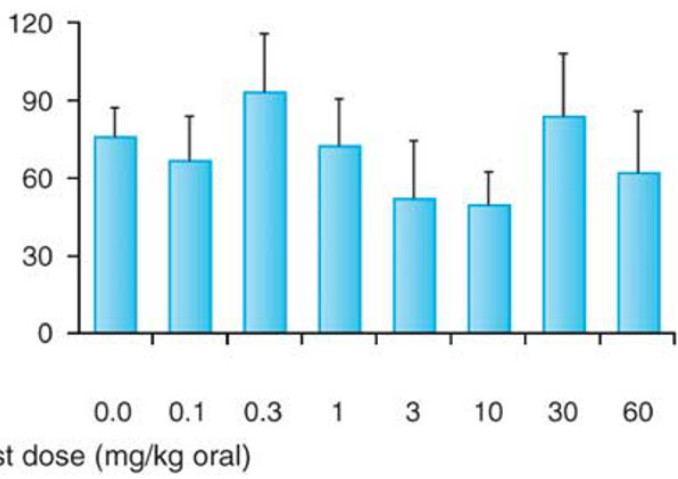

Figure 11. Rats were tested for light-enhanced startle and then fear-potentiated startle. Before each test, the selective CRF-R1 antagonist GSK876008 was administered orally (for each test, each rat received the same dose that it received in the other test). The selective CRF-R1 antagonist GSK876008 non-monotonically disrupted light-enhanced startle (a); significant quadratic trend), but did not disrupt fear-potentiated startle (b).
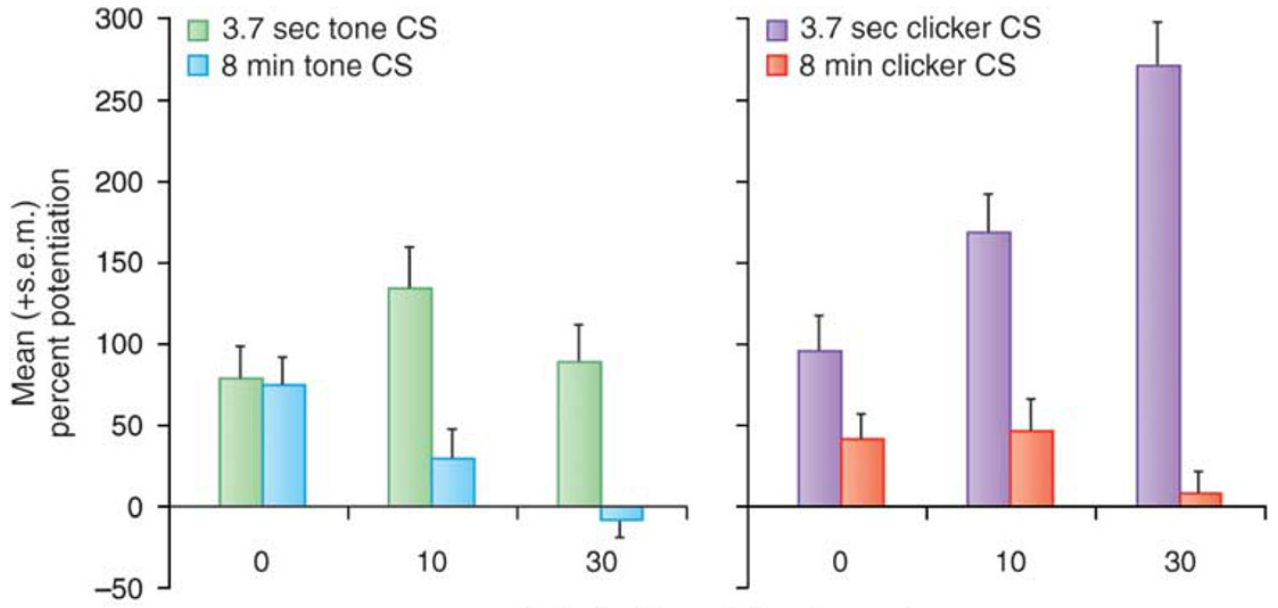

CRF 1 antagonist (mg/kg, p.o.)

Figure 12. In two different experiments using slightly different sustained fear conditioning procedures (see Figure 5), the selective CRF-R1 antagonist GSK876008 disrupted potentiated startle to an 8-min CS, but did not disrupt potentiated startle to a 3.7-s presentation of the same stimulus.

begin between 4 and $60 \mathrm{~s}$ after CS onset, although it may be several minutes before the response is fully dependent on the $\mathrm{BNST}_{\mathrm{L}}$.

This pattern does not appear to be idiosyncratic to studies in which startle is used as a response measure. Findings from Waddell et al (2006) are especially relevant, who reported that BNST lesions disrupted conditioned suppression (ie, of bar pressing for food) to a 10-min, but not 1-min clicker CS. Although these data are consistent with our hypothesis, the authors interpreted their findings somewhat differently. In particular, they suggested that the involvement of the BNST was a function of the CS onset to US onset interval. That is, the BNST would selectively mediate responses to a temporally distant US (pre- or post-encounter phases), rather than the duration of the conditioned response. This is a viable interpretation because rats in their study were trained with either 1- or 10-min clicker presentations and, for both, the footshock did not occur until the very end of the CS. As our study used USs distributed throughout the CS, interpretation by Waddell et al (2006) would not seem to account for our data. A minute-by-minute analysis of their findings might indicate whether our interpretation could be integrated with theirs. That is, we would predict that a lesion-induced disruption of conditioned suppression would become increasingly apparent toward the end of the CS (ie, as response duration grows), whereas their hypothesis would predict the opposite (ie, a lesion effect would be more apparent early on, when the US is still somewhat distant).

\section{Context Conditioning}

There is also evidence that CRF is involved in context conditioning. Several authors have reported that freezing to contextual CSs was disrupted by CRF receptor antagonists (Deak et al, 1999; Hikichi et al, 2000; Kalin and Takahashi, 1990), and recent findings from Risbrough et al (2009), as well as from our own laboratory (Walker et al, 2009), 
indicate a similar and, importantly, preferential involvement of CRF receptors in fear-potentiated startle to context but not discrete fear CSs. In the study by Risbrough et al (2009), CRF1 knockout mice showed a complete abolition of context-potentiated startle assessed immediately after conditioning, but normal fear-potentiated startle to a 30-s light/tone compound CS that had been paired with footshock $24 \mathrm{~h}$ earlier. CRF2 knockout mice also showed normal fear-potentiated startle to the discrete CS, but also some attenuation of context-potentiated startle. These effects on context-potentiated startle might reflect effects on either conditioning or expression, as the effects of CRF receptor antagonists on fear learning and consolidation have previously been noted in mice (Radulovic et al, 1999; Todorovic et al, 2007), although in these studies the lateral septum was also involved.

We also found evidence of CRF receptor involvement in context-potentiated startle using pre-test infusions of the selective CRF1 antagonist GSK876008. As noted above, we previously found that oral administration of this drug did not disrupt fear-potentiated startle to a 3.7-s light (Figure 12). In that study, the same rats were also tested for 'baseline' startle (ie, in the absence of the explicit CS) before and then again after conditioning in the same context where conditioning took place (in both cases, this occurred after rats had received the CRF1 antagonist). This allowed us to evaluate the effect of CRF1 receptors on pre- to postconditioning startle increases. Control and low-dose rats did indeed show increased 'baseline' startle that was roughly comparable in magnitude with fear-potentiated startle to the explicit 3.7-s visual CS. However, although fearpotentiated startle to the explicit CS was not disrupted by any dose of a CRF1 antagonist, the pre- to post-conditioning startle increases were disrupted at doses of between 3 and $30 \mathrm{mg} / \mathrm{kg}$. However, this effect was not observed at doses of $60 \mathrm{mg} / \mathrm{kg}$ (Figure 13) - a non-monotonic doseresponse curve similar to that previously observed with

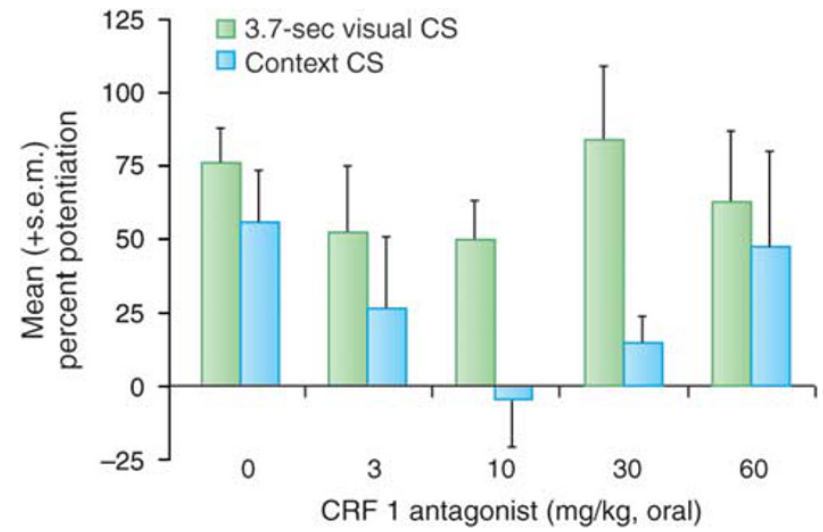

Figure 13. The effect of the CRF-R1 antagonist GSK876008 on pre- to post-shock changes in 'baseline' startle (ie, on test trials without the 3.7-s $\mathrm{CS})$, which may be a conditioned response to the context CS. The shape of the dose-response curve was similar to that seen earlier for lightenhanced startle, in which intermediate doses of GSK876008 disrupted these increases. light-enhanced startle (for a full discussion of these nonmonotonic effects and a possible explanatory hypothesis, see Walker et al, in press). As this study was not designed with the specific intent to evaluate context conditioning, we did not include context discrimination controls that would be necessary to rule out the possibility that these increases were because of non-associative sensitization. However, as longlasting non-associative sensitization also appears to be a BNST-dependent phenomenon (eg, Gewirtz et al, 1998), these findings, by either interpretation, would count as yet another example of BNST-dependent long-duration startle increases susceptible to CRF-R1 blockade. It can also be noted that in control and low-dose rats, the effects on fear-potentiated startle to the 3.7-s visual CS were not occluded by pre- to post-shock startle increases, but were instead cumulative with these increases; such a response would be expected if phasic and sustained startle increases are mediated by different systems (see previous section on occlusion, Independence of CeA and BNST fear systems). On the other hand, Gewirtz et al (1998) did not find that lesions of the BNST blocked the short-term and transient increase in startle, which occurs immediately after footshock - an effect thought to reflect rapid context conditioning (Richardson and Elsayed, 1998) - and this discrepancy has yet to be explained.

\section{CRF-Enhanced Startle}

Lee and Davis (1997) identified the BNST as the likely location of the CRF receptors that mediated the increase in startle after CRF is infused i.c.v. In particular, they showed that excitotoxic lesions of the BNST, but not the CeA, blocked CRF-enhanced startle, which infusion of the CRF receptor antagonist $\alpha$-helical $\mathrm{CRF}_{9-41}(\alpha \mathrm{hCRF})$ into the BNST, but not into the CeA, also blocked CRF-enhanced startle, and that intra-BNST CRF infusions mimicked the effect of intra-ventricular infusions. In fact, CRF receptor protein and mRNA are abundant in the BNST - much more so than in the CeA (Ju et al, 1989; Potter et al, 1994; Van Pett et al, 2000; Wynn et al, 1984). Consistent with this distribution, Liang et al (1992a) had previously shown that intra-amygdala CRF infusions, in contrast to intra-BNST CRF infusions, did not increase startle. In the same lesioned rats that were tested for CRF-enhanced startle, Lee and Davis (1997) confirmed that CeA, but not BNST, lesions disrupted fear-potentiated startle.

\section{Role of CRF in Other Animal Models of Anxiety}

The involvement of BNST CRF receptors in anxietyassociated behaviors is not limited to startle increases, but appears to reflect a more general involvement in anxiety itself (Sakaguchi et al, 1984). For example, intra-BNST CRF infusions have also been found to elicit anxiety-associated behaviors in the elevated plus-maze and social interaction tests (Lee et al, 2008; Sahuque et al, 2006), to produce conditioned place aversion to places associated with CRF infusion (Sahuque et al, 2006), to elicit cardiovascular 
responses that are associated with fear and anxiety (Nijsen et al, 2001), and to have anorectic effects which, in the same study, were not associated with intra-CeA CRF infusions (Ciccocioppo et al, 2003). Anxiogenic effects were also found after chronic inhibition of GABA synthesis in the BNST, and these effects were reversible by local infusion of muscimol into the BNST (Sajdyk et al, 2008).

\section{A MODEL TO EXPLAIN THE ROLE OF CRF IN SUSTAINED FEAR}

Figure 14 summarizes our working model of phasic vs sustained fear focusing on the BLA, CeA, and $\mathrm{BNST}_{\mathrm{L}}$ and how CRF-containing projections from the $\mathrm{CeA}_{\mathrm{L}}$ to the $\mathrm{BNST}_{\mathrm{L}}$ are involved in sustained fear. The BLA sends heavy projections to both the CeA and the BNST (Figure 7). The heaviest projections from the BLA to the CeA are to the $\mathrm{CeA}_{\mathrm{M}}$, which in turn projects to the hypothalamus and brainstem to mediate phasic fear responses. The $\mathrm{CeA}_{\mathrm{L}}$, activated perhaps by the BLA but also by the stress-sensitive PVT, and by cortical inputs, projects to and releases CRF that acts presynaptically on glutamate terminals from the

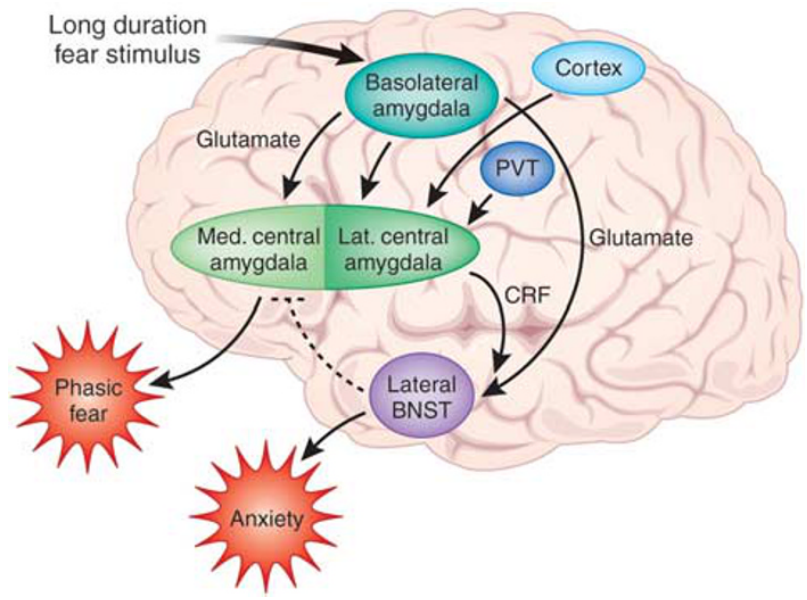

Figure 14. Schematic illustrating the hypothetical involvement of the $\mathrm{CeA}$ and BNST in short- and long-duration startle increases. Sensory information enters the basolateral amygdala complex (BLA-lateral, basolateral, and basomedial nuclei), which sends prominent projections to the medial division of the central nucleus of the amygdala $\left(\mathrm{CeA}_{M}\right)$ as well as projections to the lateral division of the bed nucleus of the stria terminalis $\left(B N S T_{L}\right)$. It also sends light projections to the lateral division of the central nucleus of the amygdala $\left(C e A_{\llcorner}\right)$, which sends a heavy, CRF-containing projection to the BNSTL. As inactivation of the BLA blocks the increase in startle produced by CRF given intraventricularly, we suggest that CRF may act presynaptically to enhance glutamate release from the $B L A$ terminals in the $B N S T_{L}$. The $C_{C} A_{L}$ also receives projections from cortical areas as well as from the highly stress-sensitive PVT. We hypothesize that a fear-eliciting stimulus rapidly activates the BLA and $\mathrm{CeA}_{M}$ to produce a short-acting phasic fear response. At the same time, inputs to the $C e A_{L}$ result in a release of CRF into the BNST to produce a more slowly acting, but long-lasting sustained fear response akin to anxiety. Inhibitory feedback from the BNST and/or $\mathrm{CeA}_{L}$ to the $\mathrm{CeA}_{M}$ may turn off the phasic fear response in order to produce a seamless transition from phasic to sustained fear. caudal BLA (see discussion below). A long duration fear stimulus activates the BLA, which then rapidly activates the $\mathrm{CeA}_{M}$ to produce phasic fear through the release of glutamate acting on AMPA/kainate receptors on $\mathrm{CeA}_{\mathrm{M}}$ neurons. Shortly thereafter, inputs to the $\mathrm{CeA}_{\mathrm{L}}$ then release CRF into the BNST to cause a long-lasting sustained fear reaction. Inhibitory feedback to the $\mathrm{CeA}_{\mathrm{M}}$ from either the $\mathrm{CeA}_{\mathrm{L}}$ or the BNST shuts down the $\mathrm{CeA}_{\mathrm{M}}$, allowing a seamless transition from phasic to sustained fear.

\section{The Role of the BLA in CRF-Enhanced Startle}

Liang et al (1992a) reported that electrolytic lesions of the CeA blocked CRF-enhanced startle when CRF was infused intraventricularly. This seems inconsistent with the fact that local infusion of CRF into the CeA failed to increase startle (Liang et al, 1992a) and that a CRF antagonist infused into the CeA failed to block CRF-enhanced startle (Lee and Davis, 1997). As shown earlier (Figure 7), electrolytic lesions of the CeA would effectively disconnect the BLA from the BNST, and we wondered what role the BLA might have in CRF-enhanced startle. Remarkably, Figure 15 shows that infusion of a cocktail of NBQX and muscimol into the BLA totally blocked CRF-enhanced startle, although, as mentioned earlier, CRF infused into the BLA has no effect on startle by itself. This result could explain why electrolytic lesions of the CeA blocked CRF-enhanced startle because these lesions would effectively disconnect the BLA from the BNST, although other possibilities cannot be ruled out. The question remains, however, as to why lesions of the BLA blocked CRF-enhanced startle. Our current working hypothesis is that CRF terminals in the BNST act presynaptically on BLA terminals within $\mathrm{BNST}_{\mathrm{L}}$, where they promote glutamate release and, therefore, excitatory drive onto $\mathrm{BNST}_{\mathrm{L}}$ neurons. In fact, very recent findings using CRF1 promotor linked to green fluorescent protein strongly suggest that many CRF1 receptors in the BNST are indeed

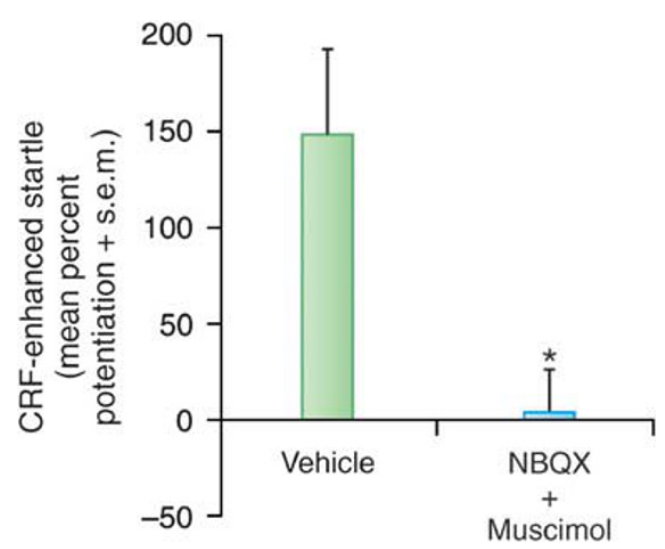

Figure 15. An intraventricularly infused cocktail of NBQX and muscimol infused into the BLA completely blocked CRF-enhanced startle. On the basis of this observation and some preliminary microdialysis, we suggest that CRF may act presynpatically on BLA terminals in the BNST to facilitate glutamate release. 
Table 2 Effects of Local Infusion or Intraventricular Infusion (i.c.v) of CRF Antagonist into Various Brain Areas in Phasic vs Sustained Fear

\begin{tabular}{lllll}
\hline Brain area & $\begin{array}{l}\text { Phasic fear } \\
\text { to short cue }\end{array}$ & $\begin{array}{l}\text { Sustained fear } \\
\text { to long cue }\end{array}$ & $\begin{array}{l}\text { Sustained fear- } \\
\text { light-enhanced startle }\end{array}$ & $\begin{array}{l}\text { Sustained fear- } \\
\text { CRF-enhanced startle }\end{array}$ \\
\hline CeA & No block & No block & No block (i.c.v) & No block \\
BNST & No block & Block & Block (i.c.v) & Block \\
\hline
\end{tabular}

located presynaptically (Justice et al, 2008), with very few post-synaptic receptors in the lateral oval nucleus of the BNST.

Results from the laboratory of Dr Maria Forray are also relevant to this model (Forray et al, 2005, and personal communication). They have found that $\left[\mathrm{K}^{+}\right]$-evoked glutamate release was persistently elevated in rats undergoing chronic immobilization stress ( $2 \mathrm{~h}$ /day for 15 days) and that this increase was normalized by intra-BNST infusions of the CRF-R1 antagonist NBI-27914. It is thus possible that stress activates the $\mathrm{BNST}_{\mathrm{L}}$ by increasing CRF levels, which then potentiate the release of glutamate from BLA terminals. In fact, chronic or repeated stress of various sorts does increase total (Chappell et al, 1986; Santibanez et al, 2006; Stout et al, 2000) as well as extracellular (Olive et al, 2002) CRF in the BNST of rats. Furthermore, both stress (Albeck et al, 1997; Hatalski et al, 1998; Hsu et al, 1998; Kalin et al, 1994; Makino et al, 1999) and the stress-related hormone corticosterone increase CRF mRNA level in CeA neurons (Makino et al, 1994b; Shepard et al, 2000; Thompson et al, 2004; Watts and Sanchez-Watts, 1995).

\section{The Role in Sustained fear of CRF Released from $\mathrm{CeA}_{\mathrm{L}}$ Neurons that Project to the BNST}

Several studies have used the 'crossed lesion technique' to investigate whether CRF acting in the BNST comes from the CeA. Jasnow et al (2004) found that social defeat behavior in Syrian hamsters was reduced by pre-defeat unilateral electrolytic CeA lesions or by pre-test unilateral intra$\mathrm{BNST}_{\mathrm{L}}$ infusion of the CRF antagonist, D-Phe $\mathrm{CRF}_{12-41}$. The combined manipulation on opposite sides of the brain had an even greater effect. On the basis of these results, they concluded that stress activates CRF-containing neurons in the CeA, which then releases CRF within the BNST. Similarly, Erb et al (2001) found that neither unilateral intra-CeA TTX infusions nor unilateral intra-BNST $\mathrm{B}_{\mathrm{L}}$ infusions of $\mathrm{D}$-Phe $\mathrm{CRF}_{12-41}$ disrupted shock-induced reinstatement of extinguished cocaine-seeking behavior, but that the combination of both treatments, again on opposite sides of the brain, did. They concluded that a pathway containing CRF from CeA to the BNST is involved in mediating the effects of CRF on the reinstatement of cocaine seeking.

Although the results of both studies are consistent with the conclusions that were drawn, they are not definitive insofar as only a partial implementation of the crossedlesion design was used. That is, neither study compared the effect of contralateral $v s$ ipsilateral CRF antagonist infusions (eg, CRF antagonist infusions in the left CeA and left BNST or the right $\mathrm{CeA}$ and right $\mathrm{BNST}$ ). Assuming that a serial CeA-to-BNST circuit is critical for the behavior in question, one would predict that the effect of the ipsilateral CeA plus BNST treatments would equal in magnitude to that obtained by unilaterally manipulating either structure alone and less than that of contralateral CeA plus BNST treatments. Moreover, electrolytic CeA lesions in the study by Jasnow et al (2004) and intra-CeA TTX infusions in the study by Erb et al (2001) would have interrupted communication between the $\mathrm{BLA}_{\mathrm{P}}$ and the $\mathrm{BNST}_{\mathrm{L}}$ (Figure 7). Thus, the observed behavioral effects in these studies might have been attributable to an interruption of this pathway instead. Additional studies are key to determining whether fibersparing inactivation of the CeA could reproduce these intriguing findings.

To further test this model, we infused CRF antagonists $\left(\alpha \mathrm{hCRF}_{9-41}\right)$ or a non-peptide CRF1 antagonist into either the CeA or BNST. Table 2 shows that CRF antagonists infused into the CeA did not affect phasic or sustained fear. In contrast, infusion of the same compounds into the BNST blocked both sustained fear conditioned to long-duration cues and CRF-enhanced startle. These results provide further evidence that sustained fear involves CRF receptor activation in the BNST.

\section{Role of Other Neurotransmitters in CeA in Sustained Fear}

Our model suggests that sustained fear depends on CRF inputs to the BNST from $\mathrm{CeA}_{\mathrm{L}}$ neurons. As anticipated and by Koo et al (2004), this could explain why electrolytic lesions of the CeA blocked context conditioning (Koo et al, 2004), which depends on the BNST (Sullivan et al, 2004) and $\mathrm{CRF}$, because electrolytic lesions of the CeA would have prevented the context-induced release of CRF to the BNST from the $\mathrm{CeA}_{\mathrm{L}}$ (Figure 7). However, if $\mathrm{CeA}_{\mathrm{L}}$ neurons are involved in $\mathrm{BNST}_{\mathrm{L}}$-dependent effects, then it is necessary to account for the failure of intra-CeA NBQX infusions to disrupt light-enhanced startle by Walker and Davis (1997b) or the late stage of fear-potentiated startle to an 8-min CS (Figure 11). One possibility is that the $\mathrm{CeA}_{\mathrm{M}}$ neurons thought to mediate short-duration fear responses through direct projections to the brainstem are AMPA-responsive, whereas the $\mathrm{CeA}_{\mathrm{L}}$ neurons that may mediate longer duration fear responses indirectly by way of projections to the $\mathrm{BNST}_{\mathrm{L}}$ are not. Perhaps, those neurons are driven instead by the activation of other receptor types such as glucocorticoid and/or calcitonin gene-related peptide (CGRP) receptors. Indeed, previous studies have shown 
that chronic corticosterone administration upregulates the CRF mRNA level in $\mathrm{CeA}_{\mathrm{L}}$ and $\mathrm{BNST}_{\mathrm{L}}$ neurons (Liu et al, 2004; Makino et al, 1994a, b; Shepard et al, 2000; Swanson and Simmons, 1989; Watts and Sanchez-Watts, 1995) and interacts synergistically with CRF to increase startle amplitude (Lee et al, 1994). CGRP is also an interesting possible mediator of sustained fear, especially given its preferential distribution (Wang et al, 2006) (Haring et al, 1991; Harrigan et al, 1994; Honkaniemi et al, 1992) and that of its receptors (Kruger et al, 1988) within the $\mathrm{CeA}_{\mathrm{L}}$ vs the $\mathrm{CeA}_{\mathrm{M}}$. These receptors, when activated, produce various symptoms associated with fear and anxiety such as heart rate and blood pressure increases (Brown and Gray, 1988; Nguyen et al, 1986), antinociception (Xu et al, 2003), and freezing (Kocorowski and Helmstetter, 2001). CGRPpositive terminals directly innervate stress-responsive CRF-containing neurons within the $\mathrm{CeA}_{\mathrm{L}}$ (Harrigan et al, 1994; Honkaniemi et al, 1992). It is therefore possible that glutamate selectively activates $\mathrm{CeA}_{\mathrm{M}}$ neurons that mediate short-duration fear responses, whereas CGRP, corticosterone, and/or other peptide receptors selectively influence $\mathrm{CeA}_{\mathrm{L}}$ neurons that mediate more sustained fear responses. In fact, we have now found that local infusion of CGRP into the CeA causes dosedependent enhancement of startle amplitude, and we will soon assess whether a CGRP antagonist infused into the CeA can block various measures of sustained fear.

On the other hand, our account cannot easily explain why neurotoxic lesions of the CeA block context conditioning in some studies (Goosens and Maren, 2001) but not in others (Koo et al, 2004), assuming the later lesions fully destroyed cells in the $\mathrm{CeA}_{\mathrm{L}}$.

\section{GONADAL STEROIDS AFFECT SUSTAINED BUT NOT PHASIC FEAR}

\section{CRF-Enhanced Startle}

Lactation is associated with high progesterone levels, and anxiolytic effects are seen during lactation, probably because progesterone and its $\mathrm{GABA}_{\mathrm{A}}$ receptor modulating metabolites (most notably allopregnanolone) increase GABA transmission (c.f., Lambert et al, 2001; Lan and
Gee, 1994) (eg, Akwa et al, 1999; Bitran et al, 1995, 1999; Brot et al, 1997). In rats, lactation reduced baseline startle amplitude but not phasic fear measured with fear-potentiated startle (Toufexis et al, 1999). As the decrease in baseline startle was attributed to decreased anxiety, we anticipated that lactating rats might show lower levels of CRF-enhanced startle compared with cycling females. In fact, although both groups showed a significant increase in startle amplitude after CRF infusions, lactating females showed significantly less CRF-enhanced startle compared with cycling females (Walker et al, 2003).

To examine the contribution of progesterone and its metabolites, we examined the effect of progesterone replacement in ovariectomized rats. Rats received an i.p. injection of $250 \mu \mathrm{g}$ estradiol (ie, to induce the expression of progesterone receptors) followed $24 \mathrm{~h}$ later by $200 \mu \mathrm{g}$ of progesterone. They were tested $4 \mathrm{~h}$ later. Control rats received vehicle injections (corn oil) only. CRF-enhanced startle was much lower in progesterone-injected rats than in vehicle-injected rats and this effect seemed to be because of its major metabolite, allopregnanolone (Toufexis et al, 2004). For example, chronic progesterone had the same effect without estrogen priming, although this would greatly reduce the number of progesterone receptors in ovariectomized animals. Moreover, chronic administration of a progesterone analog that binds to the progesterone receptor but is not metabolized to allopregnanolone had no effect. Finally, acute administration of allopregnanolone markedly reduced CRF-enhanced startle (Figure 16, left panel), indicating a blockade of sustained fear. Once again, however, this same treatment had no effect on phasic fear measured fear-potentiated startle to a short-duration visual stimulus (Figure 16, right panel).

\section{Light-Enhanced Startle}

Although light-enhanced startle has been seen across numerous studies, and has since been replicated elsewhere (eg, de Jongh et al, 2002), the finding itself has been quite varying since we began this work at Yale, and we were unable for a while to reliably reproduce the phenomenon in our new laboratory at Emory. We believe this difference was perhaps a function of basal stress levels interacting with
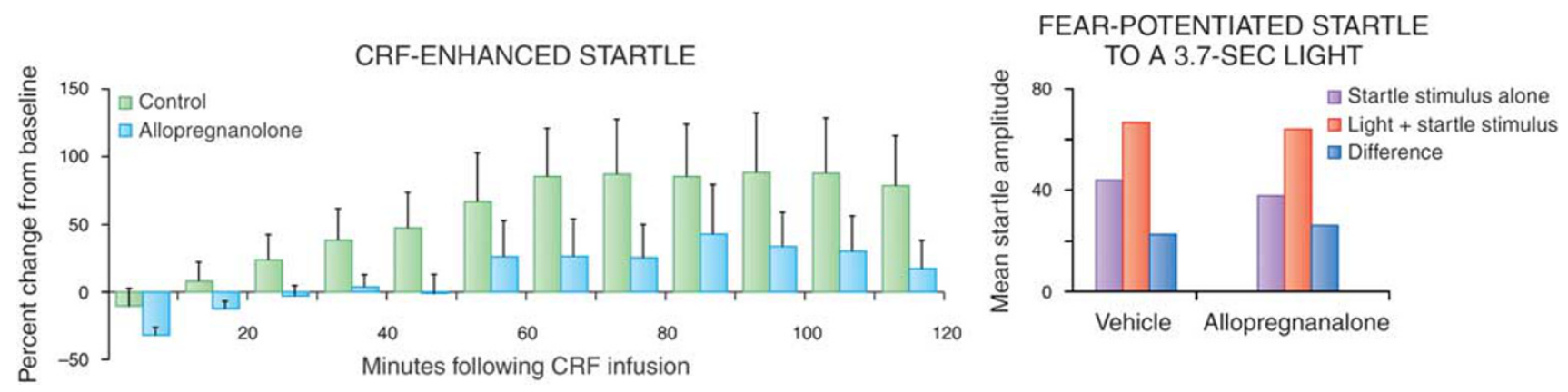

Figure 16. Chronic administration of the progesterone metabolite, allopregnanolone, blocked sustained fear measured with CRF-enhanced startle (left panel) but had no effect on phasic fear measured with fear-potentiated startle to a 3.7-s CS (right panel). 


\section{LIGHT-ENHANCED STARTLE}

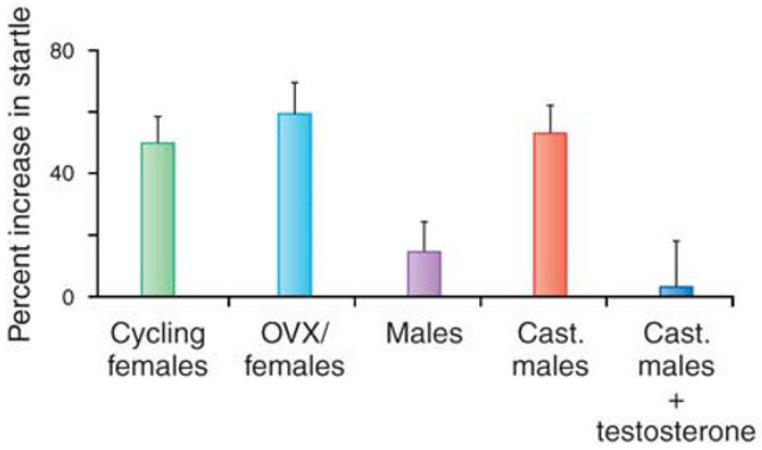

FEAR-POTENTIATED STARTLE TO A 3.7-SEC LIGHT

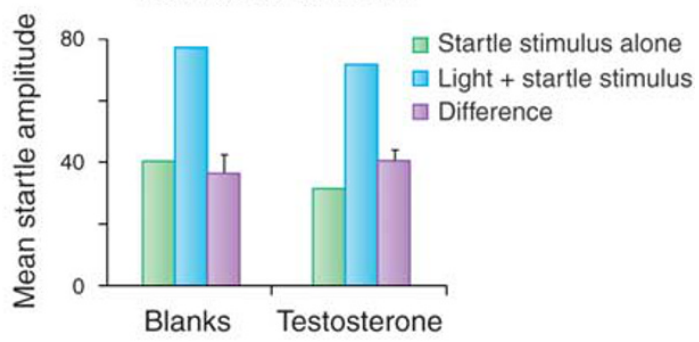

Figure 17. Testosterone reduced sustained fear measured with light-enhanced startle but had no effect on phasic fear measured with fear-potentiated startle to a 3.7-s CS.

light-enhanced startle. On the basis of evidence suggesting that gender and hormone status influence anxiety and that stress can reduce testosterone levels, we compared lightenhanced startle in intact freely cycling and ovariectomized females and intact males, castrated males, and castrated males receiving testosterone. The results are shown in Figure 17 (left panel). Light-enhanced startle was statistically significant in both female groups but statistically absent in intact male rats. In castrated males, the mean level of light-enhanced startle was comparable with that observed in females and this effect could be reversed with testosterone.

\section{Phasic Fear}

In contrast, testosterone had no effect on phasic fear-potentiated startle (Toufexis et al, 2004, 2005) (Figure 17, right panel). Overall, therefore, gonadal steroids appear to affect sustained but not phasic fear, providing further support for the idea that these different procedures produce qualitatively different forms of fear or anxiety-like behaviors.

\section{EFFECTS OF BENZODIAZEPINES ON PHASIC AND SUSTAINED FEAR}

\section{The Effects of Benzodiazepines on Phasic Fear in Rodents}

We reported that flurazepam and diazepam blocked fearpotentiated startle to a short-duration cue in rats (Davis, 1979), and this effect has since been replicated in many other studies using fear-potentiated startle, including in the study on rhesus monkeys (Winslow et al, 2007). However, in humans, results have been less clear-cut. Initial studies found that diazepam (Bitsios et al, 1999) and alprazolam (Riba et al, 2001) decreased fear-potentiated startle during a verbal threat procedure in which short-duration threat cues predicted a shock, but these findings were not confirmed in several studies using various benzodiazepines (Baas et al, 2002; Grillon et al, 2006b; Riba et al, 1999; Scaife et al, 2005). For example, Baas et al (2002) conducted four separate within- and between-subject studies and reported that neither diazepam nor oxazepam reduced fear- potentiated startle, although these drugs reduced baseline startle. In fact, it has been argued that the positive effect of benzodiazepines on fear-potentiated startle (Bitsios et al, 1999; Riba et al, 2001) did not reflect genuine reductions in fear but was artifactual, secondary to reduced baseline startle reactivity (Grillon and Baas, 2002; Walker and Davis, 2002b).

The fact that benzodiazepines do not affect fearpotentiated startle in humans seems inconsistent with results obtained in animals (Davis, 1993). There are important methodological differences between humans and animal studies that may account for these discrepancies. In particular, most human studies use verbal threat to a specific cue, which examines the expression of fear responses, whereas animal studies rely on fear conditioning, a task that depends on learning and memory. These latter processes can be disrupted by benzodiazepines (DickinsonAnson and McGaugh, 1997; Harris and Westbrook, 2001; Jensen et al, 1979; Pain et al, 2002), raising the possibility that benzodiazepines reduce fear conditioning because of their amnestic effects, rather than their anxiolytic properties when given before training. Consistent with this possibility, diazepam was found in humans to disrupt acquisition of cued fear-potentiated startle conditioning when given before training, but not when given before a performance test that assessed the expression of an acquired conditioned fear response (Scaife, 2005; Scaife et al, 2005). This effect did not appear to be due to a disruption of memory consolidation because diazepam blocked conditioned fear when given before but not after training (Scaife et al, 2005).

On the other hand, in our original study we found that in rats, diazepam did not block the acquisition of fear-potentiated startle, only its expression. Hence, another possibility is that startle in rats is much less sensitive to the sedative effects of benzodiazepines so that much higher doses can be used in rats than in humans, thus allowing anxiolytic effects in phasic fear to be measured. In fact, phasic fear in several models can be reduced by either GABA agonists or benzodiazepines in the $\mathrm{CeA}$ in rats (cf. Davis, 2000). However, this would still not account for the different effects of diazepam on fear acquisition in rats $v s$ humans. 


\section{The Effects of Benzodiazepines on Sustained fear in Rodents}

In rats, benzodiazepines given systemically block many of measures of sustained fear. Thus, chlordiazepoxide reduced light-enhanced startle at a dose that has little effect on startle amplitude in the dark phase (Walker and Davis, 2002a), CRF-enhanced startle (Swerdlow et al, 1986), and sustained fear conditioned to a 8-min clicker (L.A. Miles and M. Davis, unpublished observations). Benzodiazepines were reported to block the general elevation in startle amplitude under conditions of high background noise (Kellogg et al, 1991), to reduce conditioned suppression of drinking by a cue that signaled shock (Kopchia et al, 1992; Yadin et al, 1991), and to reduce burying of shock-associated objects (Kopchia et al, 1992; Treit et al, 1993b). It also had an anxiolytic effect in the plus-maze, another measure of sustained fear in which rats tend to avoid entering an open arm compared with a closed arm on a maze that looks like a plus (Treit et al, 1993a). Interestingly, in several cases, lesions of the CeA did not block these anxiolytic effects of benzodiazepines, although the CeA lesions tended to have anxiolytic effects on their own (Kopchia et al, 1992; Yadin et al, 1991; Treit et al, 1993b). Although one might conclude that these results reflected floor effects produced by the CeA lesion, Yadin et al (1991) found that the anxiolytic effects of chlordiazepoxide were actually larger in the lesioned rats.

To our knowledge, lesions or inactivation of the BNST have not been tested to examine whether such lesions would block the anxiolytic effects of benzodiazepines in these tests. However, midazolam reduced c-Fos activation in the BNST (McGregor et al, 2004) and both acute chlordiazepoxide and chronic fluoxetine decreased stressinduced c-Fos increases in the $\mathrm{BNST}_{\mathrm{L}}$, providing some of the first evidence that the potential anxiolytic effects of both compounds may be mediated by actions in the BNST (Bechtholt et al, 2008). Benzodiazepines facilitate GABA transmission and direct infusion of GABA agonists, such as muscimol, blocked sustained fear. For example, muscimol infused into the BNST decreased social defeat in hamsters, a long-lasting form of sustained anxiety dependent on both the amygdala and the BNST (Markham et al, 2009), as well as sustained freezing in response to the odor of fox feces, a rodent predator (Fendt et al, 2003). Inhibition of GABA synthesis in the BNST produced an anxiogenic effect in the plus-maze and social interaction test, another measure of sustained fear in which rats exposed to novel places under high illumination tend not to interact with each other; this effect was reversed by local infusion of muscimol in the BNST (Sajdyk et al, 2008).

\section{The Effects of Benzodiazepines on Sustained Fear in Humans}

Most studies in humans have found that benzodiazepines reduce baseline startle when given chronically (Voshaar et al, 2005) or acutely (Abduljawad et al, 1997, 2001; Baas et al, 2002; Bitsios et al, 1999; Grillon et al, 2006b; Murphy et al, 2008; Riba et al, 2001; Scaife, 2005). Similar effects have been reported in rodents (Guscott et al, 2000). The attenuating effect of benzodiazepines on startle is not surprising, given that these drugs have muscle relaxant and sedative properties (File, 1982). Other sedative compounds from different pharmacological classes also decrease startle amplitude in humans, including the alpha-2-adrenoceptor agonist clonidine (Abduljawad et al, 1997, 2001; Kumari et al, 1996; Samuels et al, 2007), the tricyclic antidepressant amitriptyline (Phillips et al, 2000), the atypical antipsychotic clozapine (Graham et al, 2001, 2004), and the serotonergic receptor antagonist ketanserin (Graham et al, 2002). However, it is possible that rather than simply reflecting a nonspecific side effect, the reduction in startle baseline by diazepam in humans (Baas et al, 2002) and rodents (Guscott et al, 2000) might be caused by an anxiolytic effect on contextual anxiety. An effect on contextual anxiety is also suggested by the finding that diazepam attenuated the facilitation of startle in the dark (Baas et al, 2002).

We have reported more clear-cut evidence of anti-anxiety (as opposed to anti-fear) effects associated with benzodiazepines in a verbal threat study. Subjects received each of four treatments - placebo, $0.5 \mathrm{mg}$ alprazolam, $1 \mathrm{mg}$ alprazolam, or $50 \mathrm{mg}$ diphenhydramine (Benadryl) - in a withinsubject, cross-over design over four experimental sessions (Grillon et al, 2006c). Diphenhydramine was used as a control for the sedative effects of alprazolam. Neither alprazolam nor diphenhydramine affected cued fear-potentiated startle in the predictable condition (Figure 18, left panel). In contrast, the sustained increase in startle in the predictable and unpredictable conditions was reduced significantly by the high dose of alprazolam. As shown in Figure 18 (right panel), startle magnitude during the intertrial interval (reflecting sustained fear in each condition) increased linearly from the no shock, to the predictable shock, to the unpredictable shock condition in the placebo group. This linear increase was less steep with the high-dose alprazolam treatment, indicating that as the level of sustained fear increased, the anti-anxiety effect of alprazolam increased. This effect could not be due to a sedative effect because diphenhydramine, which reduced startle to the same extent as alprazolam, did not affect contextpotentiated startle. These findings are consistent with ethological studies (Blanchard et al, 1993) and suggest that alprazolam preferentially reduced anxiety compared to fear.

\section{BUSPIRONE AFFECTS PHASIC BUT NOT SUSTAINED FEAR}

Buspirone is a mixed serotonergic agonist and dopamine D2 antagonist that has repeatedly been found to reduce the expression of fear-potentiated startle after acute administration (Kehne et al, 1988; Mansbach and Geyer, 1988), as well as light-enhanced startle (Walker and Davis, 1997a). 

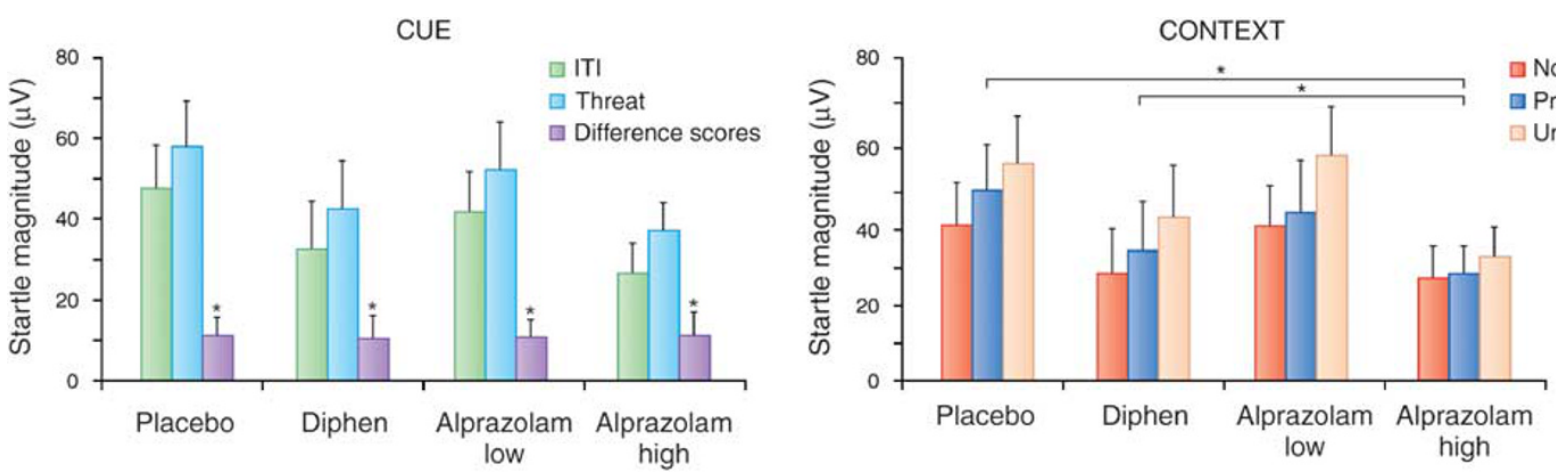

Figure 18. Effect of the benzodiazepine alprazolam on verbally mediated cued fear and contextual anxiety. The paradigm was the same as presented in Figure 4. Subjects were informed that there would be three conditions: (1) no shock (N), (2) predictable (P) shocks, and unpredictable (U) shocks. Each subject received placebo, $0.5 \mathrm{mg}$ of alprazolam, $1 \mathrm{mg}$ of alprazolam, or $50 \mathrm{mg}$ of diphenhydramine (Benadryl). Diphenhydramine was used as an active control to match the sedative properties of alprazolam on startle. (left panel) Startle magnitude during the cue and ITI in the P condition during the P conditions only. The difference scores between cue and ITI is a measure of fear-potentiated startle. Alprazolam did not affect fear-potentiated startle. (right panel) Startle during ITI (contextual anxiety) in the N, P, and U conditions. As in Figures 3 and 4, startle increased linearly from the $\mathrm{N}$ to the $\mathrm{P}$ to the $\mathrm{U}$ condition with placebo. This effect was replicated with the low dose of alprazolam and with diphenhydramine. However, there was a significant reduction in startle with the high dose of alprazolam, indicating a substantial reduction in contextual anxiety. This effect was not caused by sedation because diphenhydramine, which reduced baseline startle to the same extent as $1 \mathrm{mg}$ alprazolam, did not affect contextual anxiety. ${ }^{*}($ left panel) Significant increase in startle magnitude during the cue compared with the ITI. *(right panel) Significant condition X drug linear trend between conditions.

However, acute administration of buspirone does not reduce anxiety in humans (Hoge et al, 2004), and this effect on fear-potentiated startle to a short-duration cue has been considered as a 'false positive.' However, we have now found that buspirone fails to block sustained fear to an 8-min clicker paired with shock, although it did block fear-potentiated startle to a 3.7-s clicker (L.A. Miles and M. Davis, unpublished data). Thus, sustained fear to a long-duration cue may be a better model of human anxiety in rats, although it is still not clear why buspirone worked in light-enhanced startle.

\section{EFFECTS OF SELECTIVE SEROTONIN SSRIS ON PHASIC vs SUSTAINED FEAR}

\section{Effects of SSRIs in Rats}

Acute administration of citalopram in rats before training was reported to increase fear conditioning to a 20-s tone paired with footshock, whereas chronic administration had the opposite effect (Burghardt et al, 2004). In a subsequent study in which fear conditioning was carried out off-drug 1 day before the administration of SSRIs, acute citalopram or fluoxetine also facilitated the expression of conditioned fear; in this study, chronic administration was not carried out (Burghardt et al, 2007). However, we now have evidence that 21 days of oral administration of fluoxetine, but not acute administration, blocks the expression of sustained fear to an 8 -min clicker $(P<0.02)$, but not to a 3.7-s clicker paired with footshock (Miles and Davis, unpublished observations). Moreover, as mentioned earlier, chronic fluoxetine decreased stress-induced c-Fos increases in the $\mathrm{BNST}_{\mathrm{L}}$ (Bechtholt et al, 2008).

\section{Effects of SSRIs in Humans}

SSRIs are now the drugs of choice to treat mood and anxiety disorders. Understanding their effects is complicated by the fact that their clinical efficacy develops only after chronic treatment (Goldstein and Goodnick, 1998; Gorman et al, 1987). Furthermore, initial treatment with SSRIs can have effects opposite to those seen after chronic treatment, eg, anxiogenic rather than anxiolytic effects (Goldstein and Goodnick, 1998; Gorman et al, 1987). Experimental studies using chronic SSRI treatment in humans are scarce, because of the ethical and scientific hurdles associated with such research.

Startle studies assessing the efficacy of SSRIs during threat have also provided evidence of a dissociation between acute and chronic SSRIs on fear and anxiety. For instance, although acute citalopram increased both fear and anxiety to predictable and unpredictable shock, respectively (Grillon et al, 2007), 14 days of chronic treatment selectively reduced contextual anxiety but not cued fear (Grillon et al, 2009a). These results suggest that citalopram does not affect CeAmediated fear responses to a discrete threat cue. This is in line with the clinical observation that specific phobias respond less well to treatments such as citalopram than other pathological anxiety states (Baldwin et al, 2005) and with preclinical evidence in rodents showing that the serotonergic system may not be critical for the expression of phasic fear-potentiated startle (Davis et al, 1988). It is too early to speculate on the mechanisms responsible for the reduction of anxiety-potentiated startle by citalopram. However, given the involvement of BNST CRF in longduration startle increases (e.g., Lee and Davis, 1997), it is possible that a reduction in persistent anxious states depends on an interaction between serotonin and CRF. Indeed, there is evidence of interactions between CRF and 
SSRIs. Fluoxetine reduced CRF in depressed patients (De Bellis et al, 1993), whereas tryptophan depletion, which reduces brain serotonin, had the opposite effect (Tyrka et al, 2004).

\section{CLINICAL APPLICATIONS}

The distinction between phasic and sustained fear as operational definitions of fear and anxiety has implications in several areas of clinical research. It can be noted that it may help distinguish among fear- and anxiety-related anxiety disorders (Watson, 2005; Kruger et al, 1988) based on core underlying features and help discover vulnerability markers in individuals at high risk for these conditions. It may also have implications for the drug discovery process.

\section{Fear, Anxiety, and Clinical Anxiety}

Anxiety disorders are characterized by overlapping as well as distinct symptomatic profiles. Most share a commonality, a proneness to negative affectivity, which is a temperamental disposition to react with strong negative affect to various situations (Watson et al, 1988). Anxiety disorders also differ from each other in the primary object or specificity of threat, ranging from diffuse (eg, in generalized anxiety disorder (GAD)) to circumscribed (eg, in specific phobias), the former leading to symptoms of chronic sustained anxiety and the latter prompting strong fear (Cuthbert et al, 2003; Lang et al, 2000). Hierarchical models confirm the presence of a unique broad negative affectivity factor that cuts across most anxiety disorders (including depression), and of a separate and a unique fear factor that discriminates among anxiety disorders (Brown et al, 1998). These considerations, together with recent genetic studies, have led to the suggestion that the broad vulnerability factor loads more heavily in GAD, panic disorder, and PTSD and less on disorders with circumscribed fear such as simple phobias, with social phobia being intermediate (Chantarujikapong et al, 2001; Craske and Waters, 2005).

A somewhat different picture emerges from populationbased phenotypic factor analytic studies of comorbidity patterns among psychiatric disorders (Kruger et al, 1988; Vollebergh et al, 2001; Cox et al, 2002). These studies have reported that internalizing disorders are made up of two sub-dimensions, one representing 'fear' diagnoses (eg, simple phobia, social phobia, agoraphobia, panic disorder) and the other 'anxiety-misery' diagnoses (depression, dysthymia, GAD, PTSD). These studies are important, in that they have identified two core psychopathological processes that cut across several disorders. However, there are few biological markers with which to validate distinctions between these disorders and the core features that underlie specific diagnostic entities. The distinction between fear and anxiety states based on our model of potentiated startle may therefore provide a valuable tool when classifying anxiety states. Establishment of biological tools to identify vulnerability to anxiety disorders would also inform future studies of the pathophysiological mechanisms underlying anxiety disorders and could have major implications for prevention and intervention.

\section{Panic Disorder, PTSD, and GAD}

There is indirect evidence of enhanced anticipatory anxiety associated with unfamiliar or threatening contexts in anxiety disorders, as measured through skin conductance and heart rate. Although most studies are designed to explore reactions to a specific psychological or pharmacological challenge, examining responses before an aversive challenge provides the opportunity to assess anticipatory anxiety to distal threat, although not always in a controlled manner. These studies show increased skin conductance levels and/or subjective anxiety before psychological or chemical challenges in patients with panic disorder (Alpers et al, 2003; Braune et al, 1994; Charney et al, 1984; Hoehn et al, 1997; Parente et al, 2005). It can be noted that response to the challenge itself does not differ among controls and patients with non-disorder relevant stressors (Roth et al, 1992). Anticipatory anxiety to stressful challenges has also been reported in vulnerable individuals at risk for panic disorder (Coplan et al, 1998; Gorman et al, 1986; Liebowitz et al, 1984).

Similar results have been reported with the startle reflex. As mentioned in the Introduction, participating in an experiment involving the future delivery of aversive stimuli can be considered analogous to the pre-encounter stage of the defensive distance model and can evoke mild and measurable anxiety (Bocker et al, 2004; Grillon et al, 1998c). Anxious patients are particularly sensitive to this type of contextual anxiety as reflected by the fact that startle is exaggerated in panic disorder when tested in a threatening context (Grillon et al, 1994a), but not at baseline without obvious stressors (Amrhein et al, 2005; Ludewig et al, 2002; McTeague et al, 2009). In panic disorder, enhanced startle is associated with diffuse distal threat but not proximal threat (Grillon et al, 1994a). Similar results have been reported in PTSD (Grillon et al, 1996; Morgan et al, 1995a, b). To test the hypothesis that individuals with PTSD suffer from enhanced contextual anxiety, we conducted a two-session evaluation. In the first session, under no stressful condition, baseline startle in Vietnam veterans with PTSD did not differ from controls. In the second, more stressful session that involved the administration of shock, startle was elevated throughout the experiment in the PTSD group (Grillon et al, 1998c). Here again, phasic fear measured with fear-potentiated startle reached normative levels in the PTSD veterans (Grillon et al, 1998c).

Studies that have manipulated threat along the defensive distance continuum have confirmed the sensitivity of individuals with PTSD to distal as opposed to imminent threat. Pole et al (2009) examined the association between PTSD symptom severity and startle in urban police officers at different threat levels, ranging from distal (before placement of the shock electrodes), to intermediate (after 
placement of the shock electrodes), to proximal (under imminent shock threat). Symptom severity was strongly associated with both self-reported danger and the skin conductance response to startle stimuli under distal threat. Symptom severity was also associated with eyeblink startle magnitude under intermediate threat. None of the selfreported or physiological measures were associated with symptom severity under proximal threat. These results are consistent with the findings of the only context conditioning study conducted to date. Vietnam veterans with PTSD showed normative levels of fear-potentiated startle to a CS that predicted a shock, but enhanced context conditioning when returning to an experimental room where they had previously received shocks (Grillon et al, 1998c). Taken together, these results suggest that exaggerated startle is not diagnosis-specific and reflects an increase in sustained fear in specific situations of diffuse threat as opposed to phasic fear to an unambiguous proximal threat (Lissek et al, 2006).

These conclusions are based on studies in which contextual anxiety was not controlled experimentally. To develop a more operational measure of cue and context conditioning, we carried out two studies, one in patients with panic disorder (Grillon et al, 2008) and the other in patients with PTSD or GAD (Grillon et al, 2009b). The patients were not medicated and were compared with healthy controls. The startle reflex was elicited with an airpuff to the forehead. The aversive stimuli were not shocks, but consisted of four different 3-s duration sounds (95-dB): (1) a white noise, (2) a $2-\mathrm{kHz}$ tone, (3) a smoke alarm, and (4) a human female scream (the human scream was accompanied by a briefly presented picture of a fearful woman). We chose not to use shock to facilitate recruitment. Loud sounds are less aversive than shocks and do not generate contextual anxiety in healthy controls. However, they evoke robust cued fear-potentiated startle. Replicating previous findings, we found that the magnitude of phasic fear measured with cued fear-potentiated startle was equivalent in the PTSD and panic disorder patients and in the controls. The GAD group also showed normative levels of cued fear-potentiated startle. As expected, the panic disorder and PTSD group exhibited increased sustained fear measured with context potentiation of startle; in particular, their startle in the unpredictable condition was significantly elevated compared with that of their respective control groups (Figure 19). The GAD group did not show abnormal contextual modulation of startle. In fact, GAD patients showed affective responses to the threat cue and the context that were indistinguishable from controls.

These results confirm that although fearful responses to a nonspecific stressor do not differ between clinically anxious patients and controls, sustained contextual fear to unpredictable aversive stimuli distinguishes individuals with PTSD or panic disorder from controls and individuals with GAD. These findings are consistent with theories that emphasize the role of unpredictability in anxiety disorders.
These theories are based on the observation that animals exposed to unpredictable but not to predictable threats show behaviors reminiscent of anxiety symptoms in humans (Foa et al, 1992; Mineka and Kihlstrom, 1978). In addition, PTSD and panic disorder share common phenomenology, including the unpredictable and uncontrollable nature of the stress and enhanced anxiety sensitivity (Asmundson and Stapleton, 2008). PTSD is precipitated by uncontrollable and unpredictable traumatic events, which result in intrusive recollections of the trauma with associated hyper-arousal and anxiety (American Psychiatric Association, 1994). Panic disorder is similarly characterized by brief and intermittent unpredictable and uncontrollable aversive episodes (panic attacks) interspersed with high levels of anticipation anxiety of these aversive events, which in turn increases the likelihood of panic attacks.

Given that GAD is characterized by excessive and uncontrollable worry (Borkovec et al, 1991; Roemer et al, 2002), one might expect enhanced reactivity to unpredictable threat in GAD. However, the relationship between worry and response to experimentally delivered threats is unclear. At least two features distinguish worry from experimental models of anticipatory anxiety (Borkovec et al, 1991). First, worry is essentially a cognitive avoidance strategy, which, some suggest, serves to reduce anticipatory anxiety (Borkovec and Inz, 1990). Worrisome thinking relies on verbally mediated processes (rumination) to shift the focus of attention away from the actual threat in order to reduce anxiety. From this perspective, worry may not be equivalent with anticipatory anxiety, rather it is an attempt to cope with anxiety (Craske, 1999). Second, consistent with this view, study on physiological reactivity in GAD has found minimal evidence of hyper-arousal and some evidence of reduced arousal (Hoehn-Saric et al, 1989). In this respect, GAD differs from panic disorder and PTSD. GAD also differs from PTSD and panic disorder, in which the latter two conditions involve sudden attacks of increased arousal (paroxysm), whereas GAD involves chronically elevated anxiety in the face of no such paroxysm.

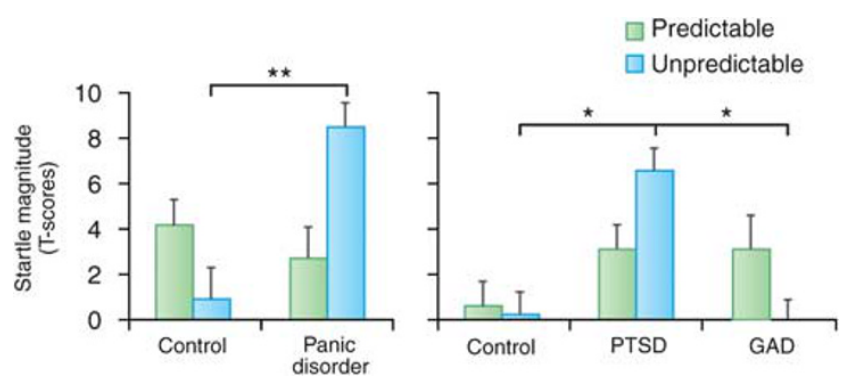

Figure 19. Patients with panic disorder have normal phasic fear to predictable airblasts but elevated sustained fear to unpredictable airblasts (left). Patients with PTSD or GAD have greater phasic fear to predictable airblasts but only patients with PTSD have great sustained fear to unpredictable airblasts (right). 


\section{Social Phobia and Simple Phobia}

Simple phobia, which is associated with fear to circumscribed objects or situations, is the archetype of a fearrelated disorder. Subjects with simple phobias would be expected to be the most reactive when confronted with their phobic objects. This hypothesis has been confirmed in several studies using various procedures. For instance, fearful subjects show significantly enhanced fear-potentiated startle compared with non-fearful participants when looking at pictures of phobic stimuli (Hamm et al, 1991a; Sabatinelli et al, 2001), when asked to imagine the content of previously seen pictures (Schupp et al, 1997), or to imagine a previously heard or memorized emotional script (Cook et al, 1991; Cuthbert et al, 2003; Vrana and Lang, 1990). Startle potentiation emerges very rapidly in these subjects when exposed to imagery of their phobic stimuli (Globisch et al, 1999), consistent with theories positing that fear can be evoked with minimal stimulus input (Zajonc, 1980) and with neurobiological evidence of a quick, lower order, and amygdala-mediated processing of stimulus information in rodents (LeDoux, 2000) and humans (Morris et al, 1998, 1999). A recent fMRI study also reported BNST activation in spider phobics, but not in controls, during anticipation of imagery associated with phobogenic stimuli (Straube et al, 2007). Social phobics also show enhanced startle when confronted with their own phobic situation (Cornwell et al, 2006; McTeague et al, 2009), or during anticipation of such situations (Cornwell et al, 2006). For these subjects, startle magnitude during the anticipation of a speech correlates with self-reported fear of negative evaluation, a core component of social anxiety, but not with Spielberger's trait anxiety, a more general measure of anxiety (Cornwell et al, 2006). Thus, social phobia seems to display an intermediate pattern of fear and anxiety between that of simple phobia and panic disorder and PTSD. However, this picture is complicated by sub-diagnostic differences within social phobia. Social phobics with circumscribed fear restricted to performance contexts exhibit defensive responses similar to those of simple phobics, in which they show elevated fear of their personal fears but not of standard fears (McTeague et al, 2009). In contrast, individuals with generalized social phobia show a range of elevated fear that extends beyond their personal fears to more generally shared fears (McTeague et al, 2009).

Taken together, the results obtained in anxious patients point to two dimensions of startle reactivity: one corresponding to high levels of phasic fear (eg, simple phobia) in the absence of heightened sustained fear and the other of heightened sustained fear (eg, PTSD, panic disorder) without elevated phasic fear. These results are not in total agreement with findings from the genetic and phenotypic studies reviewed above (Kruger et al, 1988, Watson, 2005; Vollebergh et al, 2001; Chantarujikapong et al, 2001; Hettema et al, 2006). For example, although panic disorder and PTSD are distinguishable based on phenotypic studies (Kruger et al, 1988, Vollebergh et al, 2001), startle studies suggest that these two disorders share a common susceptibility to enhanced sustained fear to aversive contexts. These results underscore the need for a comprehensive approach to anxiety disorders that does not only rely uniquely on patients' verbal reports but also on objective psychophysiological measures of underlying neural processes.

\section{Risk Factors for Developing Anxiety Measured in the Laboratory}

Although many studies report enhanced contextual anxiety in anxiety disorders, it is unclear whether this sensitivity to context is a vulnerability factor or an acquired consequence of these conditions. Various vulnerability factors have been associated with risk for mood and anxiety disorders, including a parental history of anxiety disorders (Merikangas et al, 1999), early life stress (Nemeroff, 2004), and being female (Kessler et al, 1994). A greater sensitivity to contextual threat could be a mechanism though which these risk factors are expressed. If sustained startle potentiation to uncertain or distal threat differentiates clinically anxious from non-anxious individuals, greater sensitivity to aversive contexts may also characterize individuals at high risk for these conditions. Supporting evidence comes from studies that show that nonaffected daughters and granddaughters (but not sons or grandsons) of individuals with anxiety disorders or major depression, respectively, show elevated baseline startle in threatening contexts (Grillon et al, 1997a, 1998a, 2005). The fact that only high-risk females show elevated contextual anxiety suggests gender differences in sustained anxiety, which is consistent with basic findings in rodents. As mentioned earlier, Toufexis (2007) reported equivalent levels of fearpotentiated startle to a discrete conditioned cue in female and male rats. However, female rats showed greater reactivity in various models of sustained anxiety. These results were attributed to sexual dimorphism in the BNST (Allen and Gorski, 1990) and to the action of sex hormones on these structures (Toufexis, 2007). A similar sex difference has been reported in humans. Men and women do not differ in their fear-potentiated startle to a threat cue, but women show enhanced sustained anxiety to unpredictable shocks (Grillon, 2008).

The influence of risk factors on contextual anxiety has been extended to neuroticism, a core personality dimension associated with a proneness to experience negative feelings (Costa and McCrae, 1992). Neuroticism is a widely recognized risk factor for anxiety disorders (Bienvenu and Stein, 2003; Kendler et al, 2002). A recent study found that neuroticism in youths $(N=132$; aged $16-18$ years $)$ was associated with enhanced contextual anxiety. In that study, subjects were told to anticipate a contraction of the biceps (Waters et al, 2008). Neuroticism was associated with elevated potentiation in conditions of intermediate distal threat, but not in the condition when threat was proximal or more distal. The finding that neuroticism had no effect during proximal threat is consistent with results indicating 
that individuals with or at-risk for an anxiety disorder had no increase in fearfulness to imminent danger. The authors suggested that neuroticism's lack of effect on distal threat was due to the fact that threat of stimulation of the biceps did not generate sufficiently strong contextual anxiety. This interpretation is consistent with our observation that mildly aversive stimuli do not induce contextual anxiety (Grillon et al, 2004, 2009b).

Animal data and prospective studies also point to the possibility that startle has predictive validity as a vulnerability marker. In rats, exaggerated startle levels before a traumatic stressor increased risk of developing PTSD-like symptoms after the stressor (Rasmussen et al, 2008). In humans, a prospective study in firefighter trainees $(N=84)$ found that higher startle reactivity before training was associated with higher symptoms of PTSD after training (Guthrie and Bryant, 2005). Similarly, Pole et al (2009) conducted a prospective study in police academy cadets $(N=38)$ using distal threat of shock to predict post-trauma symptoms. They found that subjective fear under distal threat (before attachment of the shock electrode) predicted PTSD symptoms. Taken together, these studies suggest that hyperexcitability to contextual threat may be an endophenotype for anxiety disorders. As such, measures of contextual anxiety may have implications for identifying vulnerable individuals and, possibly, prevent the development of anxiety disorders.

Integrating these clinical studies with the animal data, our results point to a dysfunction in the mechanisms underlying sustained fear responses to contextual cues but not phasic fear in anxiety disorders. If the same neurocircuits that have been implicated in rodents also operate in humans, one may propose preferential engagement of the BNST in anxiety disorders, perhaps because of dysregulation in the system that modulates extra-hypothalamic CRF. If so, then pharmacological treatments that specifically target the BNST may be especially helpful in various anxiety disorders.

\section{SUMMARY}

Acknowledging that fear and anxiety are similar but not identical, we have been trying to develop a more operational definition of fear and anxiety, which we term 'phasic' and 'sustained' fear. In the laboratory, phasic fear is measured using short, discrete cues that are predictably paired with an aversive event. This elicits a state of fear highly time-locked to the fear-inducing stimulus that begins quickly and dissipates quickly once the fear stimulus is removed. In contrast, sustained fear is measured using more diffuse cues, or cues associated less predictably with an aversive event. This elicits a state of fear that can last for a much longer period of time and sometimes, though not always, decays more slowly once the fear-eliciting signal is turned off.
Rodent studies suggest that phasic fear is mediated by sensory information that activates the BLA, which in turn activates the medial division of the CeA that sends outputs to the hypothalamus and brainstem in order to produce the symptoms of fear. Sustained fear is mediated by sensory information that activates the BLA that, along with the PVT and the cortex, activates the lateral division of the CeA. This part of the amygdala projects to and releases the peptide CRF in the lateral division of the BNST that sends outputs to the same hypothalamic and brainstem targets to which the central nucleus of the amygdala projects. However, the effects of CRF in the BNST can be long-lasting and hence can produce a sustained state of fear. In both rats and humans, sustained fear appears to be more sensitive to clinically effective anti-anxiety drugs or treatments, perhaps as a result of the different neural substrates of each. Finally, the clinical symptoms of several anxiety disorders can be modeled more accurately with sustained rather than phasic fear tests.

\section{FUTURE DIRECTIONS AND CLINICAL IMPLICATIONS}

As outlined above, both our rodent and human models of sustained fear appear to be more sensitive than our models of phasic fear for detecting established anxiolytic compounds and, therefore, potentially more useful for screening and developing novel anxiolytic medications. As the $\mathrm{CeA}_{\mathrm{L}}$ and BNST contribute selectively to sustained fear as opposed to phasic fear, a search for receptors uniquely expressed in the $\mathrm{CeA}_{\mathrm{L}}$ and BNST may be a key approach when developing a list of potential targets and candidate compounds. Moreover, as the clinical symptoms of several anxiety disorders can be modeled more accurately with sustained rather than phasic fear, an evaluation of differences in the levels of these receptors in clinical $v s$ healthy populations may lead to insights regarding the genetic and proteinomic factors that contribute to these disorders, as well as contribute to the development of a neurobiological-based classification of these conditions.

\section{ACKNOWLEDGEMENTS}

This research was supported by NIMH Grants MH069056, MH47840, MH57250, and MH59906 (MD), the Science and Technology Center (The Center for Behavioral Neuroscience of the National Science Foundation under Agreement No. IBN-9876754), a NARSAD Young Investigator award (DLW), The American Psychological Association Diversity Program in Neuroscience Predoctoral Fellowship 5T32 MH18882 (LM), and the Intramural Research Program at NIMH (CG). Principles of Laboratory Animal Care (NIH publication no. 86-23, revised 1985) was followed and all procedures were approved by the Emory IACUC and the NIH IRB. The CRF1 antagonist was supplied by GlaxoSmithKline (GSK) as part of the NIMH Grant 1 U19 
MH069056 funded by the NIMH. GSK did not fund any of this research. The authors thank Ioline Henter for her outstanding editorial assistance.

\section{DISCLOSURE}

Drs Walker and Grillon and Ms Miles have no financial relationships to disclose. During the last 3 years, Dr Davis received research support from Astra-Zeneca Pharmaceuticals to study compounds on sustained fear. Dr Davis also received honoraria from Astra-Zeneca Pharmaceuticals, Lundbeck Research, and Sepracor for lectures related to phasic and sustained fear-potentiated startle.

\section{REFERENCES $(*$ denotes original references relevant to this review)}

Abduljawad KA, Langley RW, Bradshaw CM, Szabadi E (1997). Effects of clonidine and diazepam on the acoustic startle response and on its inhibition by 'prepulses' in man. J Psychopharmacol 11: 29-34.

Abduljawad KA, Langley RW, Bradshaw CM, Szabadi E (2001). Effects of clonidine and diazepam on prepulse inhibition of the acoustic startle response and the N1/ P2 auditory evoked potential in man. J Psychopharmacol 15: 237-242.

Akwa Y, Purdy RH, Koob GF, Britton KT (1999). The amygdala mediates the anxiolytic-like effect of the neurosteroid allopregnanolone in rat. Behav Brain Res 106: 119-125.

Albeck DS, McKittrick CR, Blanchard DC, Blanchard RJ, Nikulina J, McEwen BS et al (1997). Chronic social stress alters levels of corticotropin-releasing factor and arginine vasopressin mRNA in rat brain. J Neurosci 17: 4895-4903.

Alheid G, deOlmos JS, Beltramino CA (1995). Amygdala and extended amygdala. In: Paxinos G (ed). The Rat Nervous System. Academic Press: New York. pp 495-578

Alheid GF, Beltramino CA, De Olmos JS, Forbes MS, Swanson DJ, Heimer L (1998). The neuronal organization of the supracapsular part of the stria terminalis in the rat: the dorsal component of the extended amygdala. Neuroscience 84: 967-996.

Alheid GF, Heimer L (1988). New perspectives in basal forebrain organization of special relevance for neuropsychiatric disorders: the striatopallidal, amygdaloid, and corticopetal components of substantia innominata. Neuroscience 27: 1-39.

Allen LS, Gorski RA (1990). Sex difference in the bed nucleus of the stria terminalis of the human brain. J Comp Neurol 302: 697-706.

Alpers GW, Abelson JL, Wilhelm FH, Roth WT (2003). Salivary cortisol response during exposure treatment in driving phobics. Psychosom Med 65: 679-687.

Alvarez RP, Johnson L, Grillon C (2007). Contextual-specificity of short-delay extinction in humans: renewal of fear-potentiated startle in a virtual environment. Learn Mem 14: 247-253.

Amir S, Lamont EW, Robinson B, Stewart J (2004). A circadian rhythm in the expression of PERIOD2 protein reveals a novel SCN-controlled oscillator in the oval nucleus of the bed nucleus of the stria terminalis. J Neurosci 24: 781-790.

Amrhein C, Pauli P, Dengler W, Wiedemann G (2005). Covariation bias and its physiological correlates in panic disorder patients. J Anxiety Disord 19: 177-191.

Asmundson GJ, Stapleton JA (2008). Associations between dimensions of anxiety sensitivity and PTSD symptom clusters in active-duty police officers. Cogn Behav Ther 37: 66-75.

American Psychiatric Association (1994). Diagnostic and Statistical Manual of Mental Disorders, 4th edn. American Psychiatric Association: Washington, DC.

Baas JM, Grillon C, Bocker KB, Brack AA, Morgan III CA, Kenemans JL et al (2002). Benzodiazepines have no effect on fear-potentiated startle in humans. Psychopharmacology (Berl) 161: 233-247.

Baas JM, Nugent M, Lissek S, Pine DS, Grillon C (2004). Fear conditioning in virtual reality contexts: a new tool for the study of anxiety. Biol Psychiatry 55: 1056-1060.

Baldwin DS, Anderson IM, Nutt DJ, Bandelow B, Bond A, Davidson JR et al (2005). Evidence-based guidelines for the pharmacological treatment of anxiety disorders: recommendations from the British Association for Psychopharmacology. J Psychopharmacol 19: 567-596.

Bartfai T, Iverfeldt K, Fisone G, Serfozo P (1988). Regulation of the release of coexisting neurotransmitters. Annu Rev Pharmacol Toxicol 28: 285-310.
Bechtholt AJ, Valentino RJ, Lucki I (2008). Overlapping and distinct brain regions associated with the anxiolytic effects of chlordiazepoxide and chronic fluoxetine. Neuropsychopharmacology 33: 2117-2130.

Beck AT, Emery G (1985). Anxiety Disorders and Phobias: A Cognitive Perspective Basic Books: New York, 368pp.

Beck CHM, Fibiger HC (1995). Conditioned fear-induced changes in behavior and in the expression of the immediate early gene c-fos: with and without diazepam pretreatment. J Neurosci 15: 709-720.

Berendse HW, Groenewegen HJ (1991). Restricted cortical termination fields of the midline and intralaminar thalamic nuclei in the rat. Neuroscience 42: 73-102.

Bhatnagar S, Dallman M (1998). Neuroanatomical basis for facilitation of hypothalamic-pituitary-adrenal responses to a novel stressor after chronic stress. Neuroscience 84: 1025-1039.

Bhatnagar S, Dallman MF (1999). The paraventricular nucleus of the thalamus alters rhythms in core temperature and energy balance in a state-dependent manner. Brain Res 851: 66-75.

Bienvenu OJ, Stein MB (2003). Personality and anxiety disorders: a review. J Pers Disord 17: 139-151.

Bitran D, Dugan M, Renda P, Ellis R, Foley M (1999). Anxiolytic effects of the neuroactive steroid pregnanolone ( 3 alpha- $\mathrm{OH}-5$ beta-pregnan-20-one) after microinjection in the dorsal hippocampus and lateral septum. Brain Res $\mathbf{8 5 0}$ 217-224.

Bitran D, Shiekh M, McLeod M (1995). Anxiolytic effect of progesterone is mediated by the neurosteroid allopregnanolone at brain GABAA receptors. J Neuroendocrinol 7: 171-177.

Bitsios P, Philpott A, Langley RW, Bradshaw CM, Szabadi E (1999). Comparison of the effects of diazepam on the fear-potentiated startle reflex and the fearinhibited light reflex in man. J Psychopharmacol 13: 226-234.

Blanchard CD, Hynd AL, Minke KA, Minemoto T, Blanchard RJ (2001). Human defensive behaviors to threat scenarios show parallels to fear- and anxietyrelated defense patterns of non-human mammals. Neurosci Biobehav Rev 25: 761-770.

Blanchard RJ, Fukunaga KK, Blanchard DC (1976). Environmental control of defensive reaction to footshock. Bull Psychon Soc 8: 129-130.

Blanchard RJ, Yudko EB, Rodgers RJ, Blanchard DC (1993). Defense system psychopharmacology: an ethological approach to the pharmacology of fear and anxiety. Behav Brain Res 58: 155-165.

Bocker KB, Baas JM, Kenemans JL, Verbaten MN (2004). Differences in startle modulation during instructed threat and selective attention. Biol Psychol 67: 343-358.

Bolles RC, Fanselow MS (1980). A perceptual-defensive-recuperative model of fear and pain. Behav Brain Sci 3: 281-323.

Borkovec TD, Inz J (1990). The nature of worry in generalized anxiety disorder: a predominance of thought activity. Behav Res Ther 28: 153-158.

Borkovec TD, Shadick RN, Hopkins M (1991). The nature of normal and pathological worry. In: Rappe RM, Barlow DH (eds). Chronic Anxiety: Generalized Anxiety Disorder and Mixed Anxiety-Depression. Guilford Press: New York. pp 29-51.

Bourgeais L, Gauriau C, Bernard JF (2001). Projections from the nociceptive area of the central nucleus of the amygdala to the forebrain: a PHA-L study in the rat. Eur $J$ Neurosci 14: 229-255.

Bourque CW (1991). Activity-dependent modulation of nerve terminal excitation in a mammalian peptidergic system. Trends Neurosci 14: 28-30.

Bouton ME, Bolles RC (1979). Contextual control of the extinction of conditioned fear. Learn Motiv 10: 455-466.

Bouton ME, King DA (1983). Contextual control of conditioned fear: tests for the associative value of the context. J Exp Psychol Anim Behav Proc 9: 248-256.

Braune SS, Albus MM, Fröhler MM, Höhn TT, Scheibe GG (1994). Psychophysiological and biochemical changes in patients with panic attacks in a defined situational arousal. Eur Arch Psychiatry Clin Neurosci 244: 86-92.

Brot MD, Akwa Y, Purdy RH, Koob GF, Britton KT (1997). The anxiolytic-like effects of the neurosteroid allopregnanolone: interactions with GABA(A) receptors. Eur $J$ Pharmacol 325: 1-7.

Brown JS, Kalish HI, Farber IE (1951). Conditional fear as revealed by magnitude of startle response to an auditory stimulus. J Exp Psychol 41: 317-328.

Brown MR, Gray TS (1988). Peptide injections into the amygdala of conscious rats: effects on blood pressure, heart rate and plasma catecholamines. Regul Pept 21: 95-106.

Brown TA, Chorpita BF, Barlow DH (1998). Structural relationships among dimensions of the DSM-IV anxiety and mood disorders and dimensions of negative affect, positive affect, and autonomic arousal. J Abnorm Psychol 107: 179-192.

Bubser M, Deutch AY (1999). Stress induces Fos expression in neurons of the thalamic paraventricular nucleus that innervate limbic forebrain sites. Synapse 32: $13-22$ 
Buchel C, Morris J, Dolan RJ, Friston KJ (1998). Brain systems mediating aversive conditioning: an event-related fMRI study. Neuron 20: 947-957.

Burghardt NS, Bush DE, McEwen BS, LeDoux JE (2007). Acute selective serotonin reuptake inhibitors increase conditioned fear expression: blockade with a 5-HT(2C) receptor antagonist. Biol Psychiatry 62: 1111-1118.

Burghardt NS, Sullivan GM, McEwen BS, Gorman JM, LeDoux JE (2004). The selective serotonin reuptake inhibitor citalopram increases fear after acute treatment but reduces fear with chronic treatment: a comparison with tianeptine. Biol Psychiatry 55: 1171-1178.

Campeau S, Davis M (1995). Involvement of the central nucleus and basolateral complex of the amygdala in fear conditioning measured with fear-potentiated startle in rats trained concurrently with auditory and visual conditioned stimuli. J Neurosci 15(3 Part 2): 2301-2311.

Cassell MD, Gray TS, Kiss JZ (1986). Neuronal architecture in the rat central nucleus of the amygdala: a cytological, hodological, and immunocytochemical study. J Comp Neurol 246: 478-499.

Chantarujikapong SI, Scherrer JF, Xian H, Eisen SA, Lyons MJ, Goldberg J et al (2001). A twin study of generalized anxiety disorder symptoms, panic disorder symptoms and post-traumatic stress disorder in men. Psychiatry Res 103: $133-145$.

Chappell PB, Smith MA, Kilts CD, Bissette G, Ritchie J, Anderson C et al (1986). Alterations in corticotropin-releasing factor-like immunoreactivity in discrete rat brain regions after acute and chronic stress. J Neurosci 6: 2908-2914.

Charney DS, Heninger GH, Breier A (1984). Noradrenergic function in panic anxiety: effects of yohimbine in healthy subjects and patients with agoraphobia and panic disorder. Arch Gen Psychiatry 41: 751-763.

Chastrette N, Pfaff DW, Gibbs RB (1991). Effects of daytime and nighttime stress on Fos-like immunoreactivity in the paraventricular nucleus of the hypothalamus, the habenula, and the posterior paraventricular nucleus of the thalamus. Brain Res 563: 339-344.

Ciccocioppo R, Fedeli A, Economidou D, Policani F, Weiss F, Massi M (2003). The bed nucleus is a neuroanatomical substrate for the anorectic effect of corticotropin-releasing factor and for its reversal by nociceptin/orphanin FQ. J Neurosci 23: 9445-9451.

Cintra A, Fuxe K, Harfstrand A, Agnati LF, Wikstrom AC, Okret S et al (1987). Presence of glucocorticoid receptor immunoreactivity in corticotrophin releasing factor and in growth hormone releasing factor immunoreactive neurons of the rat di- and telencephalon. Neurosci Lett 77: 25-30.

Cook III EW, Hawk LW, Davis TL, Stevenson VE (1991). Affective individual differences and startle reflex modulation. J Abnorm Psychol 100: 5-13.

Coplan JD, Goetz R, Klein DF, Papp LA, Fyer AJ, Liebowitz MR et al (1998). Plasma cortisol concentrations preceding lactate-induced panic. Psychological, biochemical, and physiological correlates. Arch Gen Psychiatry 55 130-136.

Cornwell BR, Johnson L, Berardi L, Grillon C (2006). Anticipation of public speaking in virtual reality reveals a relationship between trait social anxiety and startle reactivity. Biol Psychiatry 59: 664-666.

Costa PT, McCrae RR (1992). Revised NEO Personality Inventory (NEO-PI-R) and NEO Five Factor Inventory (NEO-FFI) Professional Manual. Psychological Assessment Resources: Odessa, FL.

Cox BJ, Clara IP, Enns MW (2002). Posttraumatic stress disorder and the structure of common mental disorders. Depression Anxiety 15: 168-171.

Craske MG (1999). Anxiety Disorders: Psychological Approaches to Theory and Treatments. Westview Press: Boulder, CO, 425pp.

Craske MG, Waters AM (2005). Panic disorder, phobias, and generalized anxiety disorder. Annu Rev Clin Psychol 1: 197-225.

Crawley JM (1981). Neuropharmacologic specificity of a simple animal model for the behavioral actions of benzodiazepines. Pharmacol Biochemistry Behav 15 695-699).

Cummings S, Elde R, Ells J, Lindall A (1983). Corticotropin-releasing factor immunoreactivity is widely distributed within the central nervous system of the rat: an immunohistochemical study. J Neurosci 3: 1355-1368.

Cuthbert BN, Lang JL, Strauss C, Drobes D, Patrick CJ, Bradley MB (2003). The psychophysiology of anxiety disorders: fear memory imagery. Psychophysiology 40: 407-422.

Davis M (1979). Diazepam and flurazepam: effects on conditioned fear as measured with the potentiated startle paradigm. Psychopharmacology 62: 1-7.

Davis M (1993). Pharmacological analysis of fear-potentiated startle. Braz J Med Biol Res 26: 235-260.

Davis M (2000). The role of the amygdala in conditioned and unconditioned fear and anxiety. In: Aggleton JP (ed). The Amygdala, Vol 2, Oxford University Press: Oxford, UK. pp 213-287.

Davis M, Cassella JV, Kehne JH (1988). Serotonin does not mediate anxiolytic effects of buspirone in the fear-potentiated startle paradigm: comparison with 8OH-DPAT and ipsapirone. Psychopharmacology 94: 14-20.
Davis M, Schlesinger LS, Sorenson CA (1989). Temporal specificity of fearconditioning: effects of different conditioned stimulus-unconditioned stimulus intervals on the fear-potentiated startle effect. J Exp Psychol Anim Behav Process 15: 295-310.

Davis M, Whalen P (2001). The amygdala: vigilance and emotion. Mol Psychiatry 6: 13-34.

Day HE, Curran EJ, Watson Jr SJ, Akil H (1999). Distinct neurochemical populations in the rat central nucleus of the amygdala and bed nucleus of the stria terminalis: evidence for their selective activation by interleukin-1beta. J Comp Neurol $\mathbf{4 1 3}$ $113-128$.

De Bellis MD, Gold PW, Geracioti Jr TD, Listwak SJ, Kling MA (1993). Association of fluoxetine treatment with reductions in CSF concentrations of corticotropinreleasing hormone and arginine vasopressin in patients with major depression. Am J Psychiatry 150: 656-657.

de Jongh R, Groenink L, van der Gugten J, Olivier B (2002). The light-enhanced startle paradigm as a putative animal model for anxiety: effects of chlordiazepoxide, flesinoxan and fluvoxamine. Psychopharmacology 159: 176-180.

de Jongh R, Groenink L, van der Gugten J, Olivier B (2003). Light-enhanced and fear-potentiated startle: temporal characteristics and effects of alpha-helical corticotropin-releasing hormone. Biol Psychiatry 54: 1041-1048.

Deak T, Nguyen KT, Ehrlich AL, Watkins LR, Spencer RL, Maier SF et al (1999). The impact of the nonpeptide corticotropin-releasing hormone antagonis antalarmin on behavioral and endocrine responses to stress. Endocrinology 140: 79-86.

DeFries JC, Hegmann JP, Weir MW (1966). Open-field behavior in mice: evidence for a major gene effect mediated by the visual system. Science 154: 1577

Di Fabio R, St-Denis Y, Sabbatini FM, Andreotti D, Arban R, Bernasconi G et al (2008). Synthesis and pharmacological characterization of novel druglike corticotropin-releasing factor 1 antagonists. J Med Chem 51: 7370-7379.

Dickinson-Anson H, McGaugh JL (1997). Bicuculline administered into the amygdala after training blocks benzodiazepine-induced amnesia. Brain Res 752: 197-202.

Dong HW, Petrovich GD, Swanson LW (2001). Topography of projections from amygdala to bed nuclei of the stria terminalis. Brain Res Brain Res Rev 38: 192-246.

Duncan GE, Knapp DJ, Breese GR (1996). Neuroanatomical characterization of Fos induction in rat behavioral models of anxiety. Brain Res 713: 79-91.

Dunn AJ, Berridge CW (1990). Physiological and behavioral responses to corticotropin-releasing factor administration: is CRF a mediator of anxiety or stress responses. Brain Res Rev 15: 71-100.

Erb S, Salmaso N, Rodaros D, Stewart J (2001). A role for the CRF-containing pathway from central nucleus of the amygdala to bed nucleus of the stria terminalis in the stress-induced reinstatement of cocaine seeking in rats. Psychopharmacology 158: 360-365.

Falls WA, Carlson S, Turner JG, Willott JF (1997). Fear-potentiated startle in two strains of inbred mice. Behav Neurosci 111: 855-861.

Fanselow MS (1986). Associative vs topographical accounts of the immediate shock-freezing deficit in rats: Implication for the response selection rules governing species-specific defensive reactions. Learn Motiv 17: 16-39.

Fendt M, Endres T, Apfelbach R (2003). Temporary inactivation of the bed nucleus of the stria terminalis but not of the amygdala blocks freezing induced by trimethylthiazoline, a component of fox feces. J Neurosci 23: 23-28.

Fendt M, Koch M, Schnitzler H-U (1994). Lesions of the central gray block the sensitization of the acoustic startle response in rats. Brain Res 661 163-173

File SE (1982). Chlordiazepoxide-induced ataxia, muscle relaxation and sedation in the rat: effects of muscimol, picrotoxin and naloxone. Pharmacol Biochem Behav 17: 1165-1170.

File SE, Hyde JRG (1978). Can social interaction be used to measure anxiety. Br J Pharmacol 62: 19-24.

Foa EB, Zinbarg R, Rothbaum BO (1992). Uncontrollability and unpredictability in post-traumatic stress disorder: an animal model. Psychol Bull 112 218-238.

Forray MI, Gonzales M, Hadwed N, Gonzalez MP (2005). Chronic immobilization stress increases glutamatergic transmission in the rat bed nucleus of the stria terminalis. In vivo microdialysis studies. Society for Neuroscience Abstracts: Program No. 187.183.

Gewirtz JC, McNish KA, Davis M (1998). Lesions of the bed nucleus of the stria terminalis block sensitization of the acoustic startle reflex produced by repeated stress, but not fear-potentiated startle. Prog Neuropsychopharmacol Biol Psychiatry 22: 625-648.

Globisch J, Hamm AO, Esteves F, Ohman A (1999). Fear appears fast: temporal course of startle reflex potentiation in animal fearful subjects. Psychophysiology 36: 66-75. 
Goldstein BJ, Goodnick PJ (1998). Selective serotonin reuptake inhibitors in the treatment of affective disorders - III. Tolerability, safety and pharmacoeconomics. J Psychopharmacol 12: S55-S87.

Goosens KA, Maren S (2001). Contextual and auditory fear conditioning are mediated by the lateral, basal, and central amygdaloid nuclei in rats. Learn Mem 8: $148-155$.

Gorman JM, Cohen BS, Liebowitz MR, Fyer AJ, Ross D, Davies SO et al (1986). Blood gas changes and hypophosphatemia in lactate-induced panic. Arch Gen Psychiatry 43: 1067-1071.

Gorman JM, Liebowitz MR, Fyer AJ, Goetz D, Campeas RB, Fyer MR et al (1987). An open trial of fluoxetine in the treatment of panic attacks. J Clin Psychopharmacol 7: 329-332.

Graham SJ, Langley RW, Bradshaw CM, Szabadi E (2001). Effects of haloperidol and clozapine on prepulse inhibition of the acoustic startle response and the N1/P2 auditory evoked potential in man. J Psychopharmacol 15: 243-250.

Graham SJ, Scaife JC, Langley RW, Bradshaw CM, Szabadi E, Xi L et al (2005). Effects of lorazepam on fear-potentiated startle responses in man. J Psychopharmacol 19: 249-258.

Graham SJ, Scaife JC, Verduzco AMB, Langley RW, Bradshaw CM, Szabadi E (2004). Effects of quetiapine and haloperidol on prepulse inhibition of the acoustic startle (eyeblink) response and the N1/P2 auditory evoked response in man. J Psychopharmacol 18: 173-180.

Gray TS, Magnuson DJ (1992). Peptide immunoreactive neurons in the amygdala and the bed nucleus of the stria terminalis project to the midbrain central gray in the rat. Peptides 13: 451-460.

Gray TS, Magnusson DJ (1987). Neuropeptide neuronal efferents from the bed nucleus of the stria terminalis and central amygdaloid nucleus to the dorsal vagal complex in the rat. J Comp Neurol 262: 365-374.

Grillon C (2008). Greater sustained anxiety but not phasic fear in women compared to men. Emotion 8: 410-413.

Grillon C, Ameli R (1998a). Effects of threat and safety signals on startle during anticipation of aversive shocks, sounds, or airblasts. J Psychophysiol 12: 329-337.

Grillon C, Ameli R (1998b). Effects of threat of shock, shock electrode placement, and darkness on startle. Int J Psychophysiol 28: 223-231.

Grillon C, Ameli R, Goddard A, Woods S, Davis M (1994a). Baseline and fearpotentiated startle in panic disorder patients. Biol Psychiatry 35: 431-439.

Grillon C, Ameli R, Woods SW, Merikangas K, Davis M (1991). Fear-potentiated startle in humans: effects of anticipatory anxiety on the acoustic blink reflex. Psychophysiology 28: 588-595.

Grillon C, Ameli R, Woods SW, Merikangas K, Davis M (1993a). Measuring the time course of anxiety using the fear-potentiated startle reflex. Psychophysiology 30: 340-346

Grillon C, Ameli R, Foot M, Davis M (1993b). Fear-potentiated startle: relationship to the level of state/trait anxiety in healthy subjects. Biol Psychiatry 33: 566-574.

Grillon C, Baas J (2003). A review of the modulation of the startle reflex by affective states and its application in psychiatry. Clin Neurophysiol 114: 1557-1579.

Grillon C, Baas JM, Cornwell B, Johnson L (2006a). Context conditioning and behavioral avoidance in a virtual reality environment: effect of predictability. Biol Psychiatry 60: 752-759.

Grillon C, Baas JM, Pine DS, Lissek S, Lawley M, Ellis V et al (2006b). The benzodiazepine alprazolam dissociates contextual fear from cued fear in humans as assessed by fear-potentiated startle. Biol Psychiatry 60: 760-766.

Grillon C, Baas JMP (2002). Comments on the use of the startle reflex in psychopharmacological challenges: impact of baseline startle on measurement of fear-potentiated startle. Psychopharmacology 164: 236-238.

Grillon C, Baas JMP, Pine DS, Lissek S, Lawley M, Ellis V et al (2006c). The benzodiazepine alprazolam dissociates contextual fear from cued fear in humans as assessed by fear-potentiated startle. Biol Psychiatry 60: 760-766.

Grillon C, Baas JP, Lissek S, Smith K, Milstein J (2004). Anxious responses to predictable and unpredictable aversive events. Behav Neurosci 118: 916-924.

Grillon C, Chavis C, Covington MS, Pine DS (2009a). Two-week treatment with citalopram reduces contextual anxiety but not cued fear. Neuropsychopharmacology 34: 964-971

Grillon C, Davis M (1997). Fear-potentiated startle conditioning in humans: explicit and contextual cue conditioning following paired vs unpaired training. Psychophysiology 34: 451-458.

Grillon C, Dierker L, Merikangas K (1997a). Startle modulation in children at risk for anxiety disorders and/or alcoholism. J Am Acad Child Adolesc Psychiatry 36: 925-932.

Grillon C, Dierker L, Merikangas KR (1998a). Fear-potentiated startle in adolescents offspring at risk for anxiety disorder. Biol Psychiatry 44: 990-997.
Grillon C, Levenson J, Pine DS (2007). A single dose of the selective serotonin reuptake inhibitor citalopram exacerbates anxiety in humans: a fear-potentiated startle study. Neuropsychopharmacology 32: 225-231.

*Grillon C Lissek S Rabin S McDowell D Dvir S, Pine DS (2008). Increased anxiety during anticipation of unpredictable but not predictable aversive stimuli as a psychophysiologic marker of panic disorder. Am J Psychiatry 165: 898-904.

Grillon C, Merikangas KR, Dierker L, Snidman N, Arriaga Rl, Kagan J et al (1999). Startle potentiation by threat of aversive stimuli and darkness in adolescents: a multi-site study. Int J Psychophysiol 32: 63-73.

Grillon C, Morgan CA, Southwick SM, Davis M, Charney DS (1996). Baseline startle amplitude and prepulse inhibition in Vietnam veterans with PTSD. Psychiatry Res 64: 169-178.

Grillon C, Morgan CA, Davis M, Southwick SM (1998b). Effect of darkness on acoustic startle in Vietnam veterans with PTSD. Am J Psychiatry 155: 812-817.

Grillon C, Morgan CA, Davis M, Southwick SM (1998c). Effects of experimental context and explicit threat cues on acoustic startle in Vietnam veterans with posttraumatic stress disorder. Biol Psychiatry 44: 1027-1036.

Grillon C, Pellowski M, Merikangas KR, Davis M (1997b). Darkness facilitates the acoustic startle reflex in humans. Biol Psychiatry 42: 453-460.

Grillon C, Pine DS, Lissek S, Rabin S, Vythilingam M (2009b). Increased anxiety during anticipation of unpredictable aversive stimuli in posttraumatic stress disorder but not in generalized anxiety disorder. Biol Psychiatry 66: 47-53.

Grillon C, Warner V, Hille J, Merikangas KR, Bruder G, Tenke CE et al (2005). Families at high and low risk for depression: a three-generation startle study. Biol Psychiatry 57: 953-960.

Guscott MR, Cook GP, Bristow LJ (2000). Contextual fear conditioning and baseline startle responses in the rat fear-potentiated startle test: a comparison of benzodiazepine/gamma-aminobutyric acid-A receptor agonists. Behav Pharmacol 11: 495-504.

Guthrie RM, Bryant RA (2005). Auditory startle response in firefighters before and after trauma exposure. Am J Psychiatry 162: 283-290.

Hamm AO, Globisch J, Cuthbert BN, Vaitl D (1991a). Startle modulation in simple phobics and controls. Psychophysiology 28: s28.

Hamm AO, Greenwald MK, Bradley MM, Cuthbert BN, Lang PJ (1991b). The fear potentiated startle effect. Blink reflex modulation as a result of classical aversive conditioning. Integr Physiol Behav Sci 26: 119-126.

Haring C, Humpel C, Skofitsch G, Krobath J, Javorsky F, Saria A (1991). Calcitonin gene-related peptide in the amygdaloid complex of the rat: immunohistochemical and quantitative distribution, and drug effects on calcium dependent, potassium-evoked in vitro release. Synapse 8: 261-269.

Harrigan EA, Magnuson DJ, Thunstedt GM, Gray TS (1994). Corticotropin releasing factor neurons are innervated by calcitonin gene-related peptide terminals in the rat central amygdaloid nucleus. Brain Res Bull 33: 529-534.

Harris JA, Westbrook RF (2001). Contextual control over the expression of fear in rats conditioned under a benzodiazepine. Psychopharmacology (Berl) 156: 92-97.

Hatalski CG, Guirguis C, Baram TZ (1998). Corticotropin releasing factor mRNA expression in the hypothalamic paraventricular nucleus and the central nucleus of the amygdala is modulated by repeated acute stress in the immature rat. J Neuroendocrinol 10: 663-669.

Herry C, Bach DR, Esposito F, Di Salle F, Perrig WJ, Scheffler K et al (2007). Processing of temporal unpredictability in human and animal amygdala. J Neurosci 27: 5958-5966.

Hettema JM, Neale MC, Myers JM, Prescott CA, Kendler KS (2006). A populationbased twin study of the relationship between neuroticism and internalizing disorders. Am J Psychiatry 163: 857-864.

Hikichi T, Akiyoshi J, Yamamoto Y, Tsutsumi T, Isogawa K, Nagayama H (2000). Suppression of conditioned fear by administration of CRF receptor antagonist CP-154,526. Pharmacopsychiatry 33: 189-193.

Hitchcock JM, Davis M (1986). Lesions of the amygdala, but not of the cerebellum or red nucleus, block conditioned fear as measured with the potentiated startle paradigm. Behav Neurosci 100: 11-22.

Hitchcock JM, Davis M (1987). Fear-potentiated startle using an auditory conditioned stimulus: effect of lesions of the amygdala. Physiol Behav 39: 403-408.

Hitchcock JM, Davis M (1991). The efferent pathway of the amygdala involved in conditioned fear as measured with the fear-potentiated startle paradigm. Behav Neurosci 105: 826-842.

Hoehn T, Braune SS, Scheibe GG, Albus MM (1997). Physiological, biochemical and subjective parameters in anxiety patients with panic disorder during stress exposure as compared with healthy controls. Eur Arch Psychiatry Clin Neurosci 247: 264-274. 
Hoehn-Saric R, McLeod DR, Zimmerli WD (1989). Somatic manifestations in women with generalized anxiety disorder. Arch Gen Psychiatry 46: 1113-1119.

Hoge EA, Oppenheimer JE, Simon NM (2004). Generalized anxiety disorder. Focus 2: 346-359.

Honkaniemi J, Pelto-Huikko M, Rechardt L, Isola J, Lammi A, Fuxe K et al (1992). Colocalization of peptide and glucocorticoid receptor immunoreactivities in rat central amygdaloid nucleus. Neuroendocrinology 55: 451-459.

Hsu DT, Chen FL, Takahashi LK, Kalin NH (1998). Rapid stress-induced elevations in corticotropin-releasing hormone mRNA in rat central amygdala nucleus and hypothalamic paraventricular nucleus: an in situ hybridization analysis. Brain Res 788: 305-310.

Ip NY (1994). Pattern of presynaptic nerve activity can determine the type of neurotransmitter regulating a postsynaptic event. Nature 311: 472-474.

Iwata J, LeDoux JE, Meeley MP, Arneric S, Reis DJ (1986). Intrinsic neurons in the amygdala field projected to by the medial geniculate body mediate emotional responses conditioned to acoustic stimuli. Brain Res 383: 195-214.

Jasnow AM, Davis M, Huhman KL (2004). Involvement of central amygdalar and bed nucleus of the stria terminal's corticotropin-releasing factor in behavioral responses to social defeat. Behav Neurosci 118: 1052-1061.

Jensen RA, Martinez Jr JL, Vasquez BJ, McGaugh JL (1979). Benzodiazepines alter acquisition and retention of an inhibitory avoidance response in mice. Psychopharmacology (Berl) 64: 125-126.

Johnston JB (1923). Further contribution to the study of the evolution of the forebrain. J Comp Neurol 35: 337-481.

Jolkkonen E, Pitkanen A (1998). Intrinsic connections of the rat amygdaloid complex: projections originating in the central nucleus. J Comp Neurol 395: 53-72.

Jovanovic T, Norrholm SD, Fennell JE, Keyes M, Fiallos AM, Myers KM et al (2009). Posttraumatic stress disorder may be associated with impaired fear inhibition: relation to symptom severity. Psychiatry Res 167: 151-160.

Ju G, Swanson LW, Simerly RB (1989). Studies on the cellular architecture of the bed nuclei of the stria terminalis in the rat: II. Chemoarchitecture. J Comp Neurol 280: 603-621.

Justice NJ, Yuan ZF, Sawchenko PE, Vale W (2008). Type 1 corticotropin-releasing factor receptor expression reported in BAC transgenic mice: implications for reconciling ligand-receptor mismatch in the central corticotropin-releasing factor system. J Comp Neurol 511: 479-496.

Kalin $\mathrm{NH}$ (2005). Brain regions associated with the expression and contextual regulation of anxiety in primates. Biol Psychiatry 58: 796-804.

Kalin NH, Takahashi LK (1990). Fear-motivated behavior induced by prior shock experience is mediated by corticotropin-releasing hormone systems. Brain Res 509: 80-84.

Kalin NH, Takahashi LK, Chen FL (1994). Restraint stress increases corticotropinreleasing hormone mRNA content in the amygdala and paraventricular nucleus. Brain Res 656: 182-186.

Kehne JH, Cassella JV, Davis M (1988). Anxiolytic effects of buspirone and gepirone in the fear-potentiated startle paradigm. Psychopharmacology 94: 8-13.

Kehne JH, Gallager DW, Davis M (1981). Strychnine: brainstem and spinal mediation of excitatory effects on acoustic startle. Eur J Pharmacol 76: 177-186.

Kellogg CK, Sullivan AT, Bitrain D, Ison JR (1991). Modulation of noise-potentiated acoustic startle via the benzodiazepine-gamma-aminobutyric acid receptor complex. Behav Neurosci 105: 640-646.

Kendler KS, Myers J, Prescott CA (2002). The etiology of phobias: an evaluation of the stress-diathesis model. Arch Gen Psychiatry 59: 242-248.

Kessler RC, McGonagle KA, Zhao S, Nelson CB, Hughes M, Eshleman S et al (1994). Lifetime and 12-month prevalence of DSM-III-R psychiatric disorders in the United States. Arch Gen Psychiatry 51: 8-19.

Kim JJ, Fanselow MS (1992). Modality-specific retrograde amnesia of fear. Science 256: 675-677.

Klumpers F, van Gerven J, Prinssen E, Niklson I, Roesch F, Riedel W et al (2008). Method development studies for repeatedly measuring anxiolytic drug effects in healthy humans. J Psychopharmacol (in press).

Kocorowski LH, Helmstetter FJ (2001). Calcitonin gene-related peptide released within the amygdala is involved in Pavlovian auditory fear conditioning. Neurobiol Learn Mem 75: 149-163.

Koo JW, Han JS, Kim JJ (2004). Selective neurotoxic lesions of basolateral and central nuclei of the amygdala produce differential effects on fear conditioning. J Neurosci 24: 7654-7662.

Kopchia KL, Altman HJ, Commissaris RL (1992). Effects of lesions of the central nucleus of the amygdala on anxiety-like behaviors in the rat. Pharmacol Biochem Behav 43: 453-461.

Krueger RF (1999). The structure of common mental disorders. Arch Gen Psychiatry 56: 921-926.

Kumari V, Cotter P, Corr P, Gray J, Checkley S (1996). Effect of clonidine on the human acoustic startle reflex. Psychopharmacology 123: 353-360.
Lambert JJ, Belelli D, Harney SC, Peters JA, Frenguelli BG (2001). Modulation of native and recombinant $\mathrm{GABA}(\mathrm{A})$ receptors by endogenous and synthetic neuroactive steroids. Brain Res Brain Res Rev 37: 68-80.

Lan NC, Gee KW (1994). Neuroactive steroid actions at the GABAA receptor. Horm Behav 28: 537-544.

Lang PJ, Davis M, Ohman A (2000). Fear and anxiety: animal models and human cognitive psychophysiology. J Affect Disord 61: 137-159.

Lechner SM, Valentino RJ (1999). Glucocorticoid receptor-immunoreactivity in corticotrophin-releasing factor afferents to the locus coeruleus. Brain Res 816: 17-28.

LeDoux JE (2000). Emotion circuits in the brain. Annu Rev Neurosci 23: 155-184.

LeDoux JE, Iwata J, Cicchetti P, Reis DJ (1988). Different projections of the central amygdaloid nucleus mediate autonomic and behavioral correlates of conditioned fear. J Neurosci 8: 2517-2529.

*Lee Y, Davis M (1997). Role of the hippocampus, the bed nucleus of the stria terminalis, and the amygdala in the excitatory effect of corticotropin-releasing hormone on the acoustic startle reflex. J Neurosci 17: 6434-6446.

Lee Y, Fitz S, Johnson PL, Shekhar A (2008). Repeated stimulation of CRF receptors in the BNST of rats selectively induces social but not panic-like anxiety. Neuropsychopharmacology 33: 2586-2594.

Lee Y, Schulkin J, Davis M (1994). Effect of corticosterone on the enhancement of the acoustic startle reflex by corticotropin releasing factor (CRF). Brain Res 666: 93-98.

Li S, Kirouac GJ (2008). Projections from the paraventricular nucleus of the thalamus to the forebrain, with special emphasis on the extended amygdala. J Comp Neurol 506: 263-287.

Liang KC, Melia KR, Campeau S, Falls WA, Miserendino MJD, Davis M (1992a). Lesions of the central nucleus of the amygdala, but not of the paraventricular nucleus of the hypothalamus, block the excitatory effects of corticotropin releasing factor on the acoustic startle reflex. J Neurosci 12: 2313-2320.

Liang KC, Melia KR, Miserendino MJD, Falls WA, Campeau S, Davis M (1992b). Corticotropin-releasing factor: long-lasting facilitation of the acoustic startle reflex. J Neurosci 12: 2303-2312.

Liebowitz MR, Fyer AJ, Gorman JM, Dillon D, Appleby IL, Levy G et al (1984). Lactate provocation of panic attacks. I. Clinical and behavioral findings. Arch Gen Psychiatry 41: 764-770.

Lipp OV, Sheridan J, Siddle DAT (1994). Human blink startle during aversive and non-aversive Pavlovian conditioning. J Exp Psychol 20: 380-389.

Lipp OV, Siddle DA, Dall PJ (2003). The effects of unconditional stimulus valence and conditioning paradigm on verbal, skeleton-motor, and autonomic indices of human Pavlovian conditioning. Learning Motivation 34: 31-51.

Lissek S, Pine DS, Grillon C (2006). The strong situation: a potential impediment to studying the psychophysiology and pharmacology of anxiety disorders. Biol Psychol 72: 265-270.

Liu IY, Lyons WE, Mamounas LA, Thompson RF (2004). Brain-derived neurotrophic factor plays a critical role in contextual fear conditioning. I Neurosci 24: 7958-7963.

Ludewig S, Ludewig K, Geyer MA, Hell D, Vollenweider FX (2002). Prepulse inhibition deficits in patients with panic disorder. Depress Anxiety 15: 55-60.

Lundberg JM, Rudehill A, Sollevi A (1986). Frequency- and reserpine-dependent chemical coding of sympathetic transmission: differential release of noradrenaline and neuropeptide Y from pig spleen. Neurosci Lett 63: 96-100.

Makino S, Gold PW, Schulkin J (1994a). Corticosterone effects on corticotropinreleasing hormone mRNA in the central nucleus of the amygdala and the parvocellular region of the paraventricular nucleus of the hypothalamus. Brain Res 640: 105-112.

Makino S, Gold PW, Schulkin J (1994b). Effects of corticosterone on CRH mRNA and content in the bed nucleus of the stria terminalis; comparison with the effects in the central nucleus of the amygdala and the paraventricular nucleus of the hypothalamus. Brain Res 657: 141-149.

Makino S, Shibasaki T, Yamauchi N, Nishioka T, Mimoto T, Wakabayashi I et al (1999). Psychological stress increased corticotropin-releasing hormone mRNA and content in the central nucleus of the amygdala but not in the hypothalamic paraventricular nucleus in the rat. Brain Res 850: 136-143.

Mansbach RS, Geyer MA (1988). Blockade of potentiated startle responding in rats by 5-hydroxytryptamine1A receptor ligands. Eur J Pharmacol 156: 375-383.

Markham CM, Norvelle A, Huhman KL (2009). Role of the bed nucleus of the stria terminalis in the acquisition and expression of conditioned defeat in Syrian hamsters. Behav Brain Res 198: 69-73.

Marlin N (1981). Contextual associations in trace conditioning. Anim Learn Behav 9: 519-523.

McDonald AJ, Shamman-Lagnado SJ, Shi CJ, Davis M (1999). Cortical afferents to the extended amygdala. In: McGinty JF (ed). Ann N Y Acad Sci 877: 309-338. 
McDonald J (1991). Topographic organization of amygdaloid projections to the caudatoputamen, nucleus accumbens, and related striatal-like areas of the rat brain. Neuroscience 44: 15-33.

McDonald RJ, Murphy RA, Guarraci FA, Gortler JR, White NM, Baker AG (1997). Systematic comparison of the effects of hippocampal and fornix-fimbria lesions on acquisition of three configural discriminations. Hippocampus 7: 371-388.

McGregor IS, Hargreaves GA, Apfelbach R, Hunt GE (2004). Neural correlates of cat odor-induced anxiety in rats: region-specific effects of the benzodiazepine midazolam. J Neurosci 24: 4134-4144.

McNish KA, Gewirtz JC, Davis M (1997). Evidence of contextual fear conditioning following lesions of the hippocampus: a disruption of freezing but not fearpotentiated startle. J Neurosci 17: 9353-9360.

McTeague LM, Lang PJ, Laplante M-C, Cuthbert BN, Strauss CC, Bradley MM (2009). Fearful imagery in social phobia: generalization, comorbidity, and physiological reactivity. Biol Psychiatry 65: 374-382.

Meloni EG, Davis M (1999). Muscimol in the deep layers of the superior colliculus/ mesencephalic reticular formation blocks expression but not acquisition of fearpotentiated startle in rats. Behav Neurosci 113: 1152-1160.

Meloni EG, Jackson A, Gerety LP, Cohen BM, Carlezon Jr WA (2006). Role of the bed nucleus of the stria terminalis (BST) in the expression of conditioned fear. Ann N Y Acad Sci 1071: 538-541.

Melzig CA, Weike Al, Zimmermann J, Hamm AO (2007). Startle reflex modulation and autonomic responding during anxious apprehension in panic disorder patients. Psychophysiology 44: 846-854.

Merikangas KR, Avenevoli S, Dierker L, Grillon C (1999). Vulnerability factors among children at risk for anxiety disorders. Biol Psychiatry 46: 1523-1535.

Mineka S, Kihlstrom JF (1978). Unpredictable and uncontrollable events: a new perspective on experimental neurosis. J Abnorm Psychol 87: 256-271.

Moga MM, Gray TS (1985). Evidence for corticotropin-releasing factor, neurotensin, and somatostatin in the neural pathway from the central nucleus of the amygdala to the parabrachial nucleus. J Comp Neurol 241: 275-284.

Moga MM, Weis RP, Moore RY (1995). Efferent projections of the paraventricular thalamic nucleus in the rat. J Comp Neurol 359: 221-238.

Morgan III CA, Grillon C, Southwick SM, Davis M, Charney DS (1995a). Fearpotentiated startle in posttraumatic stress disorder. Biol Psychiatry 38: 378-385.

Morgan CA, Grillon C, Southwick SM, Nagy LM, Davis M, Krystal JH. et al (1995b). Yohimbine facilitated acoustic startle in combat veterans with post-traumatic stress disorder. Psychopharmacology 117: 466-471.

Morris J, Ohman A, Doland R (1998). Conscious and unconscious emotional learning in the human amygdala. Nature 393: 467-470.

Morris JS, Ohman A, Dolan RJ (1999). A subcortical pathway to the right amygdala mediating 'unseen' fear. Proc Natl Acad Sci USA 96: 1680-1685.

Murphy SE, Downham C, Cowen PJ, Harmer CJ (2008). Direct effects of diazepam on emotional processing in healthy volunteers. Psychopharmacology 199: 503-513.

Nemeroff CB (2004). Early-life adversity, CRF dysregulation, and vulnerability to mood and anxiety disorders. Psychopharmacol Bull 38(Suppl 1): 14-20.

Nguyen KQ, Sills MA, Jacobowitz DM (1986). Cardiovascular effects produced by microinjection of calcitonin gene-related peptide into the rat central amygdaloid nucleus. Peptides 7: 337-339.

Nijsen MJMA, Croiset G, Diamant M, De Wied D, Wiegant VM (2001). CRH signalling in the bed nucleus of the stria terminalis is involved in stressinduced cardiac vagal activation in conscious rats. Neuropsychopharmacology 24: $1-10$.

Norrholm SD, Jovanovic T, Vervliet B, Myers KM, Davis M, Rothbaum BO et al (2006). Conditioned fear extinction and reinstatement in a human fearpotentiated startle paradigm. Learn Mem 13: 681-685.

Odling-Smee FJ (1975a). Background stimuli and the inter-stimulus interval during Pavlovian conditioning. Q J Exp Psychol 27: 387-392.

Odling-Smee FJ (1975b). The role of background stimuli during Pavlovian conditioning. Q J Exp Psychol 27: 201-209.

Olive MF, Koenig HN, Nannini MA, Hodge CW (2002). Elevated extracellular CRF levels in the bed nucleus of the stria terminalis during ethanol withdrawal and reduction by subsequent ethanol intake. Pharmacol Biochem Behav 72: 213-220.

Olsson A, Phelps EA (2007). Social learning of fear. Nat Neurosci 10: 1095-1102.

Otake K, Ruggiero DA, Nakamura Y (1995). Adrenergic innervation of forebrain neurons that project to the paraventricular thalamic nucleus in the rat. Brain Res 697: 17-26.

Otto T, Poon P (2006). Dorsal hippocampal contributions to unimodal contextual conditioning. J Neurosci 26: 6603-6609.

Pain L, Launoy A, Fouquet N, Oberling P (2002). Mechanisms of action of midazolam on expression of contextual fear in rats. Br J Anaesth 89: 614-621.

Parente AC, Garcia-Leal C, Del-Ben CM, Guimarães FS, Graeff FG (2005). Subjective and neurovegetative changes in healthy volunteers and panic patients performing simulated public speaking. Eur Neuropsychopharmacol 15: $663-671$.

Parr LA, Winslow JT, Davis M (2002). Rearing experience differentially affects somatic and cardiac startle responses in rhesus monkeys (Macaca mulatta). Behav Neurosci 116: 378-386.

Petrovich GD, Swanson LW (1997). Projections from the lateral part of the central amygdalar nucleus to the postulated fear conditioning circuit. Brain Res 763: 247-254.

Phelix CF, Paul WK (1990). Demonstration of distinct corticotropin releasing factorcontaining neuron populations in the bed nucleus of the stria terminalis. A light and electron microscoic immunocytochemical study in the rat. Histochemistry 94: 345-364.

Phelps EA, O'Connor KJ, Gatenby JC, Gore JC, Grillon C, Davis M (2001). Activation of the left amygdala to a cognitive representation of fear. Nat Neurosci 4: 437-441.

Phillips MA, Langley RW, Bradshaw CM, Szabadi E (2000). The effects of some antidepressant drugs on prepulse inhibition of the acoustic startle (eyeblink) response and the N1/P2 auditory evoked response in man. J Psychopharmacol 14: $40-45$.

Phillips RG, LeDoux JE (1992). Differential contribution of amygdala and hippocampus to cued and contextual fear conditioning. Behav Neurosci 106: 274-285

Ploghaus A, Tracey I, Gati JS, Clare S, Menon RS, Matthews PM et al (1999). Dissociating pain from its anticipation in the human brain. Science 284: 1979-1981.

Pole N, Neylan TC, Best SR, Orr SP, Marmar CR (2003). Fear-potentiated startle and posttraumatic stress symptoms in urban police officers. J Trauma Stress 16: 471-479.

Pole N, Neylan TC, Otte C, Henn-Hasse C, Metzler TJ, Marmar CR (2009). Prospective prediction of posttraumatic stress disorder symptoms using fear potentiated auditory startle responses. Biol Psychiatry 65: 235-240.

Ponder CA, Kliethermes CL, Drew MR, Muller J, Das K, Risbrough VB et al (2007). Selection for contextual fear conditioning affects anxiety-like behaviors and gene expression. Genes Brain Behav 6: 736-749.

Potter E, Sutton S, Donaldson C, Chen R, Perrin M, Lewis K et al (1994). Distribution of corticotropin-releasing factor receptor mRNA expression in the rat brain and pituitary. Proc Natl Acad Sci USA 91: 8777-8781.

Radulovic J, Ruhmann A, Liepold T, Spiess J (1999). Modulation of learning and anxiety by corticotropin-releasing factor (CRF) and stress: differential roles of CRF receptors 1 and 2. J Neurosci 19: 5016-5025.

Rasmussen DD, Crites NJ, Burke BL (2008). Acoustic startle amplitude predicts vulnerability to develop post-traumatic stress hyper-responsivity and associated plasma corticosterone changes in rats. Psychoneuroendocrinology 33: 282-291.

Rescorla RA, Wagner AR (1972). A theory of Pavlovian conditioning: variations in the effectiveness of reinforcement and nonreinforcement. In: Black $\mathrm{AH}$, Prokasy WF (eds). Classical Conditioning II. Current Research and Theory. AppletonCentury-Crofts: New York, 64-99.

Resstel LB, Alves FH, Reis DG, Crestani CC, Correa FM, Guimaraes FS (2008). Anxiolytic-like effects induced by acute reversible inactivation of the bed nucleus of stria terminalis. Neuroscience 154: 869-876.

Riba J, Rodriguez-Fornells A, Urbano G, Antonijoan R, Barbanoj MJ (1999). Fear potentiated startle of the acoustic startle response is preserved after lorazepam administration to human subjects. Psychophysiology 36(Suppl 1): S94

Riba J, Rodriguez-Fornells A, Urbano G, Morte A, Antonijoan R, Barbanoj MJ (2001). Differential effects of alprazolam on the baseline and fear-potentiated startle reflex in humans: a dose-response study. Psychopharmacology 157: 358-367

Richardson R, Elsayed H (1998). Shock sensitization of startle in rats: the role of contextual conditioning. Behav Neurosci 112: 1136-1141.

Risbrough VB, Geyer MA, Hauger RL, Coste S, Stenzel-Poore M, Wurst W. et al (2009). CRF1 and CRF2 receptors are required for potentiated startle to contextual but not discrete cues. Neuropsychopharmacology 34: 1494-1503.

Risbrough VB, Stein MB (2006). Role of corticotropin releasing factor in anxiety disorders: a translational research perspective. Horm Behav 50: 550-561.

Roemer L, Orsillo SM, Barlow DH (2002). Generalized anxiety disorder. In: Barlow $\mathrm{DH}$ (ed). Anxiety and Its Disorders: The Nature and Treatment of Anxiety and Panic. The Guilford Press: New York. pp 477-515.

Rosen JB, Hitchcock JM, Sananes CB, Miserendino MJD, Davis M (1991). A direct projection from the central nucleus of the amygdala to the acoustic startle pathway: anterograde and retrograde tracing studies. Behav Neurosci 105: 817-825.

Roth WT, Margraf J, Ehlers A, Taylor B, Maddock RJ, Davies S et al (1992). Stress test reactivity in panic disorder. Arch Gen Psychiatry 49: 301-310.

Sabatinelli D, Bradley MM, Lang PJ (2001). Affective startle modulation in anticipation and perception. Psychophysiology 38: 719-722. 
Sahuque LL, Kullberg EF, McGeehan AJ, Kinder JR, Hicks MP, Blanton MG et al (2006). Anxiogenic and aversive effects of corticotropin-releasing factor (CRF) in the bed nucleus of the stria terminalis in the rat: role of CRF receptor subtypes. Psychopharmacology (Berl) 186: 122-132.

Sajdyk T, Johnson P, Fitz S, Shekhar A (2008). Chronic inhibition of GABA synthesis in the bed nucleus of the stria terminalis elicits anxiety-like behavior. J Psychopharmacol 22: 633-641.

Sakaguchi A, LeDoux JE, Sved AF, Reis DJ (1984). Strain difference in fear between spontaneously hypertensive and normotensive rats is mediated by adrenal cortical hormones. Neurosci Lett 46: 59-64.

Sakanaka M, Shibasaki T, Lederis K (1986). Distribution and efferent projections of corticotropin-releasing factor-like immunoreactivity in the rat amygdaloid complex. Brain Res 382: 213-238.

Samuels ER, Hou RH, Langley RW, Szabadi E, Bradshaw CM (2007). Modulation of the acoustic startle response by the level of arousal: comparison of clonidine and modafinil in healthy volunteers. Neuropsychopharmacology 32: 2405-2421.

Santibanez M, Gysling K, Forray MI (2006). Desipramine prevents the sustained increase in corticotropin-releasing hormone-like immunoreactivity induced by repeated immobilization stress in the rat central extended amygdala. $J$ Neurosci Res 84: 1270-1281.

Scaife JC (2005). Disruption of Pavlovian fear conditioning by diazepam is prevented by flumazenil given before, but not after, CS-US pairing. J Psychopharmacol 19: A17-A17.

Scaife JJC, Langley RRW, Bradshaw CCM, Szabadi EE (2005). Diazepam suppresses the acquisition but not the expression of 'fear-potentiation' of the acoustic startle response in man. J Psychopharmacol 19: 347-356.

Schaller M, Park JH, Mueller A (2003). Fear of the dark: interactive effects of beliefs about danger and ambient darkness on ethnic stereotypes. Pers Soc Psychol Bull 29: 637-649.

Schupp H, Cuthbert B, Bradley M, Birbaumer N, Lang P (1997). Probe P3 and blinks: two measures of affective startle modulation. Psychophysiology 34: 1-6.

Schwaber JS, Kapp BS, Higgins GA, Rapp PR (1982). Amygdaloid basal forebrain direct connections with the nucleus of the solitary tract and the dorsal motor nucleus. J Neurosci 2: 1424-1438.

Shammah-Lagnado SJ, Negrao N, Silva BA, Ricardo JA (1987). Afferent connections of the nuclei reticularis pontis oralis and caudalis: a horseradish peroxidase study in the rat. Neuroscience 20: 961-989.

Shepard JD, Barron KW, Myers DA (2000). Corticosterone delivery to the amygdala increases corticotropin-releasing factor mRNA in the central amygdaloid nucleus and anxiety-like behavior. Brain Res 861: 288-295.

Shi C-J, Zhou X-L, Davis M (2002). A GABAergic projection from the central extended amygdala to the deep mesencephalic nucleus in rats. Soc Neurosci Abstr 28: Abstract 284.214.

Shimada S, Inagaki S, Kubota Y, Ogawa N, Shibasaki T, Takagi H (1989). Coexistence of peptides (corticotropin releasing factor/neurotensin and substance $\mathrm{P} /$ somatostatin) in the bed nucleus of the stria terminalis and central amygdaloid nucleus of the rat. Neuroscience 30: 377-383.

Staub E, Tursky B, Schwartz G (1971). Self-control and predictability: their effects on reactions to aversive stimulation. J Pers Soc Psychol 18: 157-162.

Stout SC, Mortas P, Owens MJ, Nemeroff CB, Moreau J (2000). Increased corticotropin-releasing factor concentrations in the bed nucleus of the stria terminalis of anhedonic rats. Eur J Pharmacol 401: 39-46.

Straube T, Mentzel HJ, Miltner WH (2007). Waiting for spiders: brain activation during anticipatory anxiety in spider phobics. Neuroimage 37: 1427-1436.

Sullivan GM, Apergis J, Bush DE, Johnson LR, Hou M, Ledoux JE (2004). Lesions in the bed nucleus of the stria terminalis disrupt corticosterone and freezing responses elicited by a contextual but not by a specific cue-conditioned fear stimulus. Neuroscience 128: 7-14.

Sun N, Roberts L, Cassell D (1991). Rat central amygdaloid nucleus projections to the bed nucleus of the stria terminalis. Brain Res Bull 27: 651-662.

Sun N, Yi H, Cassell MD (1994). Evidence for a GABAergic interface between cortical afferents and brainstem projection neurons in the rat central extended amygdala. J Comp Neurol 340: 43-64.

Swanson LW, Sawchenko PE, Rivier J, Vale W (1983). Organization of bovine corticotropin-releasing factor immunoreactive cells and fibers in the rat brain: an immunohistochemical study. Neuroendocrinology 36: 165-186.

Swanson LW, Simmons DM (1989). Differential steroid hormone and neural influences on peptide mRNA levels in $\mathrm{CRH}$ cells of the paraventricular nucleus: a hybridization histochemical study in the rat. J Comp Neurol 285: 413-435.

Swerdlow NR, Britton KT, Koob GF (1989). Potentiation of acoustic startle by corticotropin-releasing factor (CRF) and by fear are both reversed by alphahelical CRF (9-41). Neuropsychopharmacology 2: 285-292.
Swerdlow NR, Geyer MA, Vale WW, Koob GF (1986). Corticotropin-releasing factor potentiates acoustic startle in rats: blockade by chlordiazepoxide. Psychopharmacology 88: 147-152.

Thompson BL, Erickson K, Schulkin J, Rosen JB (2004). Corticosterone facilitates retention of contextually conditioned fear and increases $\mathrm{CRH}$ mRNA expression in the amygdala. Behav Brain Res 149: 209-215.

Todorovic C, Radulovic J, Jahn O, Radulovic M, Sherrin T, Hippel C et al (2007). Differential activation of CRF receptor subtypes removes stress-induced memory deficit and anxiety. Eur J Neurosci 25: 3385-3397.

Toufexis D (2007). Region- and sex-specific modulation of anxiety behaviours in the rat. J Neuroendocrinol 19: 461-473.

Toufexis D, Davis C, Hammond A, Davis M (2005). Sex differences in hormonal modulation of anxiety measured with light-enhanced startle: possible role for arginine vasopressin in the male. J Neurosci 25: 9010-9016.

*Toufexis DJ Davis C Hammond A, Davis M (2004). Progesterone attenuates corticotropin-releasing factor-enhanced but not fear-potentiated startle via the activity of its neuroactive metabolite, allopregnanolone. J Neurosci 24: 10280-10287.

Toufexis DJ, Rochford J, Walker CD (1999). Lactation-induced reduction in rats' acoustic startle is associated with changes in noradrenergic neurotransmission. Behav Neurosci 113: 176-184.

Treit D, Menard J, Royan C (1993a). Anxiogenic stimuli in the elevated plus-maze. Pharmacol Biochemistry Behav 44: 463-469.

Treit D, Pesold C, Rotzinger S (1993b). Noninteractive effects of diazepam and amygdaloid lesions in two animal models of anxiety. Behav Neurosci 107: 1099-1105.

Turner BH, Herkenham M (1991). Thalamoamygdaloid projections in the rat: a test of the amygdala's role in sensory processing. J Comp Neurol 313: 295-325.

Tyrka AR, Carpenter LL, McDougle CJ, Kirwin PD, Owens MJ, Nemeroff CB et al (2004). Increased cerebrospinal fluid corticotropin-releasing factor concentrations during tryptophan depletion in healthy adults. Biol Psychiatry 56: 531-534.

Van Pett K, Viau V, Bittencourt JC, Chan RK, Li HY, Arias C et al (2000). Distribution of mRNAs encoding CRF receptors in brain and pituitary of rat and mouse. J Comp Neurol 428: 191-212.

Veening JG, Swanson LW, Sawchenko PE (1984). The organization of projections from the central nucleus of the amygdala to brain stem sites involved in central autonomic regulation: a combined retrograde transport-immunohistochemical study. Brain Res 303: 337-357.

Veinante P, Stoeckel ME, Freund-Mercier MJ (1997). GABA- and peptideimmunoreactivities co-localize in the rat central extended amygdala. Neuroreport 8: 2985-2989.

Veinante P, Stoeckel ME, Lasbennes F, Freund-Mercier MJ (2003). c-Fos and peptide immunoreactivities in the central extended amygdala of morphinedependent rats after naloxone-precipitated withdrawal. Eur $J$ Neurosci 18: 1295-1305.

Vertes RP, Hoover WB (2008). Projections of the paraventricular and paratenial nuclei of the dorsal midline thalamus in the rat. J Comp Neurol 508: 212-237.

Vollebergh WA, ledema J, Bijl RV, de Graaf R, Smit F, Ormel J (2001). The structure and stability of common mental disorders: the NEMESIS study. Arch Gen Psychiatry 58: 597-603.

Voshaar RC, Verkes RJ, van Luijtelaar GL, Edelbroek PM, Zitman FG (2005). Effects of additional oxazepam in long-term users of oxazepam. J Clin Psychopharmacol 25: 42-50.

Vrana SR, Lang PJ (1990). Fear imagery and the startle probe reflex. J Abnorm Psychol 99: 189-197.

Waddell J, Morris RW, Bouton ME (2006). Effects of bed nucleus of the stria terminalis lesions on conditioned anxiety: aversive conditioning with longduration conditional stimuli and reinstatement of extinguished fear. Behav Neurosci 120: 324-336.

*Walker D Yang Y Ratti E Corsi M Trist D, Davis M (2009). Differential effects of the CRF-R1 antagonist GSK876008 on fear-potentiated, light- and CRF-enhanced startle suggest preferential involvement in sustained vs phasic threat responses. Neuropsychopharmacology 34: 1533-1542.

Walker DL, Davis M (1997a). Anxiogenic effects of high illumination levels assessed with the acoustic startle paradigm. Biol Psychiatry 42: 461-471.

*Walker DL, Davis M (1997b). Double dissociation between the involvement of the bed nucleus of the stria terminalis and the central nucleus of the amygdala in light-enhanced vs fear-potentiated startle. J Neurosci 17: 9375-9383.

Walker DL, Davis M (2002a). Light enhanced startle: further pharmacological and behavioral evaluation. Psychopharmacology 159: 304-310.

*Walker DL, Davis M (2002b). Quantifying fear potentiated startle using absolute vs percent increase scoring methods: implications for the neurocircuitry of fear and anxiety. Psychopharmacology 164: 318-328.

Walker DL, Davis M (2008). Role of the extended amygdala in short-duration vs sustained fear: a tribute to Dr. Lennart Heimer. Brain Struct Funct 213: 29-42. 
Walker DL, Miles LA, Davis M (2009). Selective participation of the bed nucleus of the stria terminalis and CRF in sustained anxiety-like versus phasic fear-like responses. Prog Neuropsychopharmacol Biol Psychiatry (advance on-line publication at http://dx.doi.org/10.1016/j.pnpbp.2009.06.022).

Walker DL, Toufexis DJ, Davis M (2003). Role of the bed nucleus of the stria terminalis vs the amygdala in fear, stress, and anxiety. Eur J Pharmacol 463: 199-216.

Wang J, Palkovits M, Usdin TB, Dobolyi A (2006). Afferent connections of the subparafascicular area in rat. Neuroscience 138: 197-220.

Waters AM, Craske MG, Bergman RL, Naliboff BD, Negoro H, Ornitz EM (2008). Developmental changes in startle reactivity in school-age children at risk for and with actual anxiety disorder. Int J Psychophysiol 70: 158-164.

Watson D (2005). Rethinking the mood and anxiety disorders: a quantitative hierarchical model for DSM-V. J Abnorm Psychol 114: 522-536.

Watson D, Clark LA, Carey G (1988). Positive and negative affectivity and their relation to anxiety and depressive disorders. J Abnorm Psychol 97: 346-353.

Watts AG, Sanchez-Watts G (1995). Region-specific regulation of neuropeptide mRNAs in rat limbic forebrain neurones by aldosterone and corticosterone. J Physiol 484(Part 3): 721-736.

Weller KL, Smith DA (1982). Afferent connections to the bed nucleus of the stria terminalis. Brain Res 232: 255-270.

Whim MD (1989). Frequency-dependent release of peptide cotransmitters from identified cholinergic motor neurons in Aplysia. Proc Natl Acad Sci USA 86: 9034-9038.
Winslow JT, Noble PL, Davis M (2007). Modulation of fear-potentiated startle and vocalizations in juvenile rhesus monkeys by morphine, diazepam, and buspirone. Biol Psychiatry 61: 389-395.

Winslow JT, Parr LA, Davis M (2002). Acoustic startle, prepulse inhibition and fearpotentiated startle measured in rhesus monkeys. Biol Psychiatry 51: 859-866.

Wray S, Hoffman GE (1983). Organization and interrelationship of neuropeptides in the central amygdaloid nucleus of the rat. Peptides 4: 525-541.

Wynn PC, Hauger RL, Holmes MC, Millan MA, Catt KJ, Aguilera G (1984). Brain and pituitary receptors for corticotropin releasing factor: localization and differential regulation after adrenalectomy. Peptides 5: 1077-1084.

Xu W, Lundeberg T, Wang YT, Li Y, Yu LC (2003). Antinociceptive effect of calcitonin gene-related peptide in the central nucleus of amygdala: activating opioid receptors through amygdala-periaqueductal gray pathway. Neuroscience 118: 1015-1022.

Yadin E, Thomas E, Strickland CE, Grishkat HL (1991). Anxiolytic effects of benzodiazepines in amygdala-lesioned rats. Psychopharmacology 103: 473-479.

Yasui Y, Saper C, Cechetto D (1991). Calcitonin gene-related peptide (CGRP) immunoreactive projections from the thalamus to the striatum and amygdala in the rat. J Comp Neurol 308: 293-310.

Zajonc R (1980). Feeling and thinking: preferences need no inferences. Am Psychol 35: $151-175$ 